\title{
RECONSTRUCTED Memory
}

\author{
By Courtenay Northcott
}

February 2013 


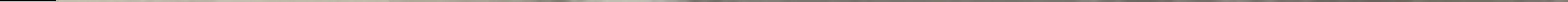


RECONSTRUCTED Memory

Courtenay Northcott

A 120 point thesis

submitted to the Victoria University of Wellington in fulfilment of the requirements for the degree of Masters of Landscape Architecture

Victoria University of Wellington 19th February 2013 
Acknowledgements

This past year could not have been achieved without the help and support of all the friends and family in my life.

Firstly I would like to thank my family, especially my parents, Caroline and Barry. Without your love and immense support, I would not be where I am today. This past year has had its ups and downs, and you were always there
for me with words of wisdom and unfailing belief that I could achieve my goals. I love you both more than I could ever tell you. Thank you.

To my supervisor, Philippe Campays. Thank you for always challenging my ideas and pushing me throughout the year. I am honoured to be your one landscape architecture student, I hope I have done you proud.

To my fellow landscape students, you know who you are. You are the greatest group of people I could have everhoped to go through this experience with. I will never forget the late nights of insanity in studio, the potluck dinners and crazy road trips. So many stories and so many laughs. Some of you were also very helpful with feedback and advice on all of my tangents throughout the year, so thank you.

And finally, to Jamie. For always being there for me, especially the numerous times I announced I was 'giving up.' You helped to pick my spirits up and keep my stress levels down through sane reasoning. Thank you, I could not have got through it all without you. 
How can the abstract idea of memory be represented through the discipline of landscape architecture? How could this be more specifically achieved within the man-made landscape, using materiality and time as tools within the design process?

This thesis essentially addresses the relationship that may exist between landscape archilecture and the In this case, the definition of memory can be defined by site and urban context. The exploration of theories relating to collective and individual memories, identity in the man-made landscape, materiality and trace will aim to define and anchor meny within tan hitecture.

The first part of the research will examine the works of Sebastien Marot, Mark Crinson and Paul Tyrer. On structure and rhetoric. He suggests that memory cannot be physically represented as the same idea for everyone, leaving memory very subjective. On the other hand, Marot works around the concept of social frameworks of memory. He describes how it is important for landscape architects to understand ities and their spatialised design systems. These eflect the conditioning of memories, described as dense accumulations of traces within the environment (collective memories). The connection between site, social frameworks of memory and the urban realm wil be tested through a variety of design interventions. Importantly, a decision needs to be made on whether to design for the collective or individual memories of the site.

The second part of this thesis addresses the idea of memory within the man-made landscape. How the natura landscape, which has in turn affected the collective memory of the site within the large urban environment. The selected site for this research is the former Air Force Base at Shelly Bay, Miramar. Originally a submarine mining depot the coastal area was reclaimed for military purposes corld War One. The land has recently been bought by the local Iwi as part of a Treaty of Waitangi Setlement, who plan to develop the site for the public of Wellington. This site is an example of memory bound within a city, providing interstitia spaces to test designs of memory against the collective and individual memories, both manmade and natura.

The design experimentation will investigate how memory can be recreated and represented on into tesporary and pelly Bay. An investigation including materiality and weathering will allow a more in-depth exploration of memory to take place upon the site. The materiality of landscape elements establishes the form and design ideas. The process of the weathering and durability over time makes the design intent visible, and displays the character and identity of the landscape. The ability to bridge the gap between a fixed idea of memory and the realization of that built idea over time could be achieved by allowing for process and change to occur within the design and the site.

These concepts will be tested upon the site of Shelly Bay through three specific design interventions. These interventions will aim to test and represent different memories upon the site, both man-mad d natural. 

1.1 Memory and the City 1.3 Capturing and Revealing Memory -Case Studies

1.4 Significance of Research

2. Site Analysis 2.1 History of Site 2.2 Current Site Condition 2.3 Approach to Design 2.4 Summary

3. The Man-Made Landscape 1 Identity in the Landscape: Man versus Nature 3.2 Remembrance and Recreation 3.3 Memory Collection we the Built Landscape 3.4 Conceptual Design

\section{Contents}

3.5 Memory Collection within the Built Landscape -Case Study: Parc de Lancy

3.6 Conceptual Desig
3.7 Summary

4. Time and Permanence

4.1 Temporary Design

4.2 Materiality, Weathering and Trace

4.3 Process and Change

4.4 Dimensions of Process and Change

Case Study: Crissy Field

4.5 Summary

5. Design Experimentation 5.1 Introduction: Initial Concepts 5.2 Developed Design: Option On 5.4 Developed Design: Option Two 6. Reflection

7. List Of Figures 
"History has repressed the subjective and
instrumentalised the past, the modernist city itself washed from the slate of memory, and we have lost the interpretative means to translate memories and traditions into meaningful contemporary forms (Crinson, pxiii, 2005).

It has been argued that memory can be revealed in tangible and intangible ways, interpreted subjectively by an individual and collectively through the design of the city. Capturing and revealing memory through design is not the same as memorializing the past. Anchoring memory within a site allows for be achieved by designing for changes in materis be acheved by designing for changes in materiality fabric. While commemortive sites and memorials can be seen to capture a historical event they do so within a framed time. This does not allow for adaption and change over time. Sebastien Marot considers the design of memory in the city as 'social frameworks of memory'. Designers must understand that cities are no longer passive and conditioning of memories (dense accumulations of traces and recollections) but also as active and conditioned memories - as systems of constructed mnemonic places (Marot, 2003).

This thesis proposes that acknowledgement of time as a complex system, and the effects on materiality; performance and aesthetics, within the designs of social memory frameworks in the city, is lacking within landscape archinecture, especially within New Zealand. The anchoring of memory within these frameworks and spechic sltes needs to be addressed. the history ond memorialsation, but by reintegrating public environment In response to these issues, the thesis investigntes memory within an urban context How to design for memory integrate it and anchor it within the future development of urban environments. By using the element of time and the discipline of landscape architecture, "memory can be seen as a process of transformation within the city, and like the city, it develops by the re-articulation, layering andreuse of fragments, in short, by reconstruction" (Marot, 2003, p28).
The investigation into the design of memory will start a a larger scale, identifying concepts of how to ancho memory within an expanding urban realm. You may consider memory as conveying a sense of place as it extrapolates moments in time when certain events have unfolded, imprinted and become a part of a city or a country. These moments become ingrained within landscapes. This happens physically, with the action of built memorials, the decay of buildings, and the vernacular designs of different eras. This can also occur in intanglole ways, on smaller scales. Fo example, visual corridors through sites can expose memory, lights, shadows, and seasons can create place.

The interpretation of these moments into memories (t) argues that memory is linked intimately with collective experience, describing memory as binding community and recharging the spaces within it (Halbwachs, 1950). However Mark Crinson disagrees with Halbwach, stating that memory works as a guide or the individual within interstitial spaces. The stance of this thesis aims to join these two concepts togethe memory with the collective, and memory within the individual. Using a specific site that has historical value within the city, a design can be realized that is capable of becoming a revived public space. The design can as an activation for the past, while in

The first part of this thesis will address current theories surtounding the design of memory vithin the city "Mency is periods of time, only to suddenly be re-awakned perough approprition and manpultion" (Crinson p.xii). Drawing on concepts found within research on memory and the city, and collective versus. subjective memory, triggers can be found and created within the landscape that capture, reveal and create memory. A case study will investigate the industria city of Ancoats. How the landscape architects have mplemented designs within the city will help to connect the theoretical studies with a real site design.
The next step will be to analyse the chosen site of Shelly Bay, located in Miramar, Wellington City. This site embodies a range of events and moments in Wellington's history, as well as reflecting a range of typologies, natural and intervened. The layers of memory collected in this bay, whether visible or not reflect the identity of Wellington City, its culture, and its people. The area is currently in a state of partial abandonment, as a hand over of ownership of the land took place in 2008 from Wellington City Council to Taranaki Whanui ki Te Opoko O Te lka as part of a Treaty of Waitangi Settlement. The public use of the city to a quiet waterfront setting. However this enviry to a aill wange with she deveris land in the future rezoning of Wellington City.

The second part of this thesis, research through design, will explore how to anchor the memory of this site within the impending future development of it. It will also aim to provide designs that respond to the environment, the culture, and the city across time and into the future. The design investigation will create a journey and access to memory that can be manifested through the experience of the man-made landscape and the developments that have impacted on the natural landscape and cultural identity of the site. Land reclamation has fast become a common design outcome to Wellington's waterfront spaces, and Shelly Bay has not escaped this. However, it has created a more usable site but at the cost of altering it's history and blurring the natural boundaries. The memory of the occupation of the site, the appropriation of the will form conceptual designs for the development Shelly Bay.

Materiality and weathering will also be explored through the encompassing idea of time and permanence. This research will aim to bring the permanence. This research will aim to bring the
design of memory into the detail of the spaces. The concepts generated from this research will allow for the site to be activated in the present development of Wellington, while also challenging how the site will transform over time, and in turn, how the future development of Shelly Bay should take place.
This thesis will investigate memory within an urban context. How to design for memory, integrate it, and anchor it within the future development of urban of of landscape architecture. Through design theories will be investigated, and the man-made landscape will be challenged, while archiving the degradation of the site and anchoring it's memory within a public space programme. The outcome is expected to create an uban framework and masterplan for the future development of Shelly Bay, as wes the che that reflect the identity of the place and people. 


\section{Anchoring Memory}


"The past is everywhere and it is nowhere" (Crinson, 2005, p. xi).

'Memory and the City' is an extremely broad subject. Within landscape architecture it is very generalized ye highly subjective, however it has become lost within ities, buildings and plaques pay hom sto part events that have impacted upon it In some cases, the city skyline, building forms and the dense urban centre skyline, building forms and the dense urban centre
have provided the visual memory forms of a city, for have provided the visual memory forms of a city, for the urban fabric in relation to the topography creates its identity within New Zealand. This thesis will investigate the affects that rapidly developing cities will have upon memory. The site chosen to test the design theory upon is on the boundary of the urban centre, and within Wellington Council's 'Fifty Year Development Plan.' It is anticipated that in the future, the site will become encroached upon by the urban realm, and in filled with housing and businesses (appendix one)

One may ask how in expanding cities, previous forms of buildings can remain memorialised references for the public. Mnd fon as a guidh to a city may be more landscape; one that anchors the memory of the place yet does not memorialize it so that it remains stuck in time Memory is on a continuous spectrum flowing in all directions. To anchor memory, the design must also flow throughout time, "all cities change constantly, they have no static moment that enables inventoried description, and their spatial and architectural forms change in myriad ways; rapidly reproducing themselves, in fits and starts, or in the longer duress of decay and slow decline" (Tyrer, p67, 2005). To define memory in relation to site, this thesis will explore the ability to anchor memory within different scales of design using materiality, program, temporality, and time.

Scales of Design

The landscape, the spatial layout of a site and the historical, present and future uses of it create collective and individual memories of a place. These can be seen as triggers, both sensory and physical, that define a sites memory within a spectrum of time. When developing a stie with the intention of anchoring memory, landscape architects can utilise their expertise in spatial design. The site can be design - This could navigate the past collective memories of events with the individual memories of the site, for example, the way the landscape has influenced the public access, current program and the industry on site. "The city can be seen as a palimpsest or as a spatialised system for recalling the past" (Tyrer, p66, 2005). This spatialised memory system could be used in different scales, on different sites around the city, recalling memories in different ways, but ultimately anchoring memory within the city in one coherent way.

With the concept of memory within the city, and taking into consideration how the city will grow and expand, Paul Tyrer states that it is important to design sites within the city as part of a larger system. Mark Crinson takes another view on this concept, stating in 'Urban Memory that each space or memory site takes on their own form and framework depending in maduced into a part of space, it When a group is image but at the same time it ields and adapts itself to certain material things which resist it It encloses itself in the framework that it has constructed. The image of the exterior environment and the stable relationships that it maintains with it pass into the realm of the idea that it has of itself (Crinson, pXiii)"

The design aspect of this thesis will explore how to combine these two theories. The site presents a place that can be designed as part of a larger system. By reflecting individual relationships between people and the surrounding environment, a design can be achieved through different scales of design. The connection the sle has to the rest or Wellington can be implemented and activated through design. Shelly Bay resides on Wellington's harbour edge, so concepts on alternative forms of transpor, for example ferries, 
Tyrer suggests this is why materiality is an inporte Thertant Serge to represent time and memory. Michael

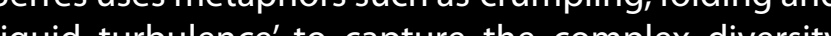
liquid turbulence' to capture the complex diversity Cor arger un context, means time, permanence controls the permanence of materiality as well site context and climate. However, there are tools andscape architects can utilise to incorporate materiality weathering and trace into the design memory. By undertaking an in-depth site analysis materiality can expose the current site conditions, natural and man-made. It can reflect the climate while also be incorporated into future changes such as rising sea levels. Permanence, time and program can be reflected in how the design on the site decays (or remains) in the future development of the site.

Can the alteration of memory and the creation of new memories upon a site still maintain and eflect historical events, as well as collective and Sebastien Marot works around the concept of socis Serser wow understanding cities and their spatialied design systems, their conditioning memories (dense accumulations of traces and recollections), as wel as active memories, work together to construct mnemonic places (Marot, 2003, p18). Over time Shelly Bay can be activated in a specific way through andscape architecture. The memory and history of the site can be displayed through subtle design moves. The built form in relation to the topography the materiality, the permanence of the design and the scales of design will reflect new and old collective memories on the site in the future.

Summary

Memory can be designed as a guide of the landscape, the site, and the history. Within Shelly Bay, sensory and physical triggers can create controlled moments in time, while the program of the site can create a fluid exploration of the site. The connection between the site, the social frameworks of memory, and the urban realm can be tested through different design on whether to design for the collective or individu memories of the site. These can be interpreted in many ways, and ultimately will decide the future place the site has within the developing urban realm and Wellington City.

For this thesis, memory will be defined specifically on the site of Shelly Bay. In terms of past memories, the analysis of the site will help to define the appropriate design and program to reflect these. The materiality and permanence will reflect the site of Shelly Bay in the future development of Wellington. An investigation into time and scales of design will help to represent
how the site may be activated and connected with the urban realm. 


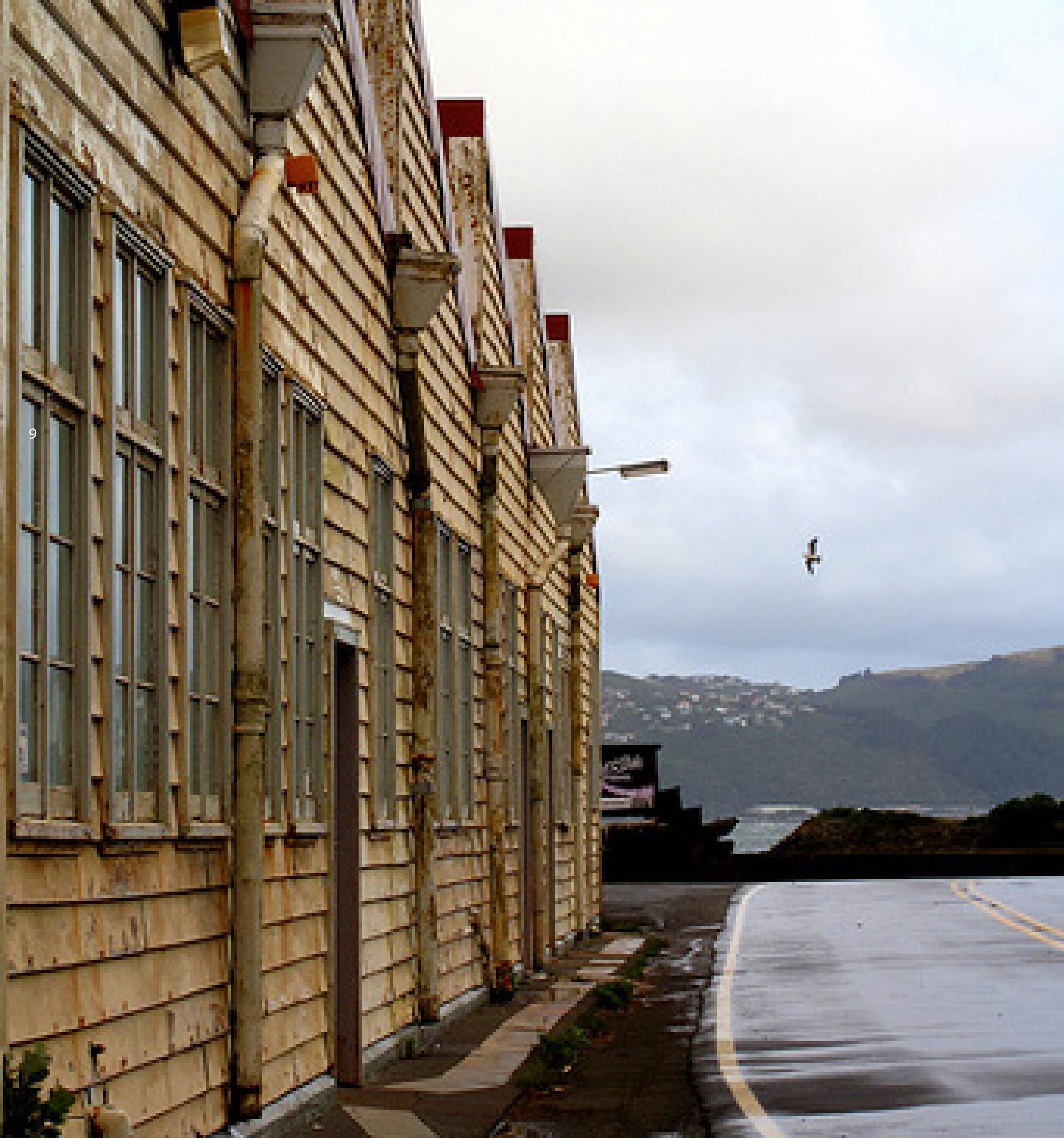

Memory is an extremely subjective concept. According to Mark Crinson, memory has two interlinked aspects. The first is of a residue of past experiences that has somehow stuck or become active in the mind while other experiences have been forgotten. The second is of an ability of faculty by which we recollect the past. These aspects that Crinson refers to describes memory as an individual aspect (Crinson, pxii, 2005). Halbwachs argues that the idea of memory is to be found in society rather than in the individual and that "the collective memory finds its supporting basis in spatial images"(Marot, p30, 2003). These theorists give two ways of approaching memory, from an individual or collective point of view. When creating and testing designs that anchor memory, approaching it from a collective point of view would allow for memory to become connected to a larger spatial design scheme. become a"system of logic of mearing of chronology, fo topography that anticipates memory, creating for it a general system of the past that calls up the role and the place of each particular memory" (Marot, p30, 2003).

This thesis suggests that, it is important to allow for spatial design to not be stagnant within its own site. That it must be connected to the rest of the urban realm, and signify that it is directed towards the collective memory. Does this however mean that individual memory should be completely disregarded in this design research situation. It is proposed that individual memory can be represented and translated within the detail, the scale, and materiality. It is important to retain this within the spatial design of the site as it reflects a process of reconstruction, "an activity of localization and configuration functioning essentially from and within socially elaborated time and space)" (Mart, p30, 2003). The design will seek to represent and situate memory within these frameworks, or devlop a capacity to move between the collective and individual memories.

The site, Shelly Bay, is currently a public recreation space, and development plans need to take this into Figure 3. Shelly Bay wharf buildings, 2012. Photo by author. consideration. Connections with users need to be made, as well as connections with the surrounding memories need to be represented.

A formation of new memories upon the site would allow for a connection in the developing city over time and generations of users. Temporary and permanen designs can be used to test Crinsons and Halbwach theories. Some places within the city experience "amnesia", while others hold memory captive. Maro references Aldo Rossi who wrote that "the city is the locus of the collective memory" (Marot, p30 2003). Marot also brings up a problem that Sigmund Freud raised, that our ability to represent locally the situ but depe and perhes and terity in visu" (Mary in situ but also, and perhaps primanlly, in visu" (Marot, sites of memory that not only rect the collective memory within the city, but also the collective memory of the local site.

According to Hauser, in 'Making Museums of Industria Heritage Sites', museums, monuments and memorials alone can distance public users from a site and from the collective memories of a place. Hauser suggests an 'Ecomusee' as constituting the collective memory of a historical or industrial site. An 'Ecomusee' combines the creation of industrial heritage sites with the development of a cultural landscape that is simultaneously old and new, "These museums were thus perceived as a kind of substantive collective regional memory that would constantly nourish and renew remembrance" (Hauser, 2006, p281). However, once the generation with the vital connection to these heritage sites dies, what maintains the importance and memory of the site within the collective identity integrated design, past, present and future must be the underlying programm. It must ruspond to cultura and ecological developments, as well as commercial developments that activate the site. 
It can be deduced from Hauser's research that museums distance people from heritage, whereas Ecomusuees allow cultural history to be interacted ayers to be added to the sites memory over tims and design of museums and memorials can be re-worked through the discipline of landscape architecture. through the discipline of landscape architecture. To spatialise the memory and history of a site, within
the collective regional identity, scales of design and the collective regional identity, scales of design and design lead research, the detail and materiality (how the design weathers over time) will be considered for the individual experience of memory. 
Ancoats is being rebuilt again. Not just in terms of buldings, but culturally and as a community. This is "I discovered a real problem with in his response. continuity. Ancoats has been such an importan place. and now it's a wasteland. It's going from industrial to domesticity..."(TheShriekingViolet, 2011, para.3).
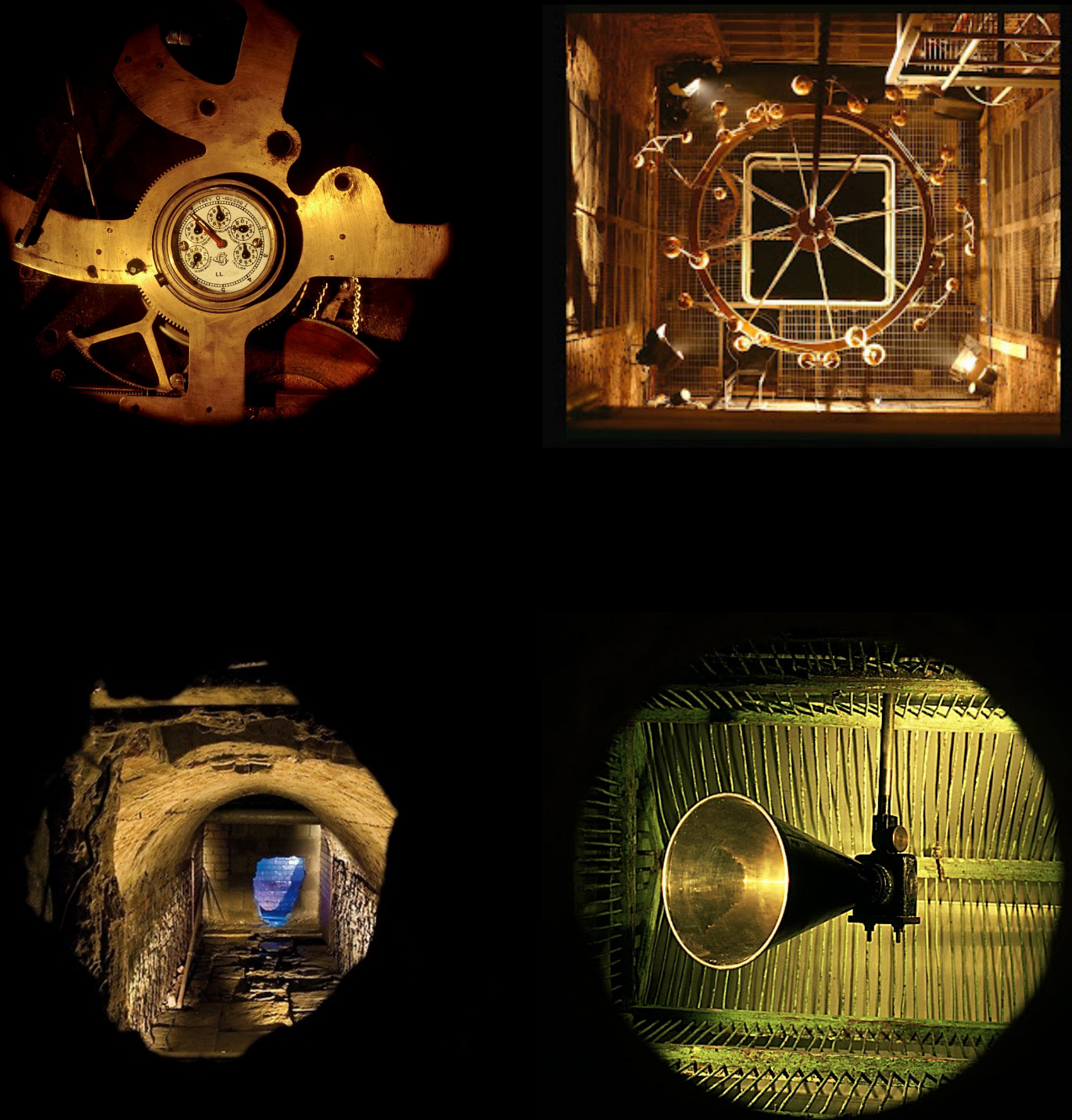

Figures 4, 5, 6, 7. 'The Peeps' by Dan Dubowitz.
Sourced from http://wwww. civicworks. net 02 .
Dubowitz's approach to the context and history of the site, as well as looking towards the future habitation, allowed him to create a subtle celebration of the presence of absence. The Peeps (figures 4-7)are an artistic intervention that has brought a new dimension to public space design within Ancoats. Each Peep' was installed on a building site, with the idea that they ... would become features in the street and a part of the streetscape, where you'd usually put benches" (TheShriekingViolet, 2011, para.7). The Peeps creates a journey through the redeveloping suburb, but withis on mold fozen in time, framing scenes rooms where nature has tapen over. Dubowitz has created an intimate relationship between the public and the spaces. His attention to detal and materiality within his photography connects with the individual memory. The scale of the intervention, peep holes into lost spaces, connects the user to the site, as well through a continuous scheme.

An issue with Dubowitz's intervention is its permenance. The Ancoats company commissioned a memorial design, and although Dubowitz's innovative approach precedes any sculptural design, it is very temporal and one dimensional in its program. As the suburb develops around the Peeps, including the demolishment of the buildings they target, one questions how will the area remain anchored in the collective memory. This has been achieved in one area of Ancoats, Cutting Room Square (figure 8), where Dubowiz's photographs are displayed. Howeverthese new concrete structure, reflective of the changing collective identity of the site. as providing connections throughout the suburb

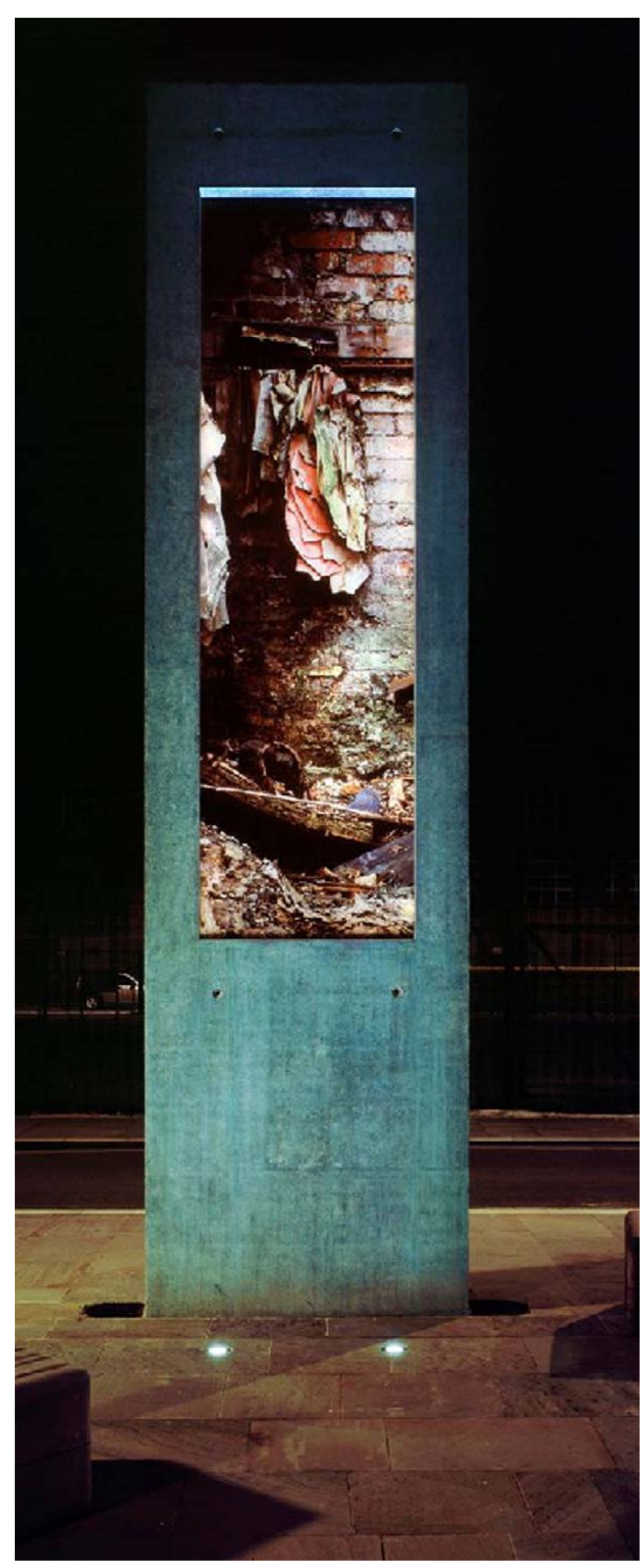


Landscape Architecture Study

Camlins

'Ancoats Public Realm'

The landscape architecture team that was also commissioned to work on the public realm design of Ancoats also project managed the design of within the building network, a space reminiscing a forgotten building or awaiting a new one" (Camlins, Ancoats Cutting Room, 2011, para.1). Dubowitz's photos sit within light boxes in the square, sitting within The Frames (figure 8). The five planar precast concrete structures represent windows that evoke the remains of a former building. The Cutting Room ties together the work of the landscape architects and Dan Dubowitz, wifting up the public space framework Which was set up by Camlins and the Ancoats Urban Village Company.

15 The Cutting Room and Canal Square are the new, and only, public spaces within Ancoats. The Cutting the Peeps, as well as providing large open spoces for public use. The open spoce planning of both squ contrasts the historical rigorous grids and the Can Square connects the new space with the historice transportation network of the Rochdale Canal.

The material choices, a mix of concrete and stone bricks, fit within the historical aesthetic (figure 9), while also contributing a modern simplistic design. Paul Tyrer, author of 'Clocking off in Ancoats: Time and abinty that he urbandesignscheme has toconnecthe different quarters of the suburb. With clear movement channels for pedestrians and vehicles, wide open spaces, and public seating and recreational spaces, the trial of the public space strategy set up urban spaces that create a new interesthg envionment that responds to the rich history of the site. Whin the design having simple strategies, different scales of and rections of the and clean material pallete and streetscape layout.

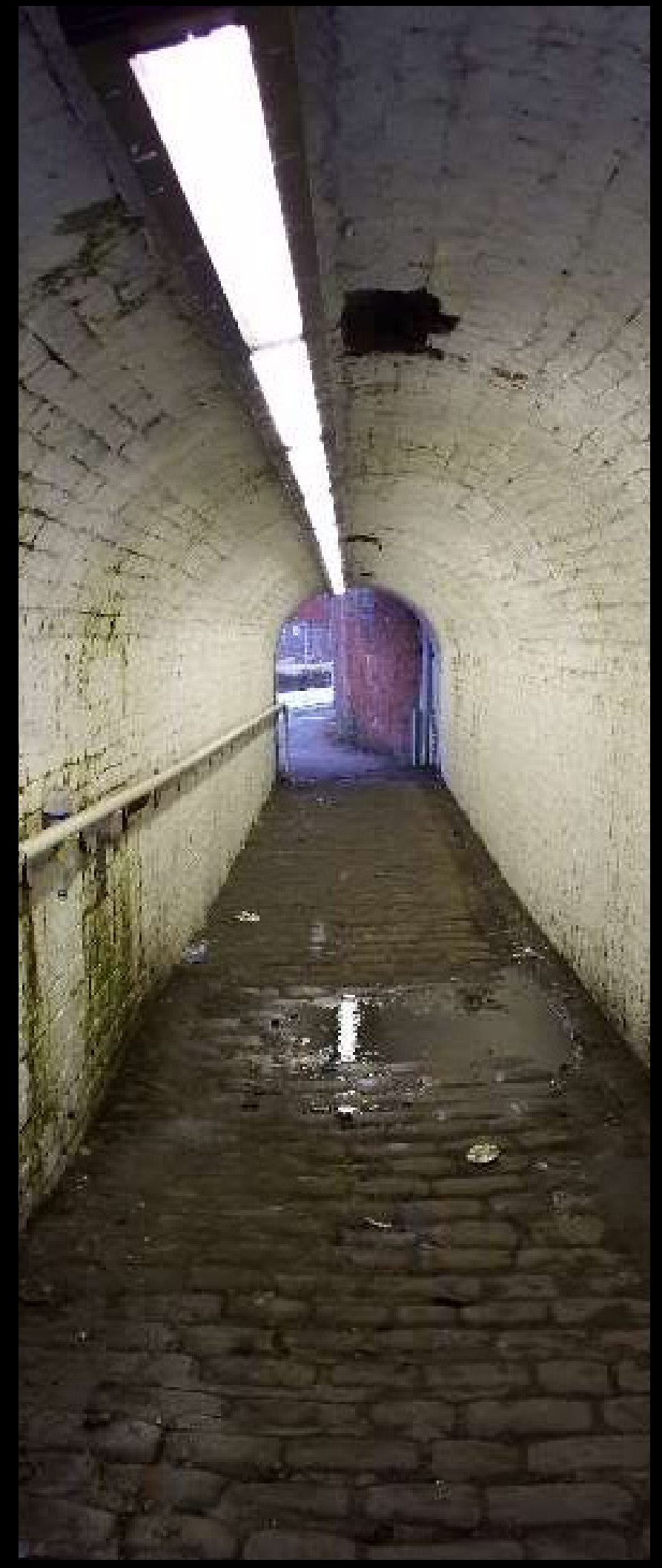

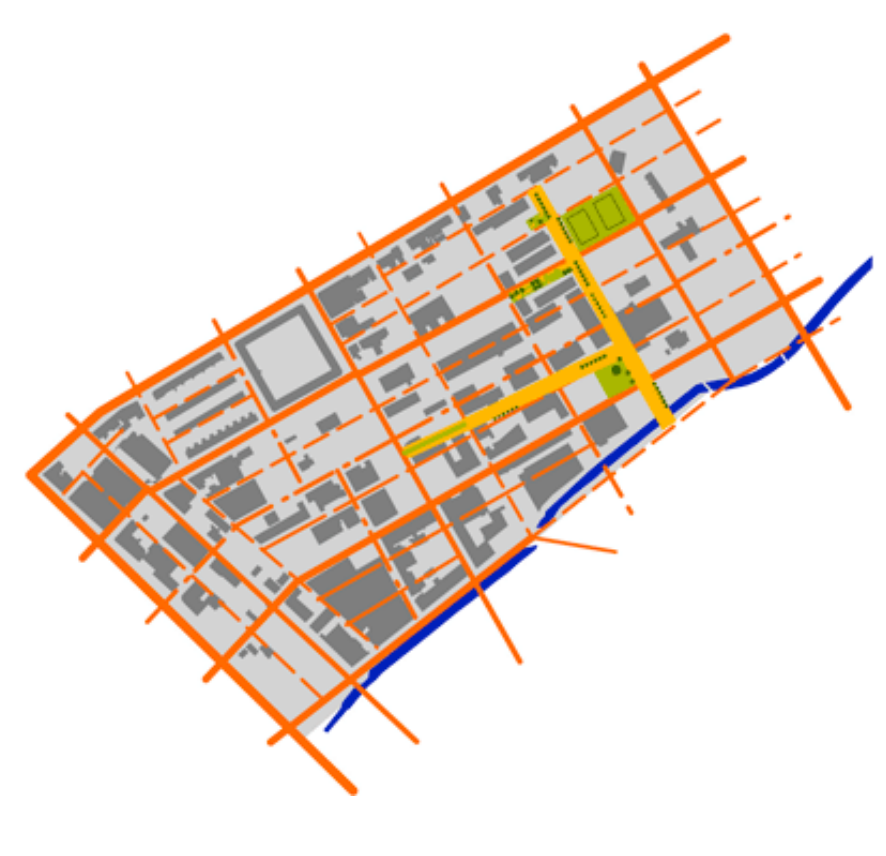
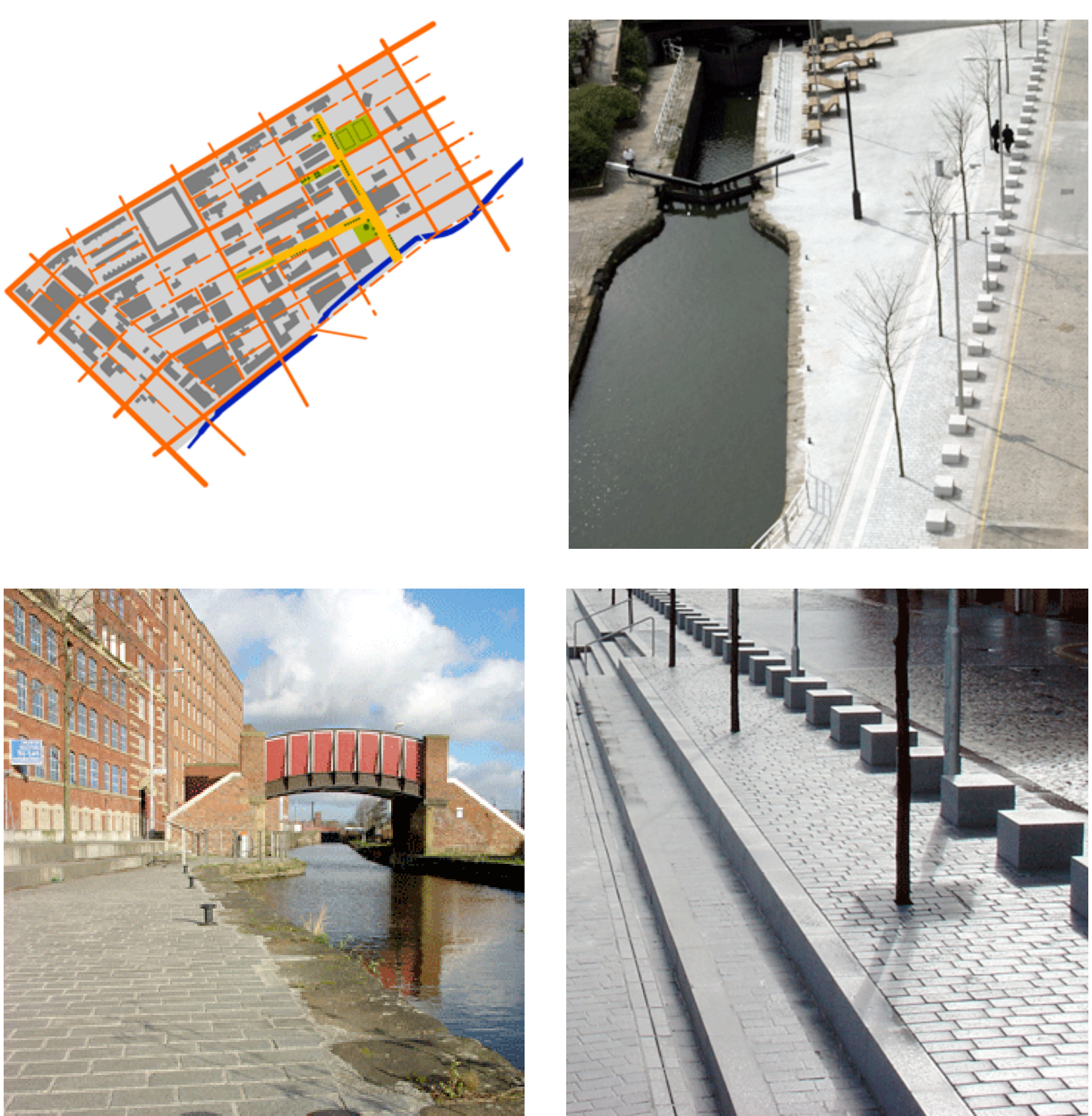

Figure 10. Ancoats public realm strateg

Figure 11. Canal Square, Ancoats
Figure 12. Canal Square, Ancoats

Figure 13. The Cutting Room, Ancoats
All sourced from http://www.camlins 
This thesis will form an exploration of memory within the landscape. Through design, this research will test theories on the translation and representation of memory. In "Urbanism and the Art of Memory, a landscape that itself is relatively artificial" (Marot, 2003, p12).

The significance of this research within the current landscape architecture practice is to test the ability to apply designs of the past and future into an activation of the present. The design on the site of Shelly Bay will define a new way of anchoring memory. As memorials are constructed around the world, this site could begin to influence the way landscape architects approach the subject of memory and re-define the memoria landscape.

The approach to design, subsequent concepts and ideas, and site analysis reforms an approach to landscape architecture that allows the abstract Wellington City. The final design will answer questions formed through current knowledge, while creating formed through current knowledge, while creating designers to consider for future developments of urban spaces. 


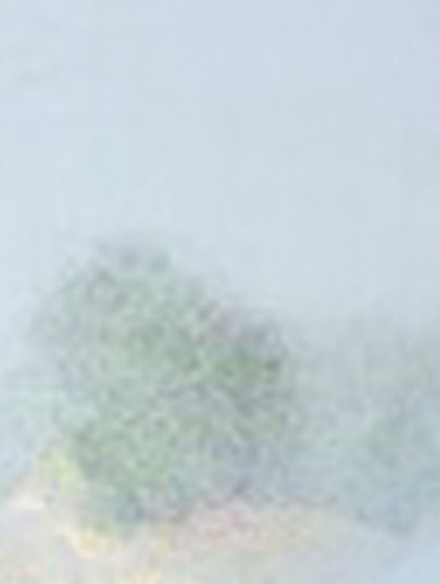

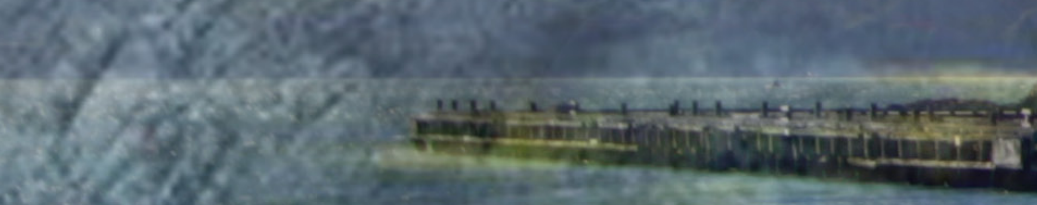

nete

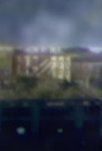
i.

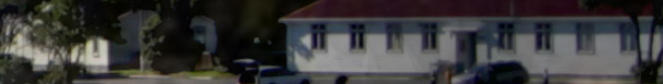
. 4. 5 Cinta Fit) पit:

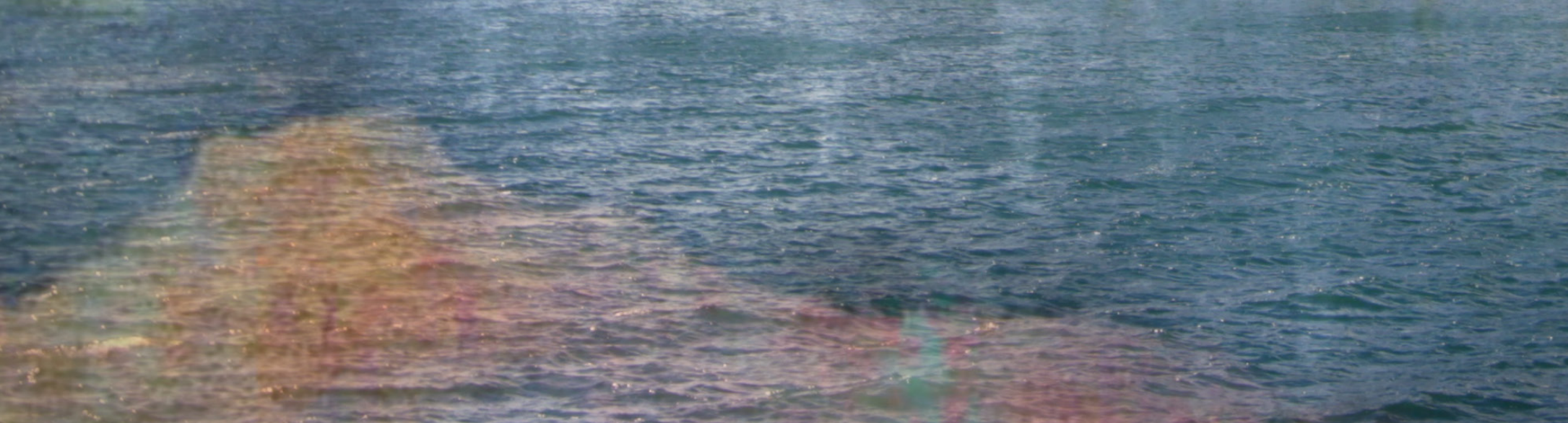
2. Site Analysis

Shelly Bay Miramar Wellington
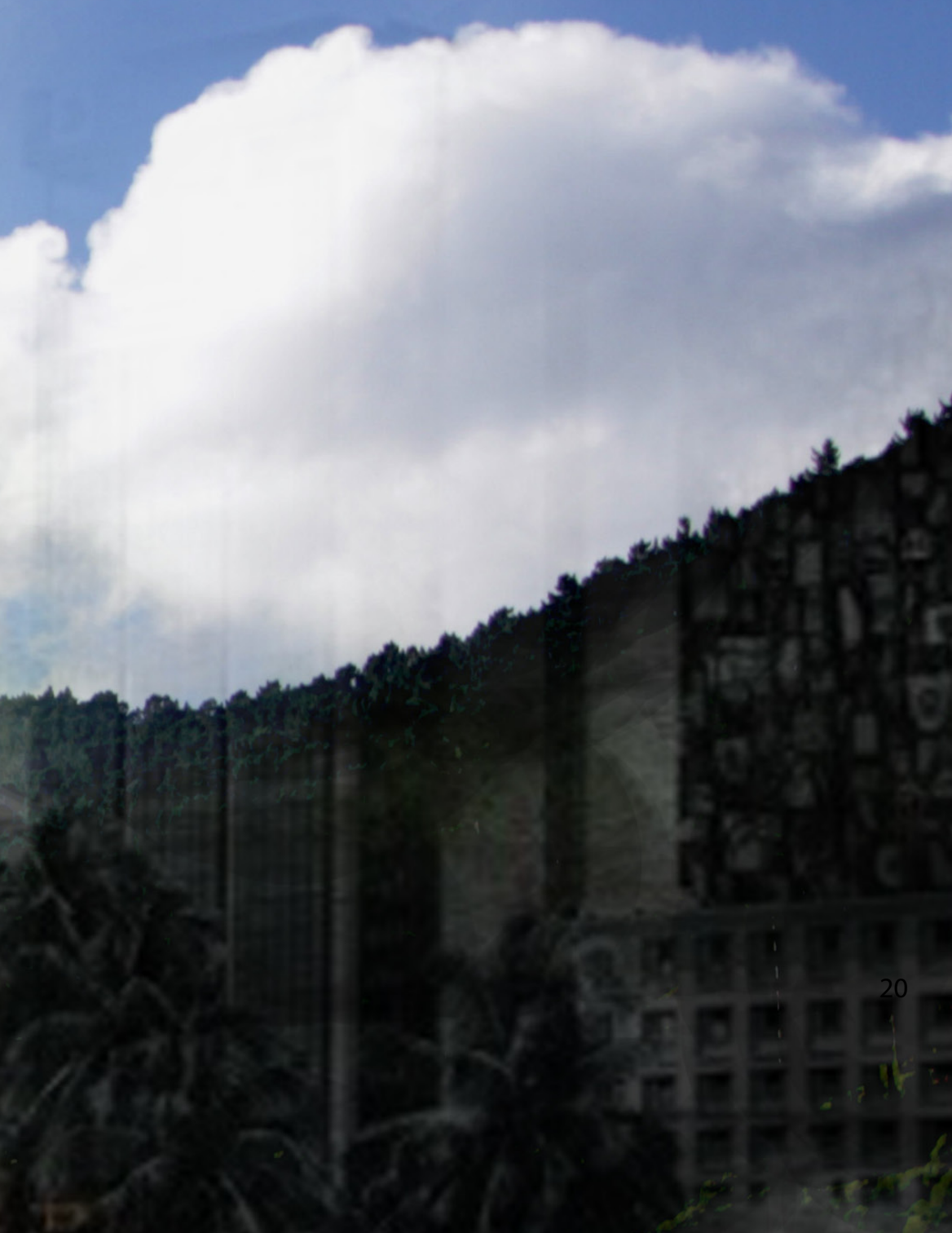

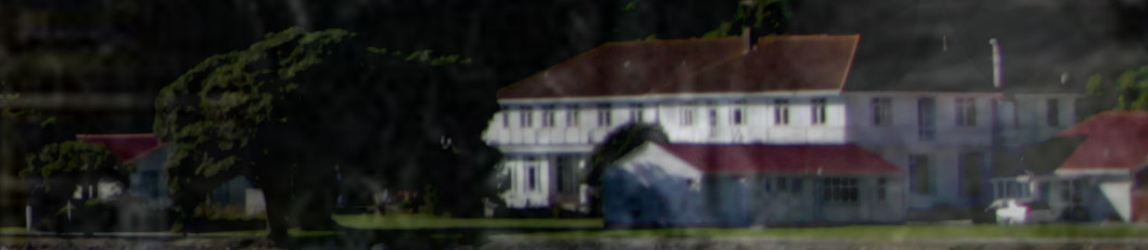
izs ton?

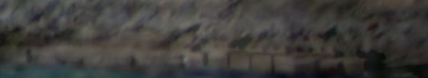

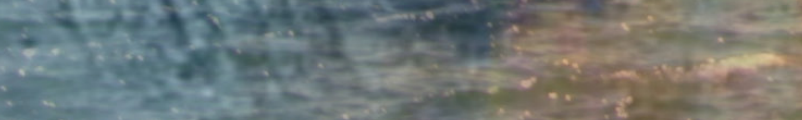

-

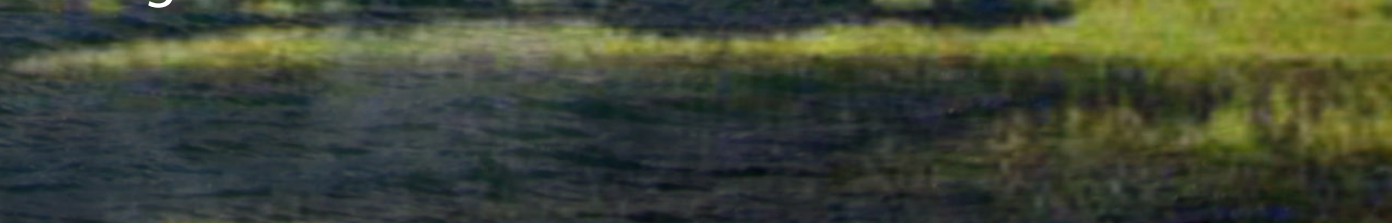



To anchor the memory of the site, it is essential to and influences upon it.

Shelly Bay has been used by a number of different groups over the past. The appropriation of the land and how the different users have functioned and maintained the area has shaped how it appears today. Occupation of the land as a resource for food, dredging of the bay for ships, reclamation of land for housing settlement, and buildings to house an air force base are the main actions contributing to the development of the bay.

The 1855 earthquake in Wellington lifted the land out of the sea, as it did around most of the harbour, creating the shelf along which the foothills of Shelly a beaphes ant the coast of the Mirmed a number The spaces and beaches created provided an area to situate the village of (Miramarpeninsula, ShellyBay, 2012, para1).

As ownership of land changed from the Maori to the European settlers, the site was selected to be suitable for relocating the Submarine Mining Depot in 1885 . The ownership transferred hands again in 1907 to the Navy. This led to the construction of armament depots situated in the hillside behind Shelly Bay. In 1942 reclamation work started as flat land was need to construct buildings for the naval base. In 1946 the ownership of the site was transferred again. The area became formally known as the Shelly Bay Air Force Base (Waters, 2002).

In 2008, a hand over of ownership of the land took In 2008, a hand over of ownership of the land took
place. The land was bought back from Wellington City
Council by Taranaki Whanui ki Te Opoko O Te lka as part of a Treaty of Waitangi Settlement.

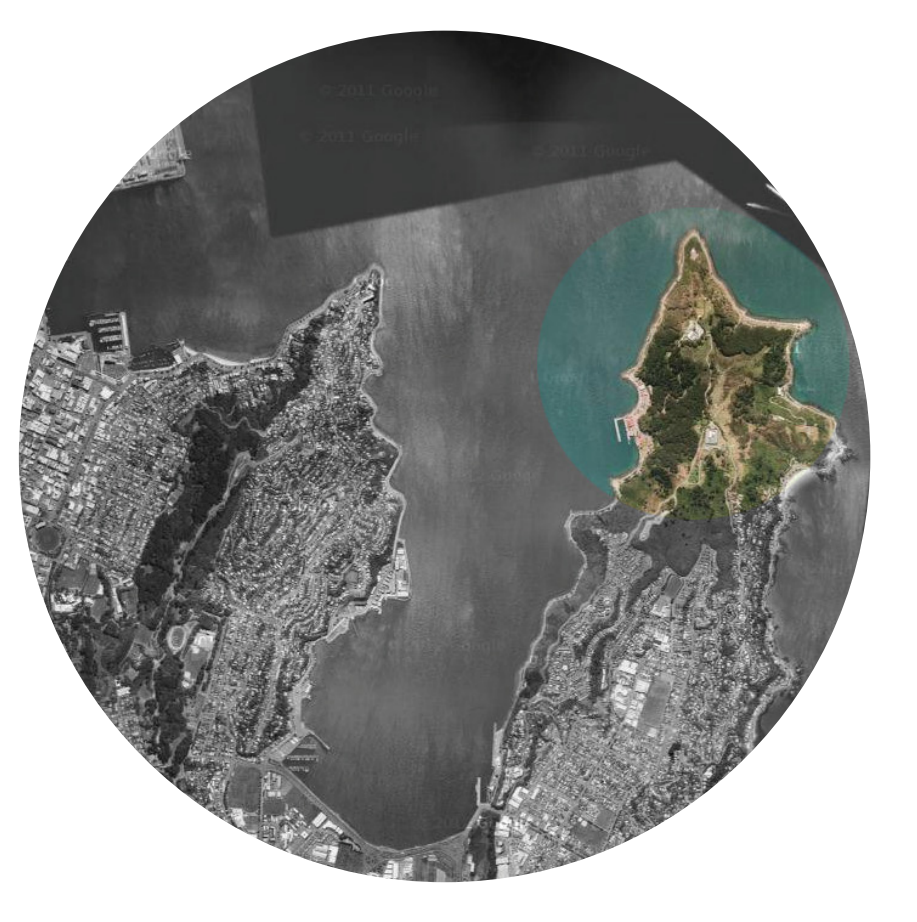



Miramar Peninsula, onto which Shelly Bay sits, has a the site of Shelly Bay.

"The former Air Force Base at Shelly Bay was once a Te Ati Awa village called Maru-Kai-Kuru. The village was situated at the north end of Shelly Bay and was connected to other settlements on the western side of the Peninsula. Settlement of this site dates back from the earlier migration (heke) from Taranaki when MaruKai-Kuru was populated by the Ngati Mutunga kin of Te Ati Awa" (Miramarpeninsula, ShellyBay, 2012, para1) The bay was used as a food collection site (kainga) as well as becoming an established village. What is interesting about the ownership and appropriation of the land in Shelly Bay is the start and end points. Kuru and today the land has been bought back by the Taranki Whanui ki Te Opoko O Te lkaght back by area has changed dramatically since the $1800^{\prime}$ 's. This thesis will investigate how the relationship between the sea, the land and the former/current owners can be regained.

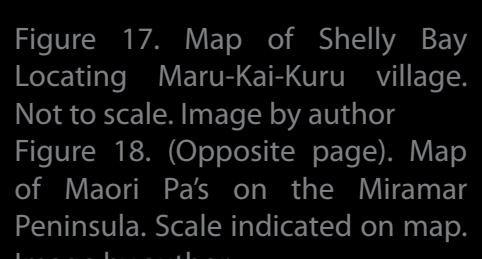

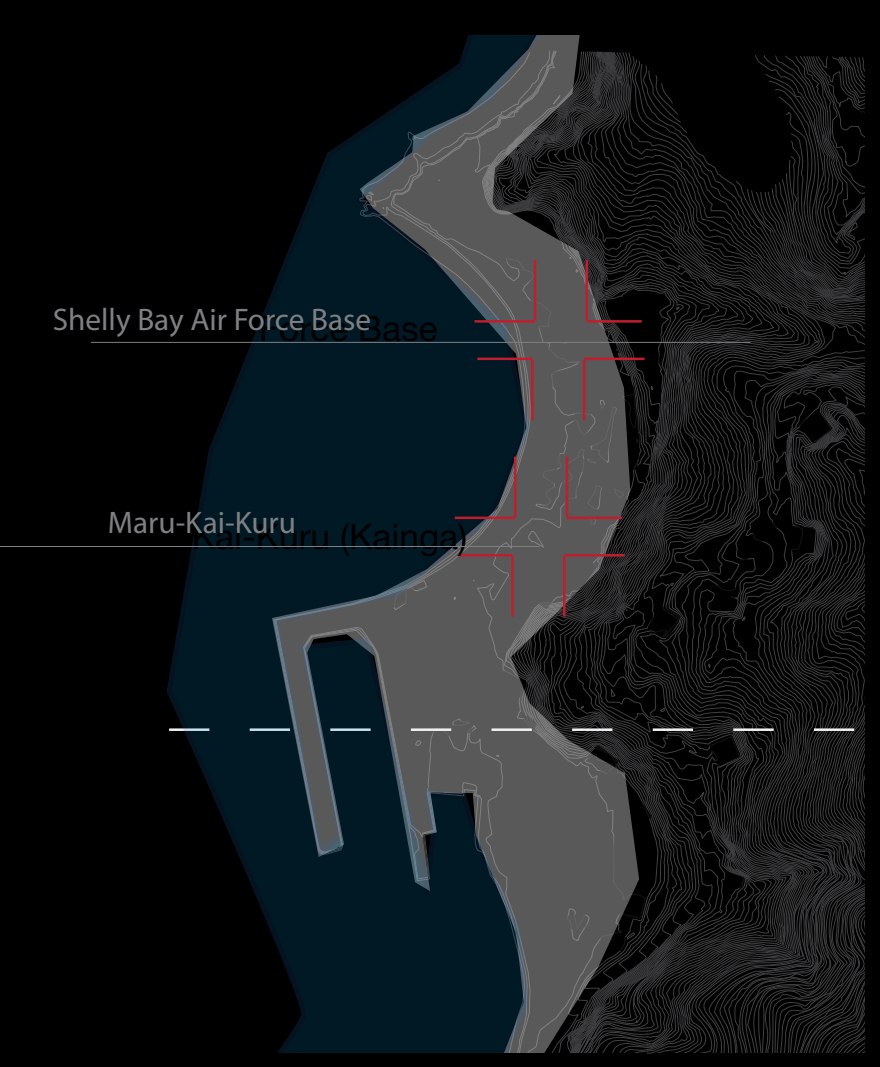

24 
In the 1890s a naval volunteer reserve unit was established at Shelly Bay to carry out mine laying operations (Miramarpeninsula, ShellyBay, 2012 para2). This was the beginning of a military ownership over Shelly Bay, passing through a number of divisions.

The buildings, wharves and spatial layout that exists currently are all formed from the military occupation. Shelly Bays buildings are weathered timber, with simple structures flaunting bright red rooves and doorways. These details characterise the current collective memory of Shelly Bay for tourists and the public of Wellington. The spatial layout consists of the road dominating the coastline, with the buildings charecterise the site in plan view as the shorves lhach in a very mante in plan view as they shape the

25 land in a very man-made way. The military occupation
formed Shelly Bay's label of an industrial suburb within Wellington City Council's urban drial suburb strategies (appendix two). The buildings that have formed the basis
of the current character and collective memory of Shelly Bay

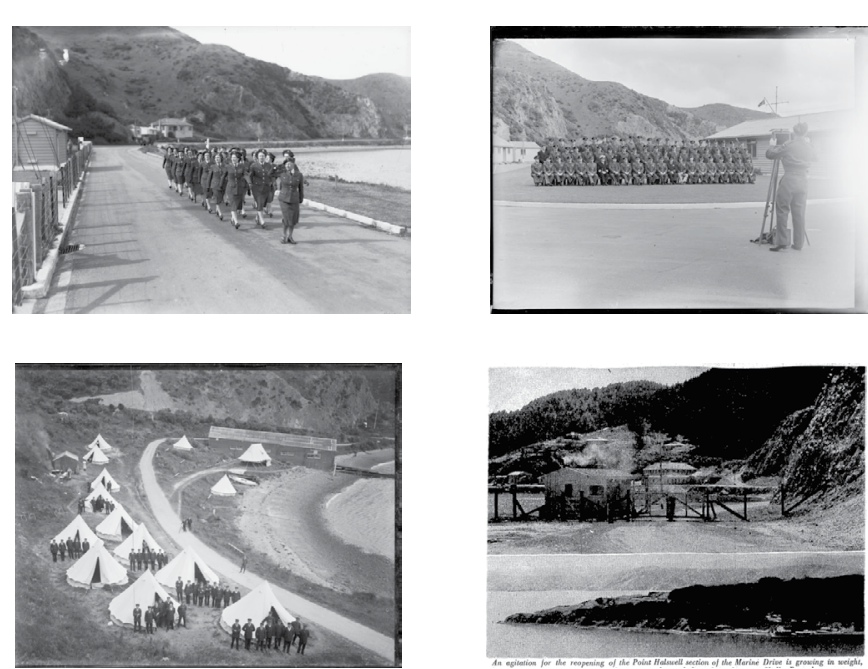

The Air Force Base dominated the Shelly Bay area from 1942. The road access was reduced to the bay, restricting the public from using the peninsula recreationally.
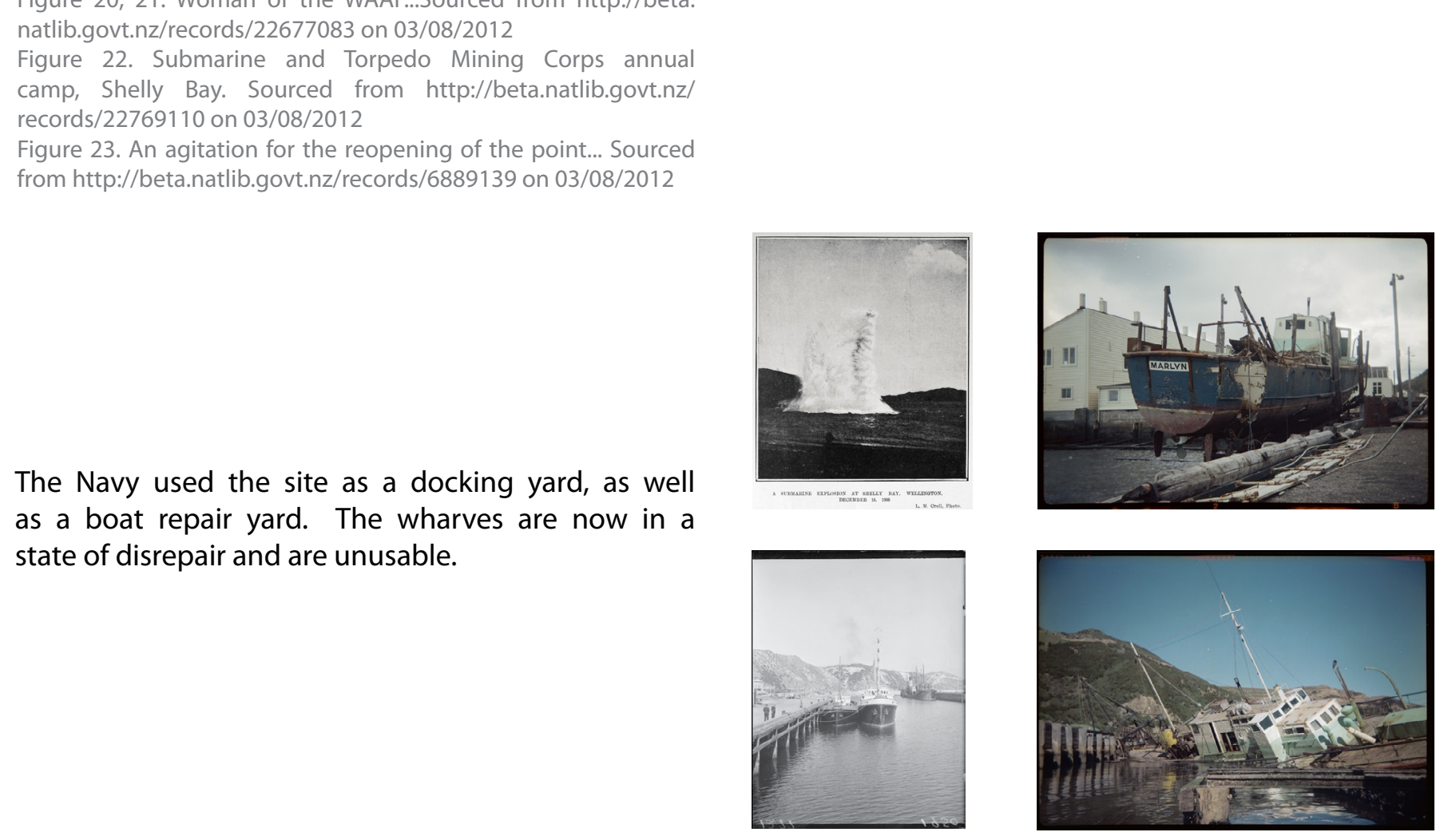
hittp://beta.natlib.govt.nz/records on 03/08/2012 Figure 25. Launch Marlyn under repair at Shelly Bay. Sourced from
http://beta.natilib.govt.nz/records/23221236 on 03/08/2012 Figure 26. Evans Bay and Miramar Wharf. Sourced from http://beta nattib.govt.nz/records/23259171 on 03/08/2012
Figure 27.Launch Marlyn sunk at Shelly Bay. Sourced from http://

26 
The appropriation of the land by the Navy and Air
Force forced reclamation to occur within Shelly Bay. In

Force forced reclamation to occur within Shelly Bay. In

(Waters, 2002). Land was attained for the reclamation

by excavating adjacent hillsides surrounding Shelly

Bay.

Another major change to the topography was the dredging of the bay in preparation for the wharves

to be built. This would allow major ships to dock at

the bay. This started occurring simultaneously to the reclamation
27

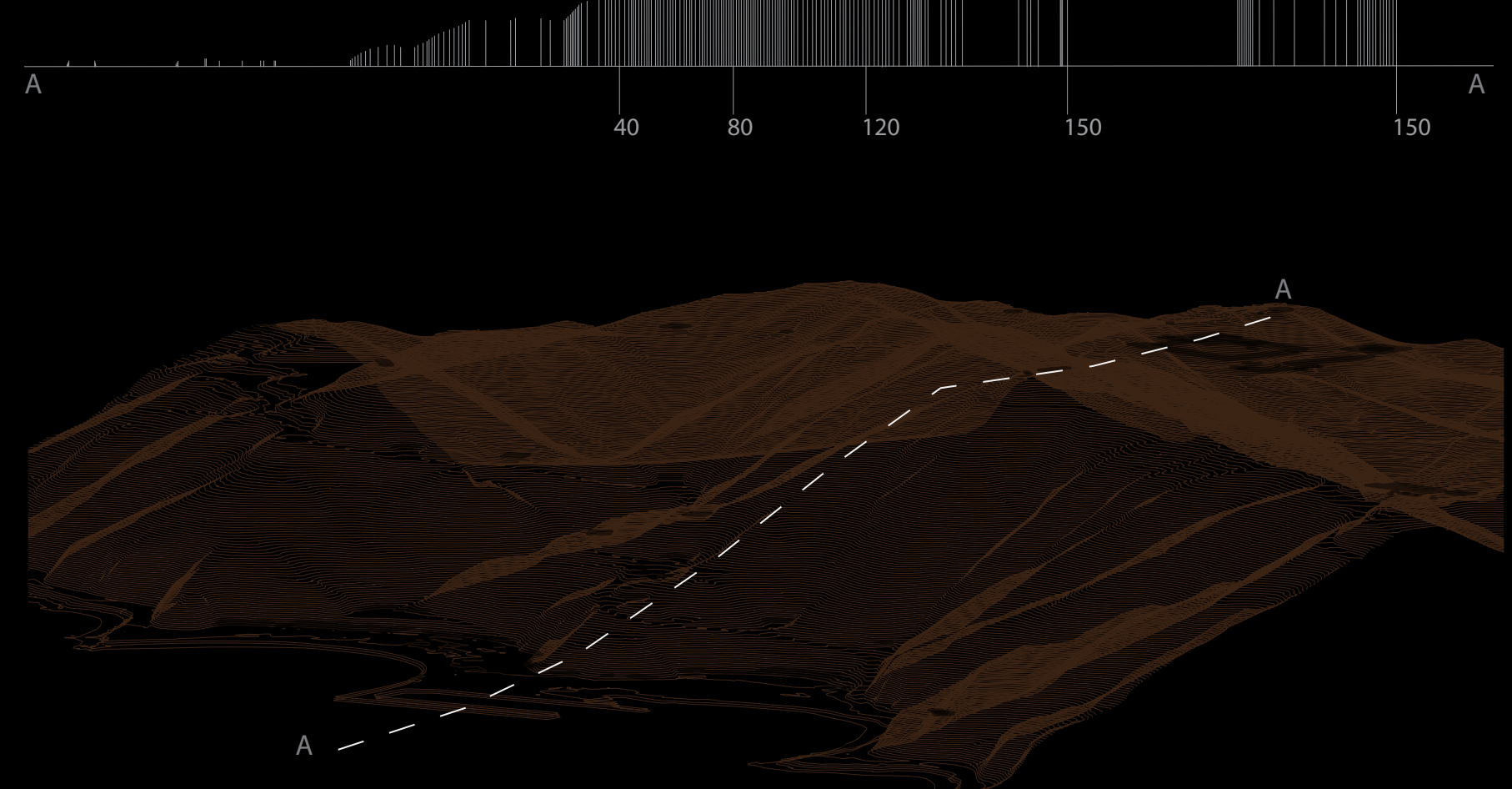

7,4

This image shows the reclaimed land and wharves in relation to the dredged harbour. The new depth created is quite significant and would allow for a development of transport to the site through ferry

172

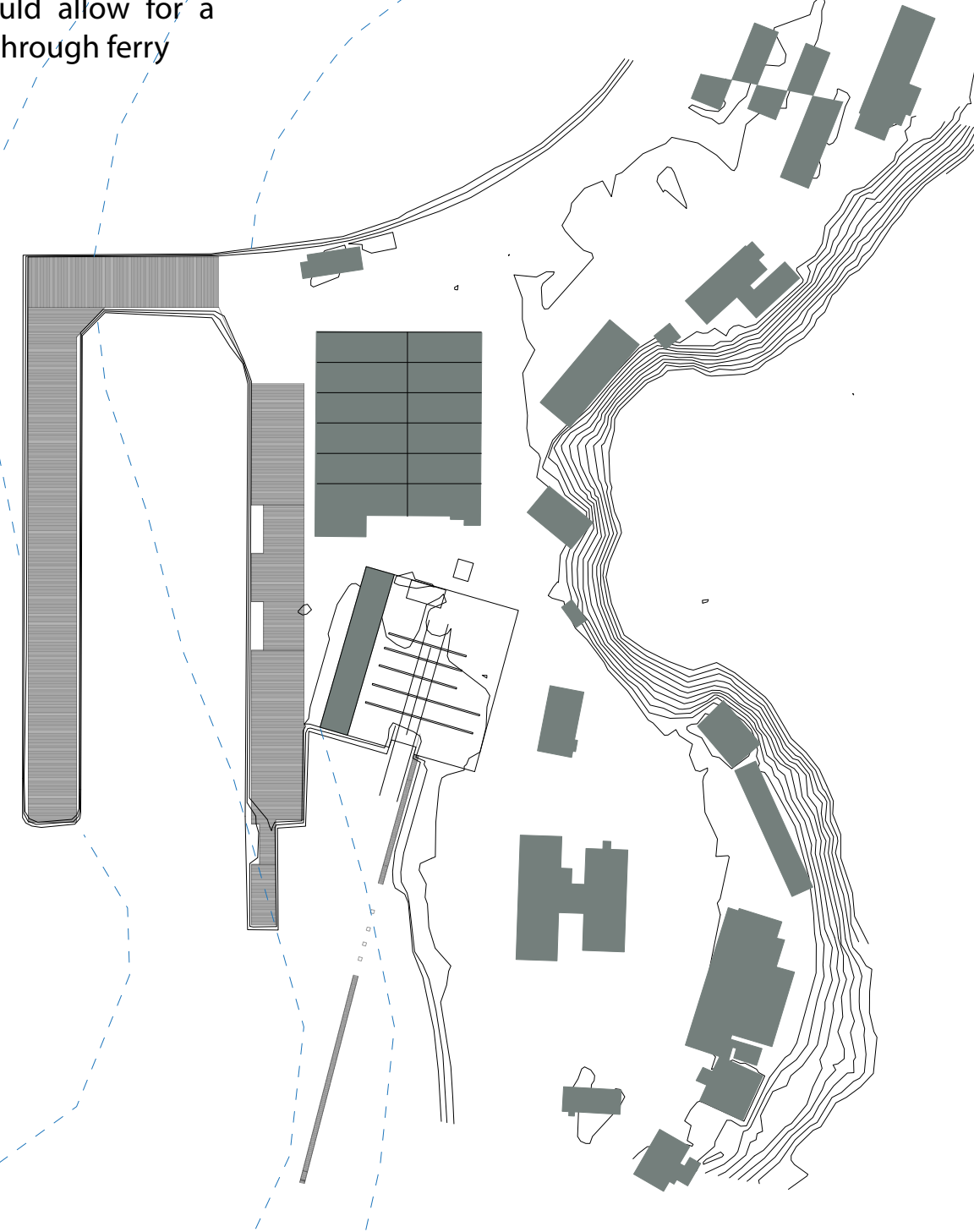

5.4 


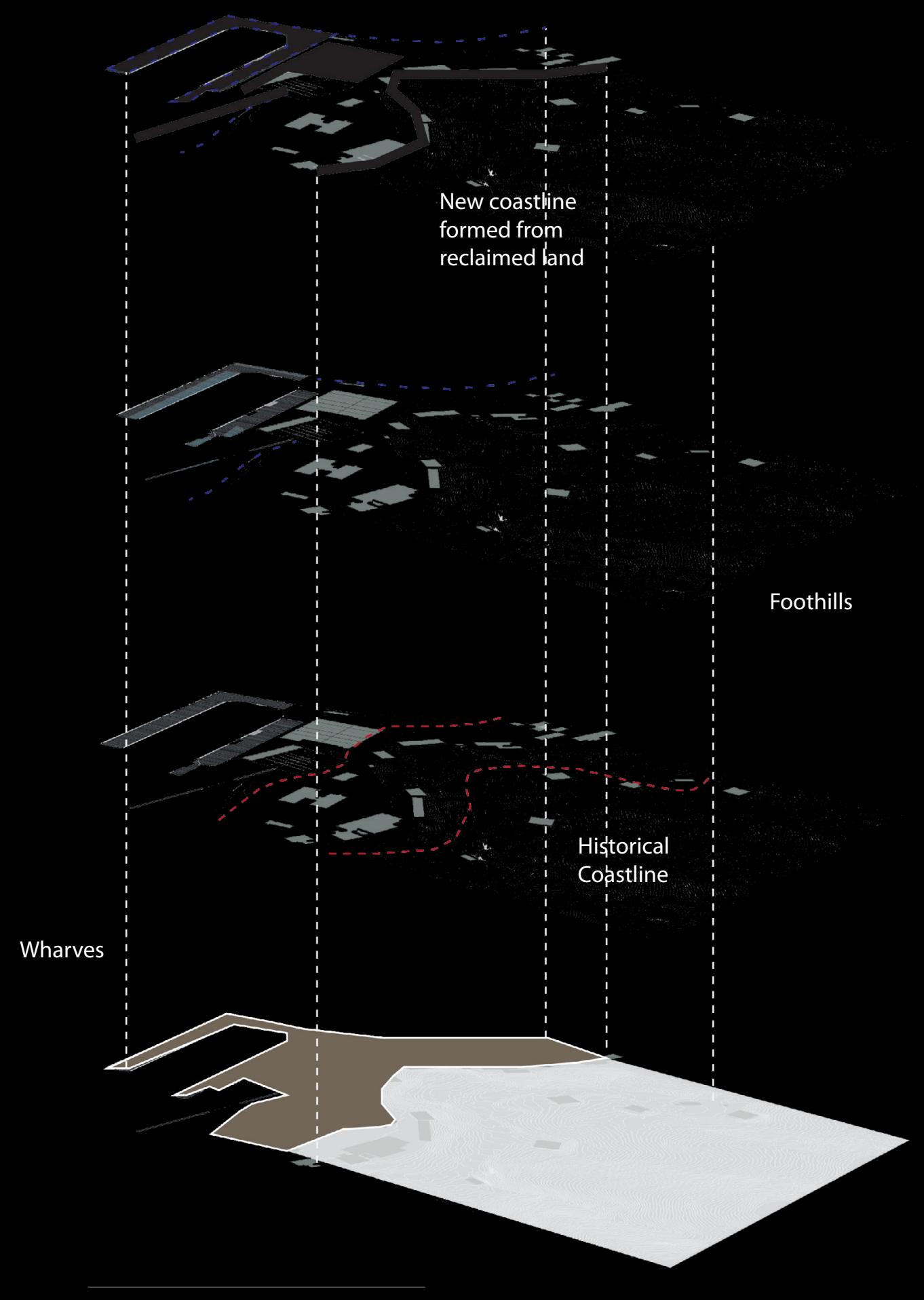

Since the closing of the Air Force Base in 1995, Shelly

Bay has remained unchanged, "The function of the

Buildings are almost exclusively limited to the flat land

in between the harbour and the steep escarpment to

the east" (WCC, 2006)

Figure 32. Perspective of
Shelly Bay. Sourced from
Google Earth and altered
by author.

Direction of Wellington City CBD
and Waterfront in relation to site

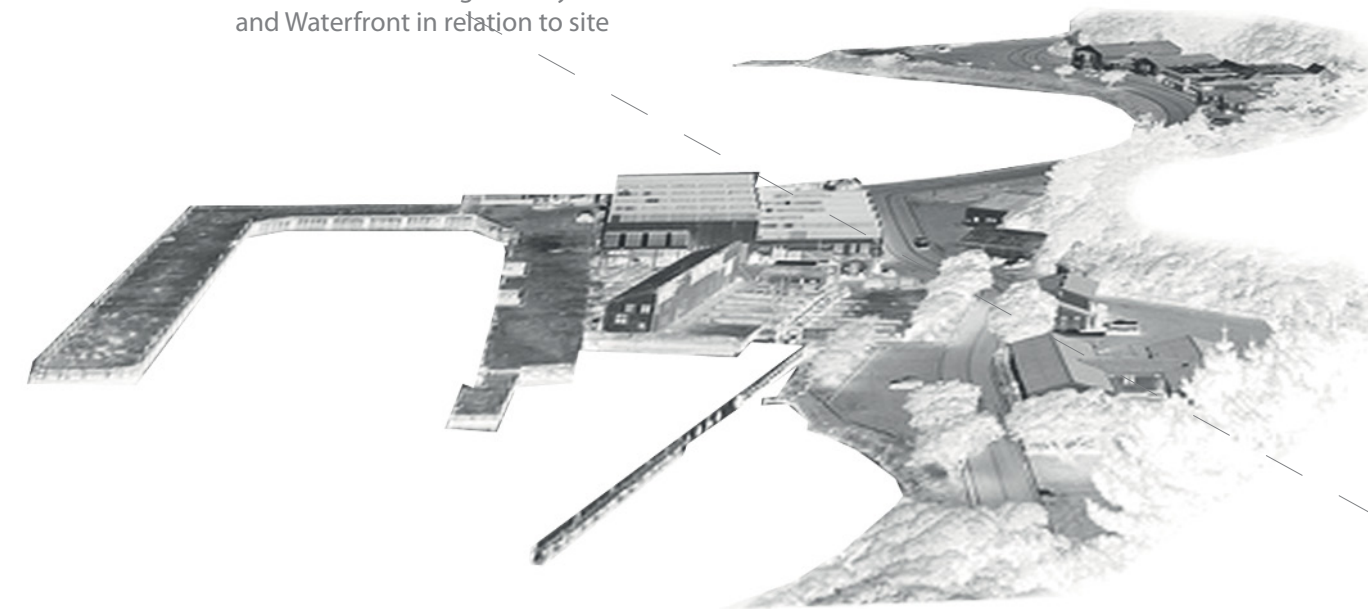


"To ensure that future growth and change reinforces the physical and spatial characteristics that make Wellington so distinctive, and contribute to the stimulating and intense urban experience it offers, the Strategy" (WCC, 2006, p2).

The strategy developed from the Wellington City Council reinforces the problem that will occur in Wellington City by 2026; population growth and radical urban expansion. The council expresses relevant urban development concerns for the city: "threats to heritage, poor quality interface between public space and private buildings, poor urban design significance improving the quality and design individual buildings" (WCC, 2006, p3).

31

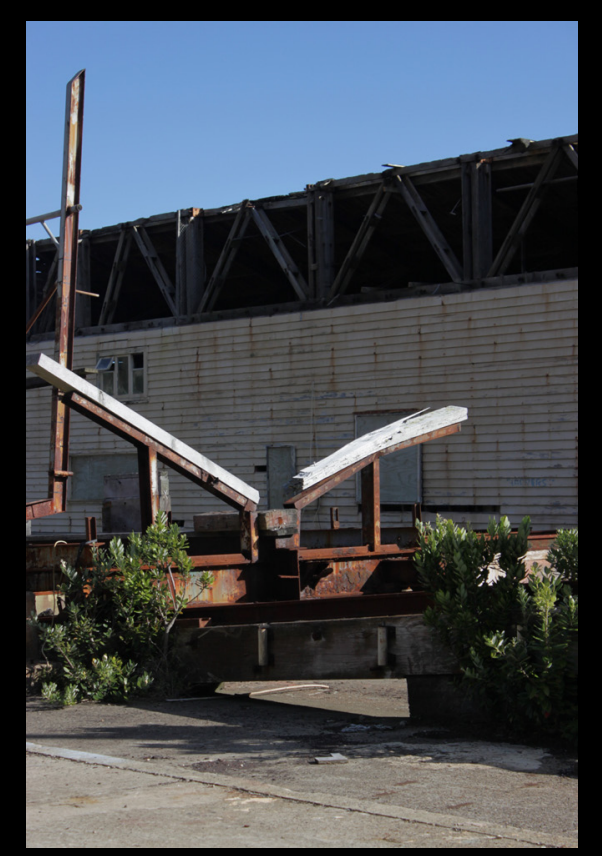

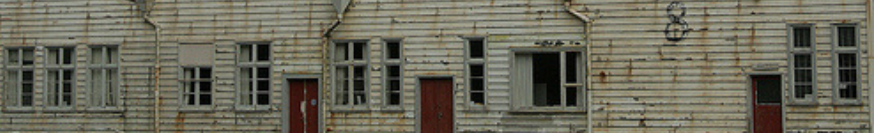
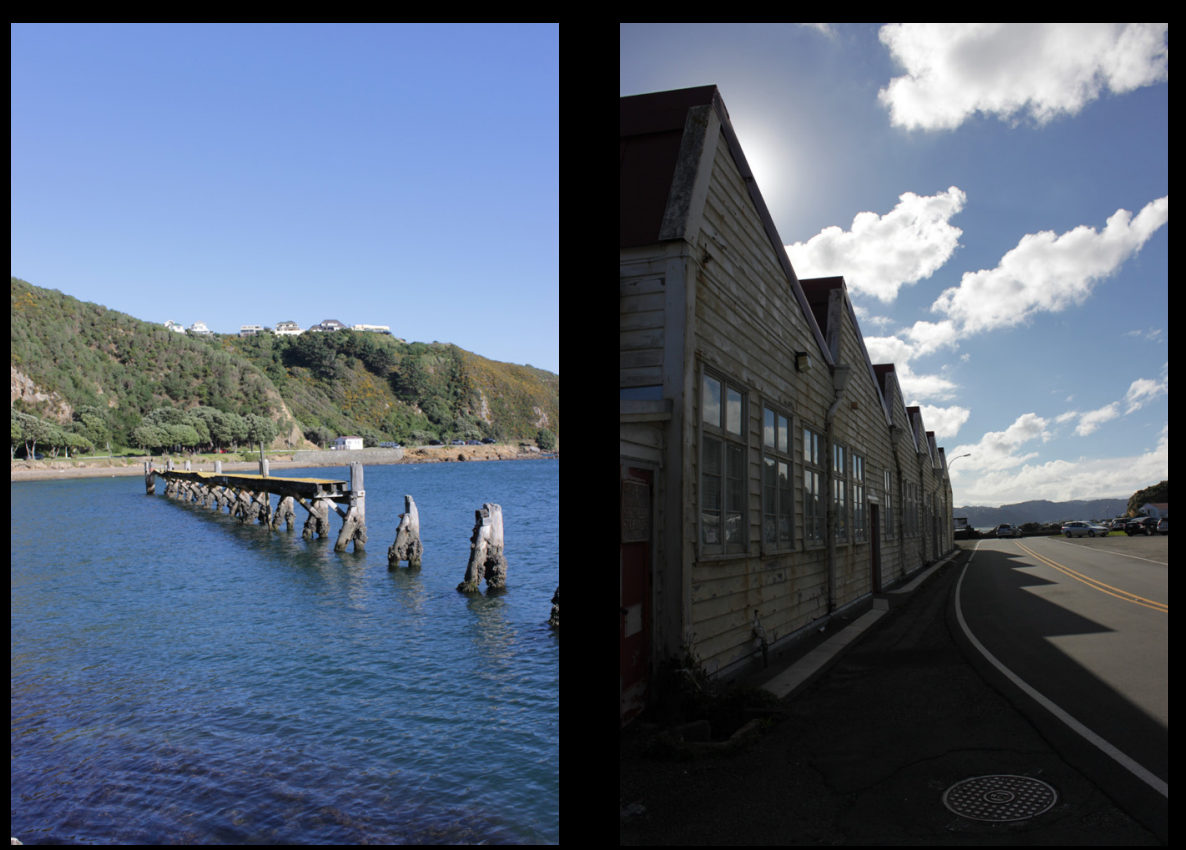

Shelly Bay is included in the council's scheme as capital project developed within the growth management framework, along the 'urban spine' of Wellington's urban growth plan (appendix, p200). Shelly Bay currently has a loose collection of medium sized timber buildings that are the remains of the Navy and Air Force occupation, "Shelly Bay is not a town centre in the traditional sense. The layout and design of buildings very much reflects the sites history as a miltary base. Buldings are sporadically spread within a landscaped setting" (WCC, 2009, p61). The council insists in its scheme that due to the prominence of Shelly Bay and its value to the community, redevelopment of the area will be carefully considered. In order to achieve a high quality urban design, the council have proposed that Shelly Bay be rezoned from a 'suburban centre to 'Shelly Bay mixed use character of the area while allow for the activation of new spaces and activities in the future. 
Sebastien Marot highlights four necessary steps in undertaking landscape projects within the urban environment, referred to in the book 'The Return of the Landscape' (Desvigne, 1998, p2-3).

These steps and approaches to designing the landscape, particularly ones within the current and future urban realm, allow an in-depth process to be taken on by a landscape architect. Marot's four steps include; anamesis, preparation, in-depth vision and relative thinking. In summary of Marot's steps, the first act is to decipher the signs visible upon the landscape that show the unique characteristics of its memory and history, and how these have shaped the landform today.

Next, the processes and the products of them, either existing or historical, need to be identified and pond cyclical processes. Following an investigation

into the relationships between the processes and the andforms needs to be taken; finding the habitats and spaces that exist between them. Lastly, how to insert a design onto a site depends on these relationships, and the transitions, sequences and visual connections between them. The design should amplify and respond to the unique characteristics, process and relationships within the landscape. 
- Anamnesis - "This consists looking upon an area of land or a public space as an expression of an ancient culture, as a sort of palimpsest on which one can discern the signs, visible with which one can discern the signs, visible with on the site over time and has contranspired the shaping of that specifc space of londsce to the making it what it is and not som landscape, Ans A particularly over the course of time" (Desvigne

The investigation of the history of the site revealed a number of groups that occupied Shelly Bay, contributing to the signs that are visible on the site today. These signs show spaces than have be excumple the old coastline was historically a good source of food for the Maru-Kai-Kuru

Design concepts will be developed considering the reinterpretation of these signs on the collective memory of the site and the topographical memory. A seam needs to be formed between the historical culture (the Maori and military occupation) and the future use of the site within the public urban environmen of Wellington.

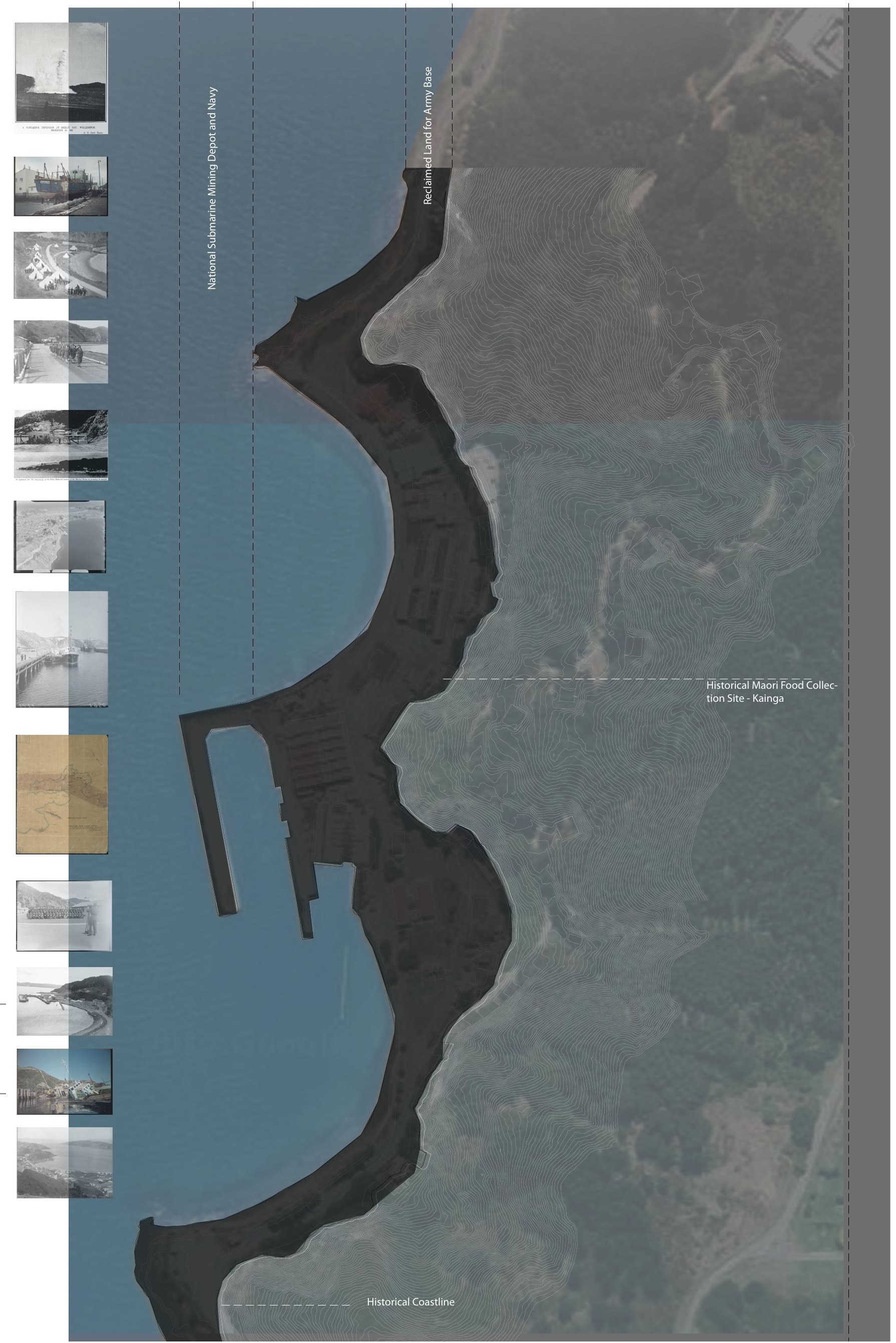

36 
- Preparation - "Since a landscape is looked upon more as a process than product any project should take on the character of an open-ended trategy" No reading or portrayal of a site can be all inclusive a landscape can provide a process or ication of being through the elements of the che f such as the seasons, thecliche of water, day and night, and growth and decline. "By bringing these back to life, one seeks to give the residual spaces, those that have been abandoned or cast aside, the ability to revive and rejoin the present - and history - by accepting or demanding uses that are not yet foreseeable (Desvigne, 1998, p2).

37

First impressions of site on visit:

A degraded man-made environment, where the hatural elements have taken over the site. The rocky coastine dominates the end point of Shelly Bay. The fiat reclaimed land is dominated by the road and buildings.

These impressions led to the understanding of the contextual and climatic conditions of Shelly Bay. The character the site inflicts upon the man-made materials natural affect an be utilised within a new design to reveal different aspects of the environment.
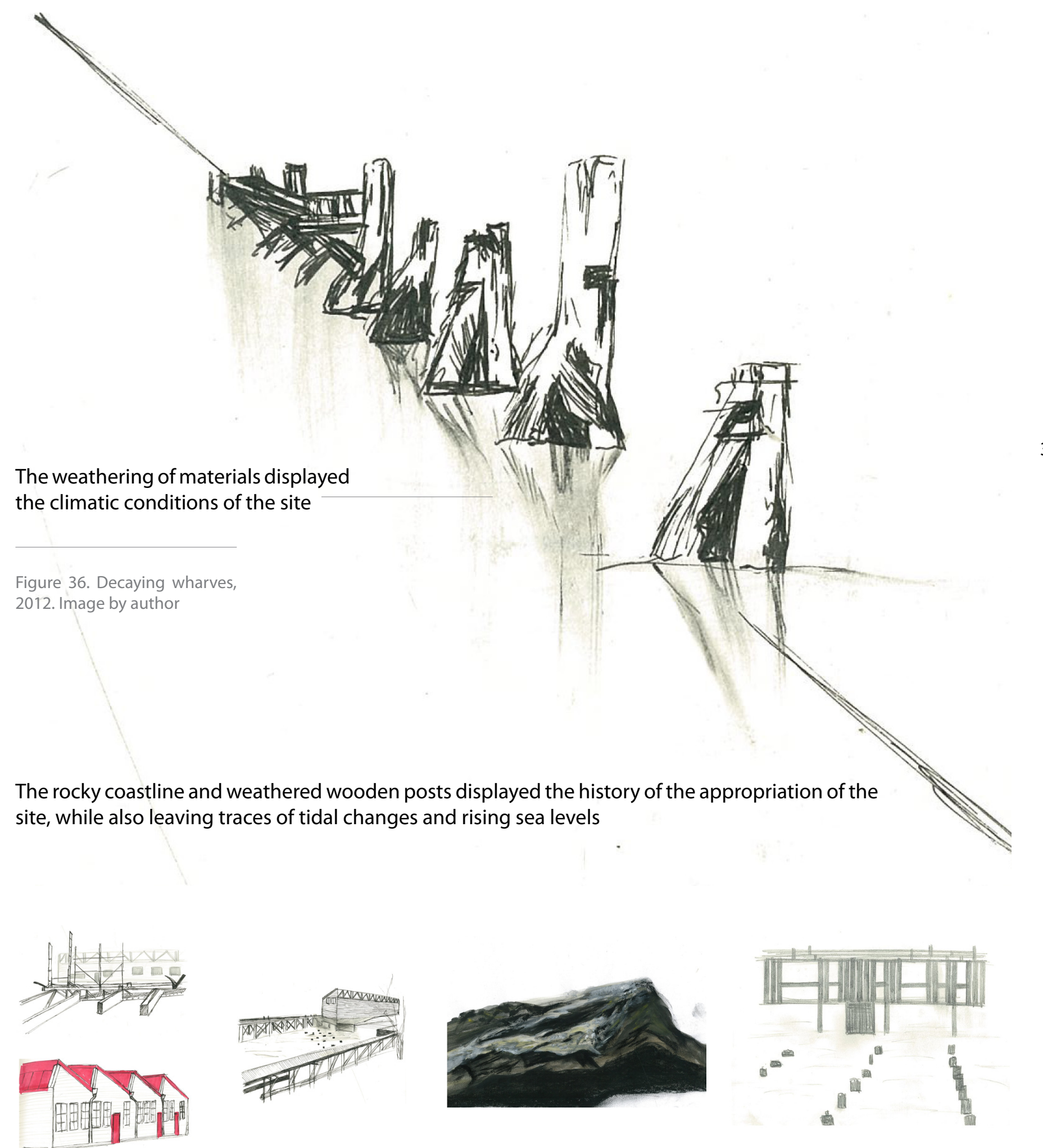
- In-depth vision - "Rather than reading an open space as an emptiness defined by a series of surfaces and by light, in-depth vision sees the open space as a habitat in which the sky and what is underground engage in multiple relationships defined by the nature of each of them. This investigates the layers and multiple meanings of a site and their relationships between each other" (Desvigne, 1998, p2).

The relationships on site between the reclaimed land foothills and harbour create an interesting open space that reveals a number of historical and contextual (1) elements about the site.

A design can be created that explores these elements and the relationships that may or can exist between them. How the design interacts with these elements site- der

The development of the site over time, and the development of the connections and retainships on site need to be determined These relationships could then be extended beyond the site and connect to other parts of Wellington City. Again this will be determined by the program and public use of the site.

Relationships and Connections on Site

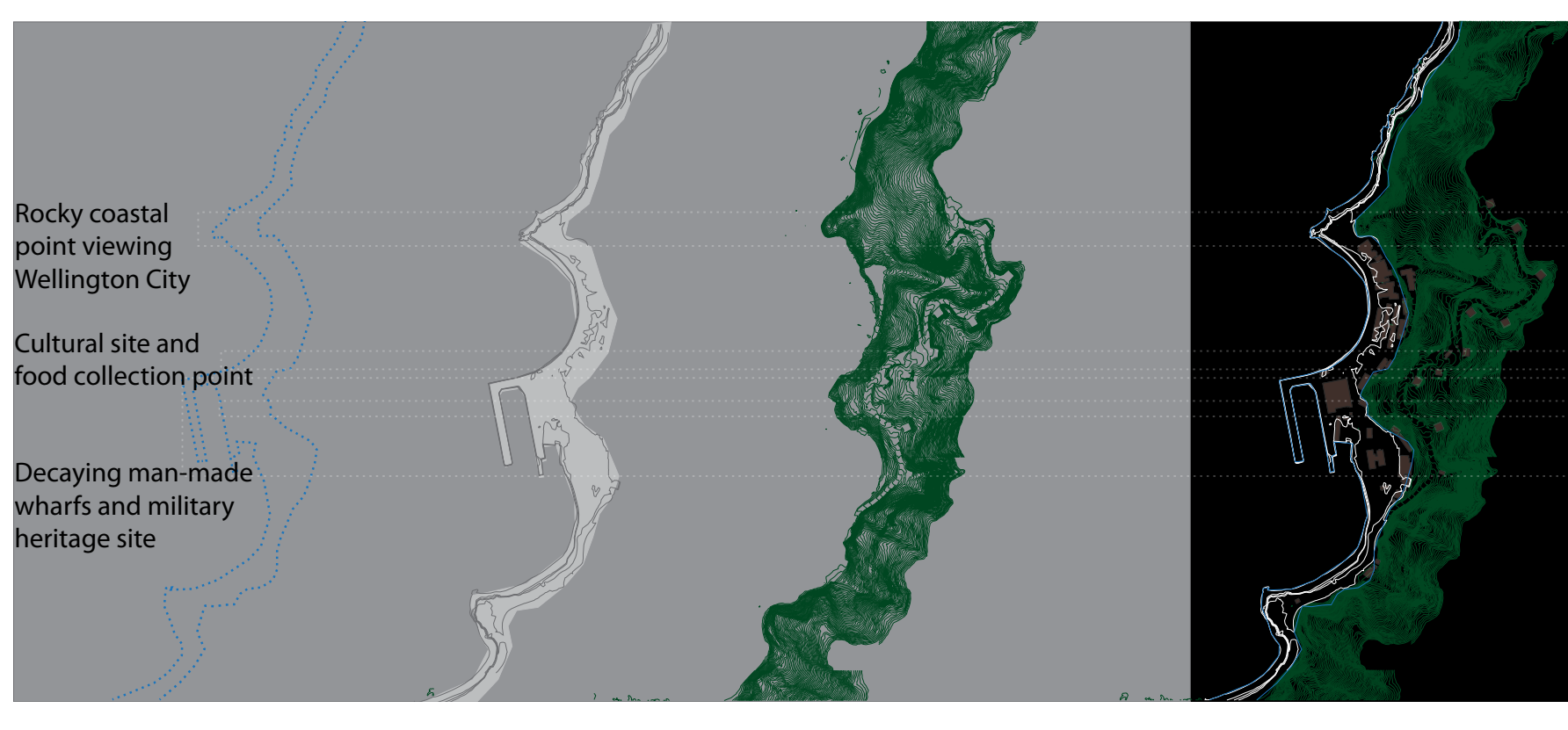

Coastlines Reclaimed Land

Foothills Man-made
developmen Figure 38. Image by author

Urban Encroachmen

The possible future relationship between Shelly Bay and Wellington's Urban Development Plan

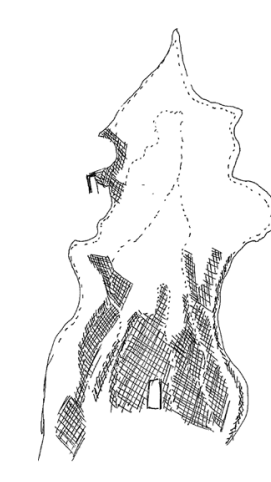

Density 2012

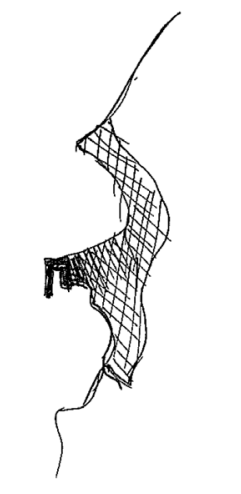

Possible stages
of developmen

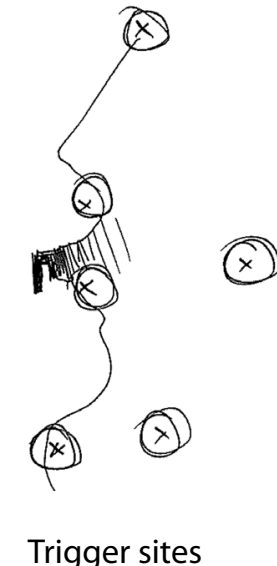

(

Trigger sites
40 
Relative Thinking - "The art of insertion, transition and transplantation... The quality of any public space depends not so much on the perfection of its buildings or its services, but rather on the quality of the relationships among them. These relationships are constituted by transitions, sequences, and visual connections (Desvigne, 1998, p3).

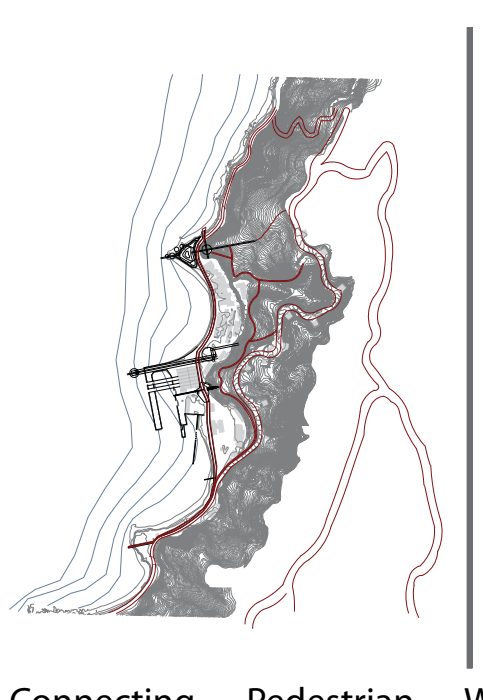

Connecting Pedestrian Walkways relationships based on 'In-depth Vision'

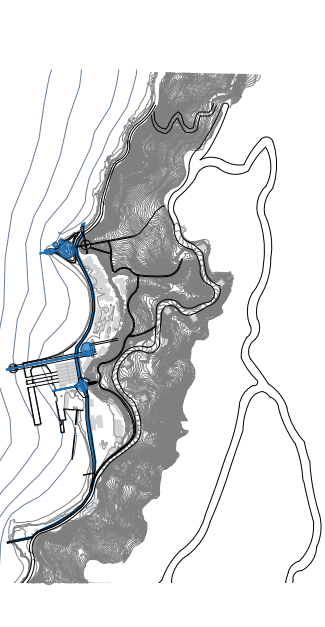
Highlighting historical

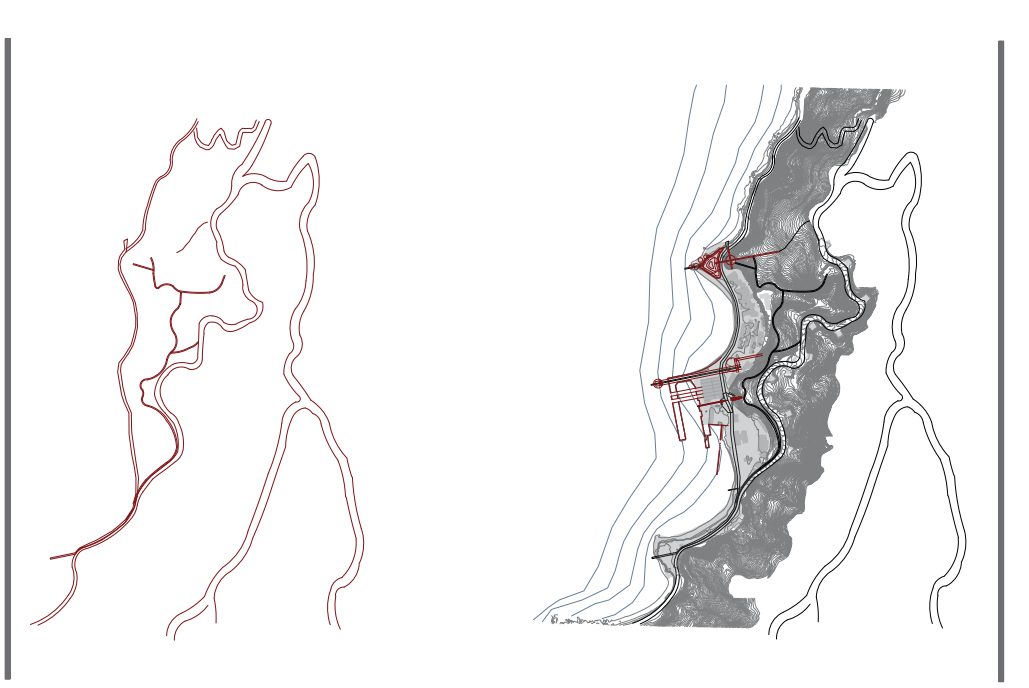

Physical Trigger Sites based on'Anamnesis'

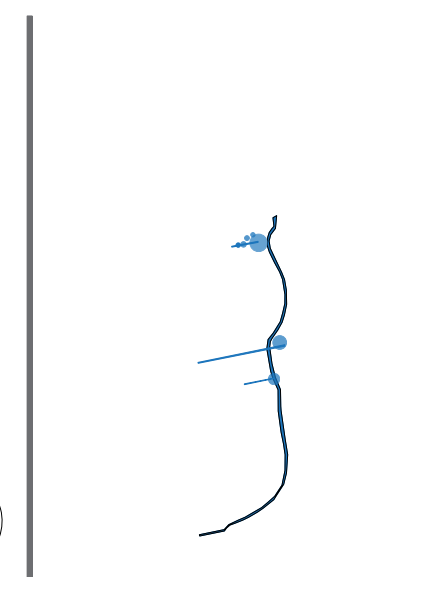

trigger sites in relation to sit=

trigger sites in relation to

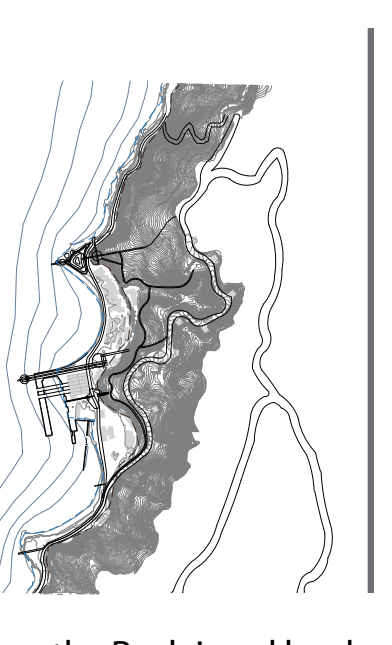

Investigating the Reclaimed land and edge condition design interventions. into the topographical history needs to be explored

Designs will create connections and seams with the natural harbour and foothills, bridging the reclaimed andscape.
42 

Research conducted into the history of Shelly Bay; cultural, military and topographical, has revealed occupation of the Maru-Kai-Kuru and Kainga sites as well as the military occupation (naval, army and as well as the military occupation (naval, army and
air force), have been formed around the natural and developed topography of Shelly Bay. A study of the
dir force), have been formed around the natural and developed topography of Shelly Bay. A study of the
current site conditions revealed the climatic elements affecting the site and built materials. Utilising Marot's four steps in approach to site, existing relationships, processes, visual connections and characteristics were identified.

This analysis has led to identifying possible trigger sites, access ways, and areas to implement different programs. An investigation into the man-made landscape combined with an analysis of time and permanence within the built and natural landscape porm a design experimentation within shelly Bay. 


\section{The Man-Made Landscape}

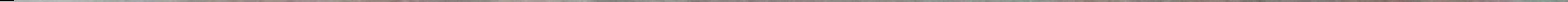




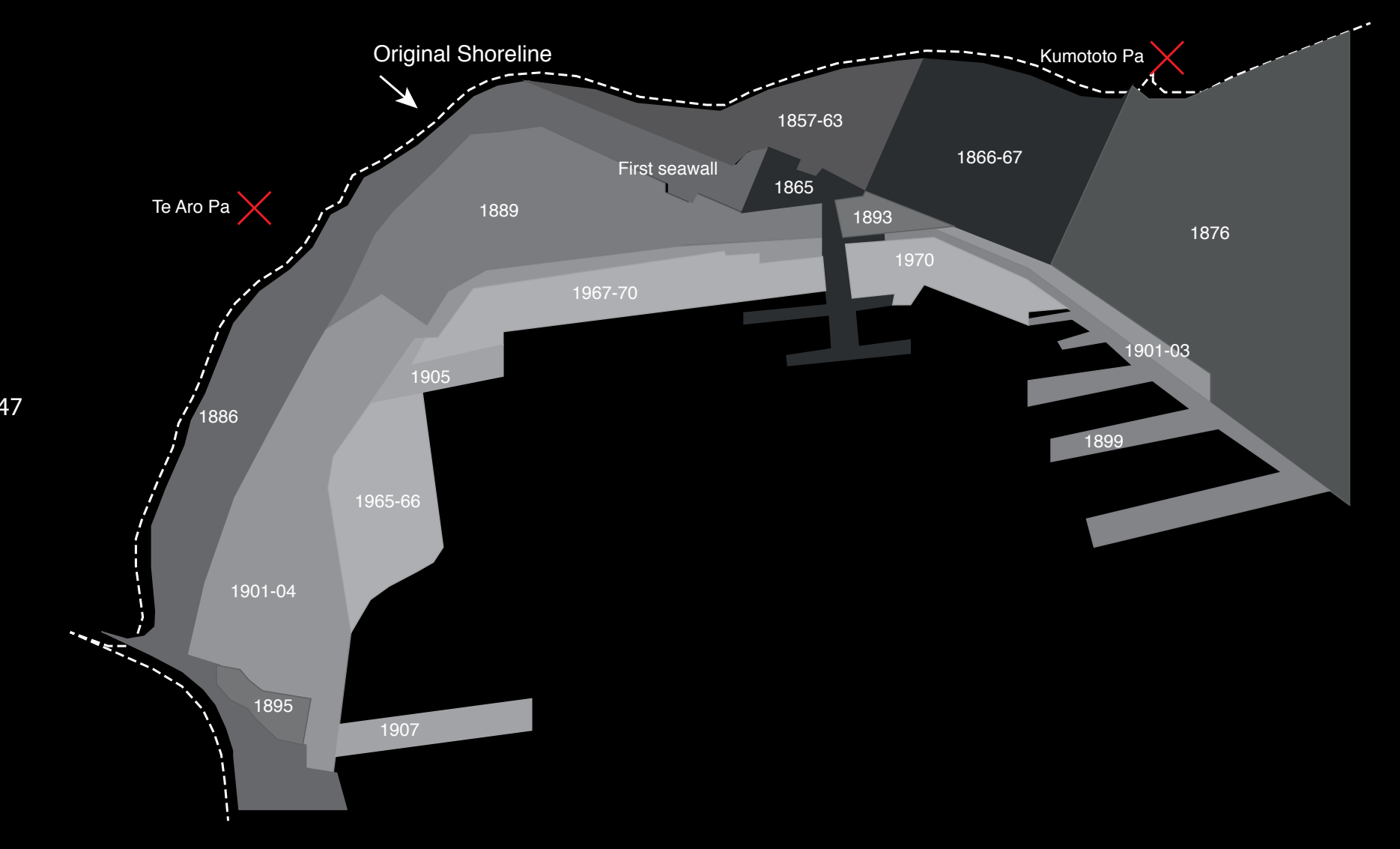

Wellington Waterfront

Reclamation Map Following Marot and Crinson's ideas, landscape the landscape, can represent how the historical forms of the topography have been shaped by the utilitarian infrastructure imposed upon the site. In the book Memory and Transformation, identity is a concept that Hoekstra and Meggelen believe is a constant changing theme in relation to landscape. Identity can be designed to bring together the fragmented cultures of our society, as people search for their identity in the regional landscape, "The landscape is not an abstract, but an environment in which we live and which we experience materially... The landscape is constantly changing, sometimes to regain itself, sometimes to change its identity (Jandirk Hoekstra, 2008, p. 17). Can this concept also relate to man-made structure as society and culture changes with it? This identity with the same idea in Marc Treib's 'Nature Recalles as he addresses the need for Landscape Architects to design for time and change.

Reclamation is a part of societies process for expansion, to gain more space to build upon most commonly within the urban realm and along waterfront areas. However, reclaimed sites may also be heritage sites, layered in time and culture. Wellington has a number of reclaimed sites, including Shelly Bay. Landscape architects need to be able to design these landscapes to reflect the layers of memory upon them. Simon Schama, landscape architect theorist, states that "Landscape is stratified heritage. Landscape is culture laden with values...changes cannot be implemented with impunity as though the landscape were no more than a means of production (Jandirk Hoekstra, 2008, p. 17). Reclamation may be a part of a site's Tratified heritage. Kt is clear from Dim Silimon's essay and Transformation) that a meaningful engament and understanding with history is one of the most important tasks in designing as a landscape architect. By engaging with the layers of memory on the site. This may include the act of reclamation.

Figure 41. (Previous page). Decaying building in Shelly Bay, 2012. Photo by author
Figure 42 . Wellington waterfront reclamation map. Not to scale.
Image by author
Identity and traces can be implemented into the design process to reflect the collective memory of the community and the memory of the landscape, "Many people have seen the landscape they grow up plays an import..That is what affects people. That aspect of a district, region or country" (Huisman, 2008, p. 145). This may also affect the identity of the people themselves.

Reclamation can be seen as making a new place. Through the implementation of man-made design and materials upon the natural landscape, a collaboration of memory and identities are formed. One can argue that reclaiming land, taking land from the sea and giving it over to the city to increase urban density Hects of the history of the area, it may now be a part of the collective memory of the site. Perhaps here lies the opportunity for designers and policy makers to make the public aware of the forcible changes man-made infrastructure has had upon the natural systems and formations of the landscape. In a way to highlight what was or was not there originally, knowledge can be given to the public of the city and landscape they live within.

In the essay 'Implications for Place-Making', the autho Speed explores the Sacred Environment and whether its value is innate or intrinsic. How we experience place determines how we perceive it, and how we perceive it determines our attitudes and behaviour towards it. The reclamation of Wellington's harbour has shaped the waterfront public and commercia space realm. The limited flat area within Wellington City, especially around the harbour, has provoked the therefore allowing for a growth in urban public spaces, "Land was scare in Wellington from the beginning. with few spaces for public buildings or parks and public access to the harbour restricted to the northern end of the town. The need for expansion out into the harbour was soon realised..." (PWW, WaterfrontReclamation, 2004, para.2).
48 
The Historic Places Trust has placed 14 plaques around the city from Thorndon Quay to Oriental Parade, tracing the original shoreline, marking and reminding the public how much the development of the city owes to the act of reclamation (PWW, WaterfrontReclamation, 2004). One questions if these plaques are the most relevant and engaging designs to display the memory of Wellington's waterfront. Static designs that do not allow public interaction and experience, may fail to become relevant, especially as the city conthues to velop while these designs remain stuck in time.

dentity and memory are not stable and objective hings, but representations or constructions of reality and invoked by constructing non-reality. The idea of highlighting the extreme act of reclamation, one that takes land from the sea as well as redefining the natural forms of the landscape seems crucia in representing the layers of history and memory upon Shelly Bay. This will be investigated within the concepts of remembrance and recreation within the man-made landscape.

"Such a re-examination of infrastructural space involves the recognition that all types of space are valuable, not just the privileged spaces of more traditional parks and squares, and they must therefore be inhabitable in a meaningful way...Landscape urbanism also suggests that this happens by an instrumental engagement with ecological processes as well as with the function of infrastructure and the social and cultural needs of the community..." 


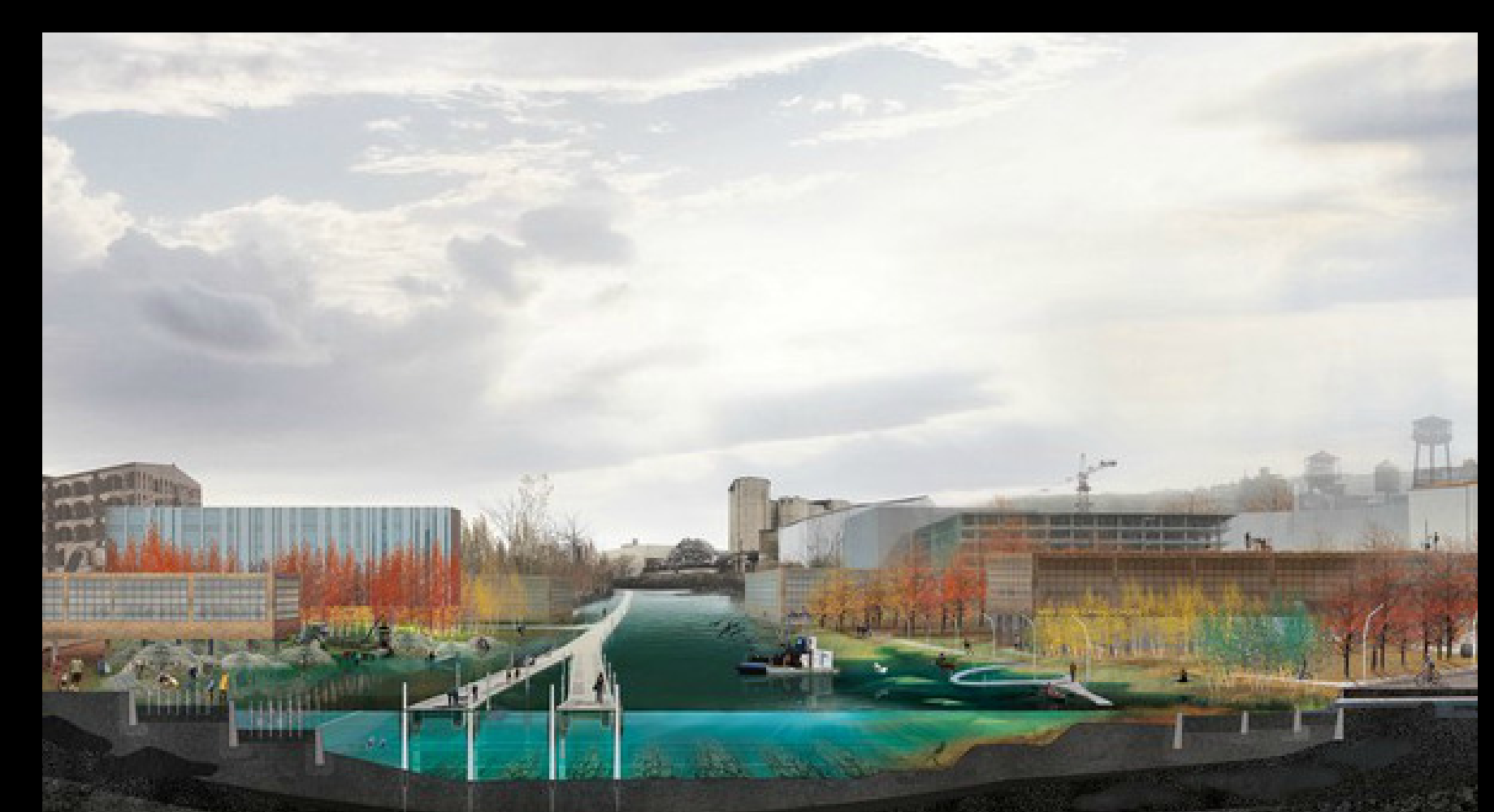

53

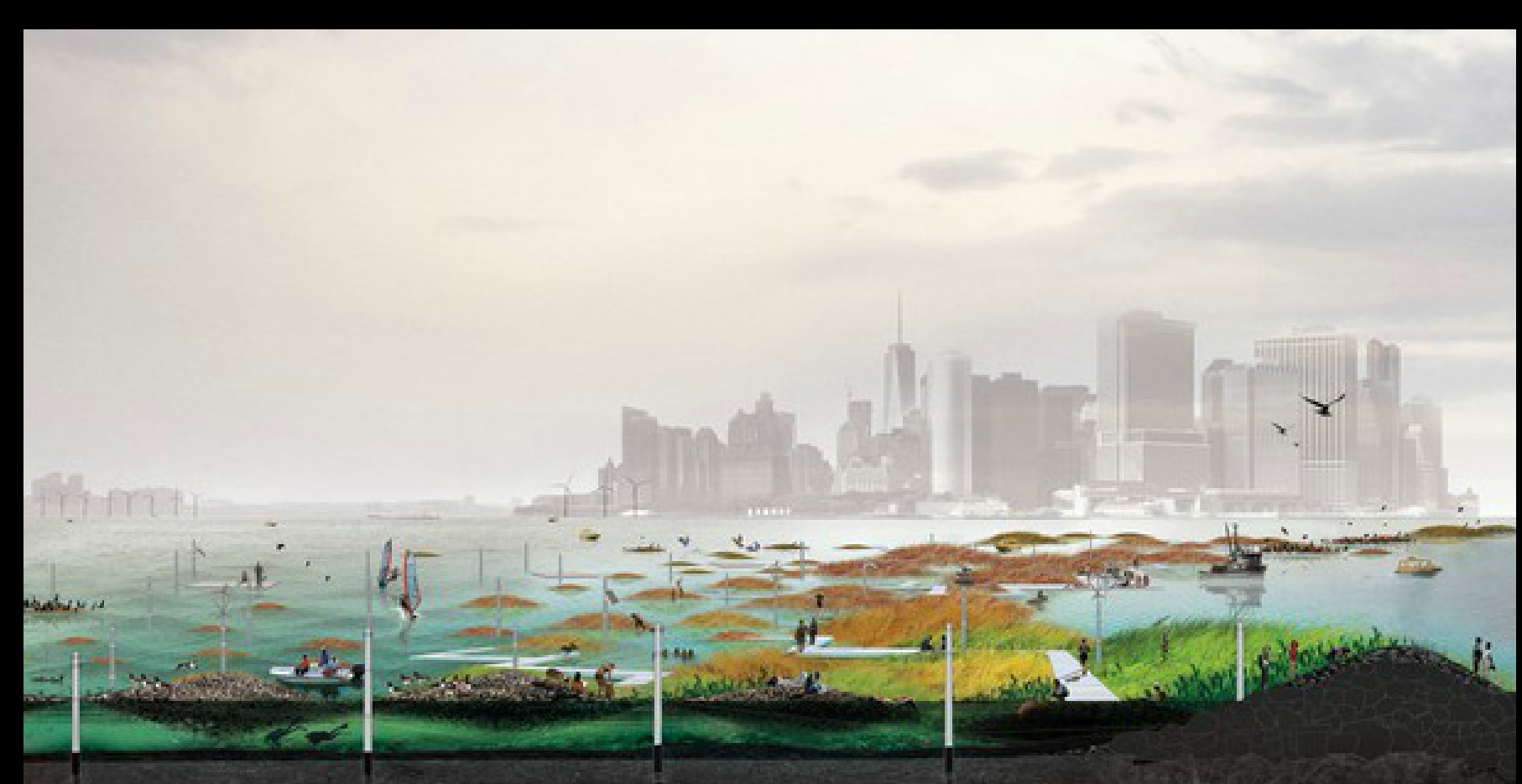

C.
3.3 Memory Collection Within the Built Landscape

Case Study: Oyster Tecture,
The Gowanus Canal, Scape Landscape Architects

Based within New York Harbour and the Gowanus Canal, a nativeoyster and marinelife has been designed to grow within the shallow waters constructed on piles of a woven web of fuzzy rope. This project represents a vision for the future of the harbour as it prefigures the city's return to the waterfront, cleans millions of gallons of harbour water and restores the native oyster to the marine environment. The structure of the design supports oyster and mussel grown and bu

Recreating Natural Processes The way in which the designers have analysed the site polluted waterwaysin Americandispro thos The designers have identified historical processes and signs that give the canal its unique characteristics. As a result, Scape Landscape Architects chose to revive the natural oyster growth of the canal, using their natural filtering processes to help clean the contamination of the harbour, "We propose to nurture an active oyster culture that engages issues of water quality, rising tides, and community based Brooklyn's Red Hook and Gowanus Canal" (Scape OysterTecture, 2010, para.1).

The design, dubbed 'Oyster-Tecture,' generates a new public landscape, activating the post-industrial canal edge. The creation of a series of oyster nurseries, combined with underwater scaffolding and reefs, takes Fon the Gowanus community. Currents' exhibition (figures $44,45,46$ ), thansition spaces and pedestrian walkways connect the oyster nurseries. These would generate relationships between the natural processes, the regeneration of the harbour, and the developing waterfront community.

This design responds to a site layered in history. The site was once upon the edge of the urban realm which is now encroaching upon it. The architects response to these issues is relevant to this thesis as the relationships and processes created respond to memory, past, present and future, within an expanding urban environment.

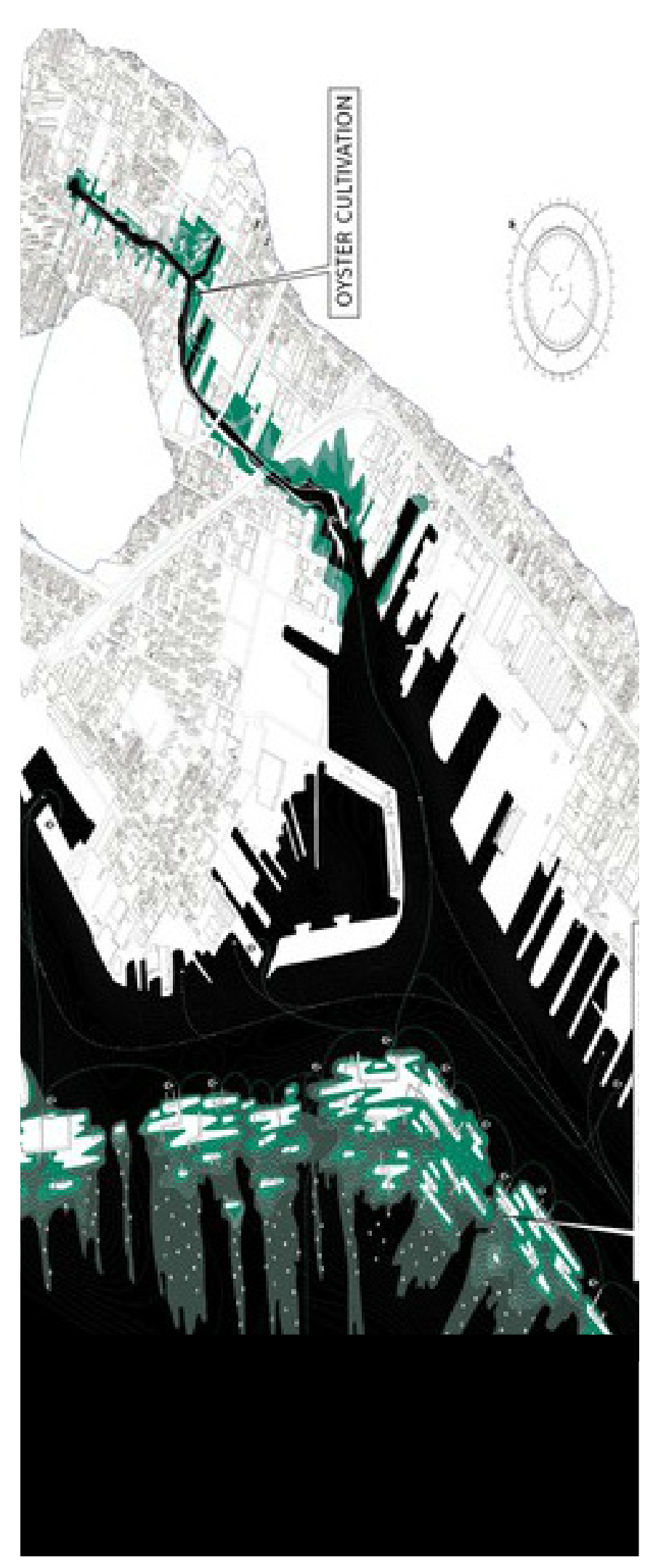

Figure 46. Plan of Oyster Tecture design by Scape, Sourced
from hitpip//www.scapestudio.com/projectstloyster-tecture/ on 


\subsection{Conceptual Design}

A decision needs to made on whether to A decision needs to made on whether to
accentuate the sites existing memory forms and typologies, or rather blur the edges of the sites memory, creating contrasts that spark past stes memory, creating contrasts that spark pas

These concepts explore how to amplify and respond to the unique characteristics, processes and to the unique characteristics, processes and
relationships within the landscape by applying Marot's four steps and the Gowanus Canal case study. It may be possible to re-create memory by highlighting the palimpsest of signs still visible upon on the landscape. This concept is shown within diagram two. Diagram one is exploring the possibility of blurring the edges of remembrance. The typology memories on the site reflect the historical occupations as well as the remaining built structures. However the context of the site, climate and time have influenced these signs to create a weathered man-made landscape. New design interventions could explore how to blur the historica events and signs with a new program on the site.

To explore the idea of recreation and remembrance details in the design also needs to be considered. The material and weathering can display the memory of the collective memory of Shelly Bay. The detailing of the design can show re bielly bay. The detaing of may on site. This may also reflect the in memory of the site with the interprettion of these

Diagram 1: Blurring the Edges

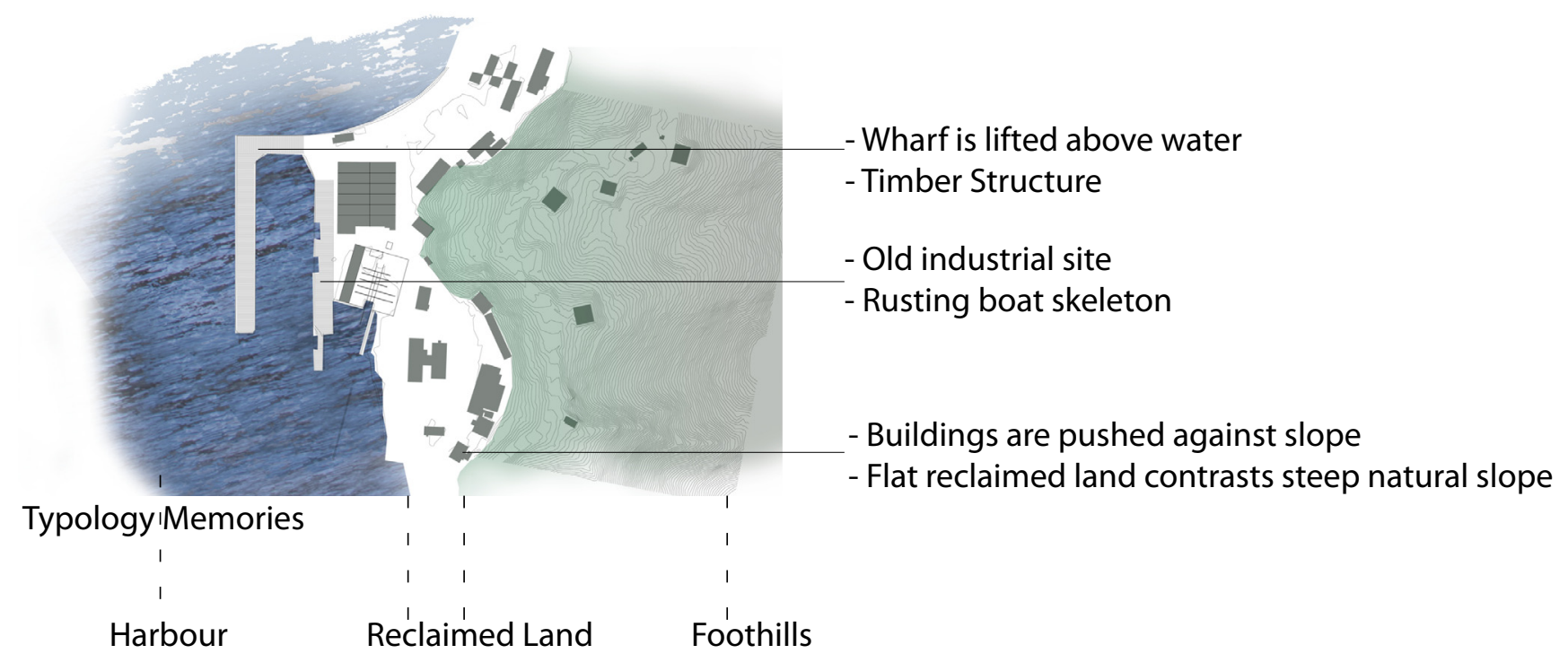

Diagram 2: Accentuating Existing Memory Signs

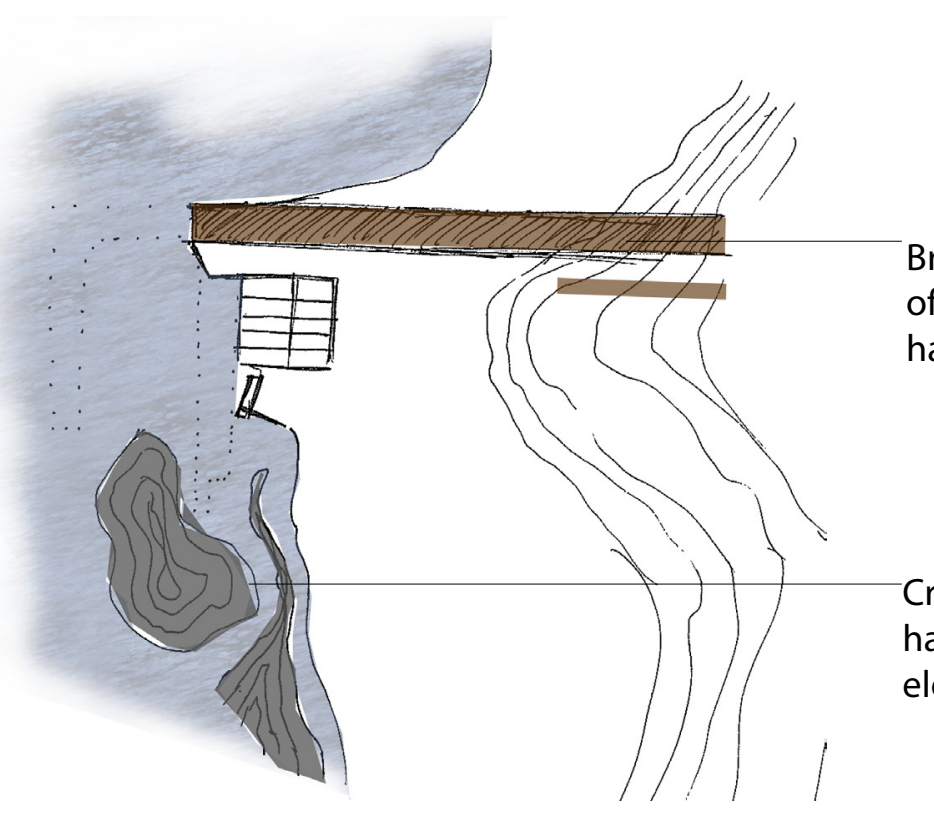

Bridge structure of wooden walkway linking old form Dharves to hillside, providing access to views of harbour and Wellington City.

Creating elevated areas within the shallow spaces of harbour, possibly creating tide pools and contrasting elevations in memory and existing forms. 


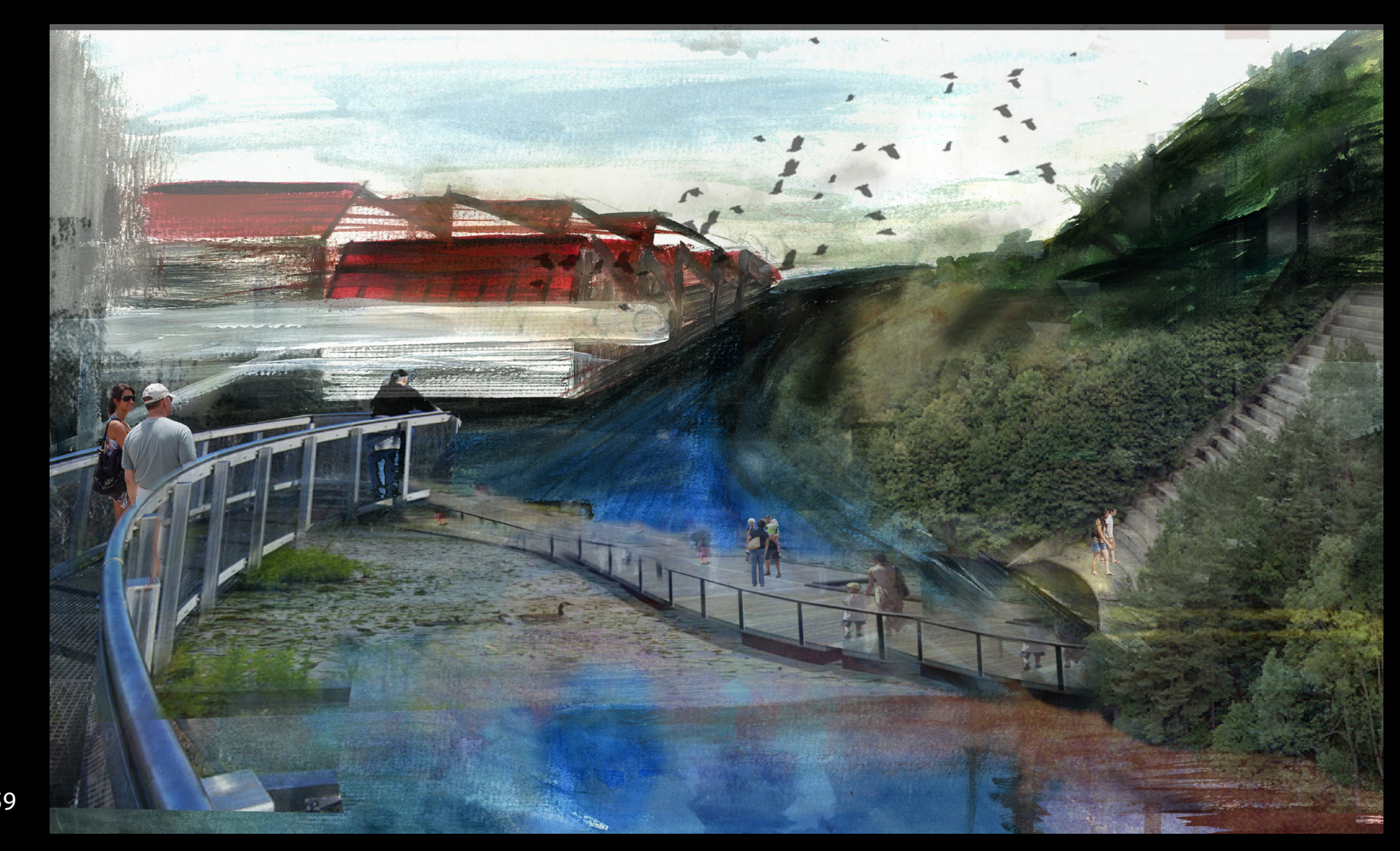

Further exploration of possible conceptual design options can reflect the identity of the site, both de and natural, through recreation and remembrance. The following images are an avenue of investigation
explored on site. The design concept reflects the history of the site and the occupation. Through the analysis of Marot's four steps on approach to site, this initial site design has been created.

The intervention of a man-made canal traversing the foothill edge is responding to the typological history of the site. By recreating the historical coastline through a man-made infrastructure, the change in form of the land is remembered. A new typology has also been created, a cycling of water that could be incorporated into a filtration process, cleaning the harbour water.

The canal has been designed to act as a connection between the different programs on the site.

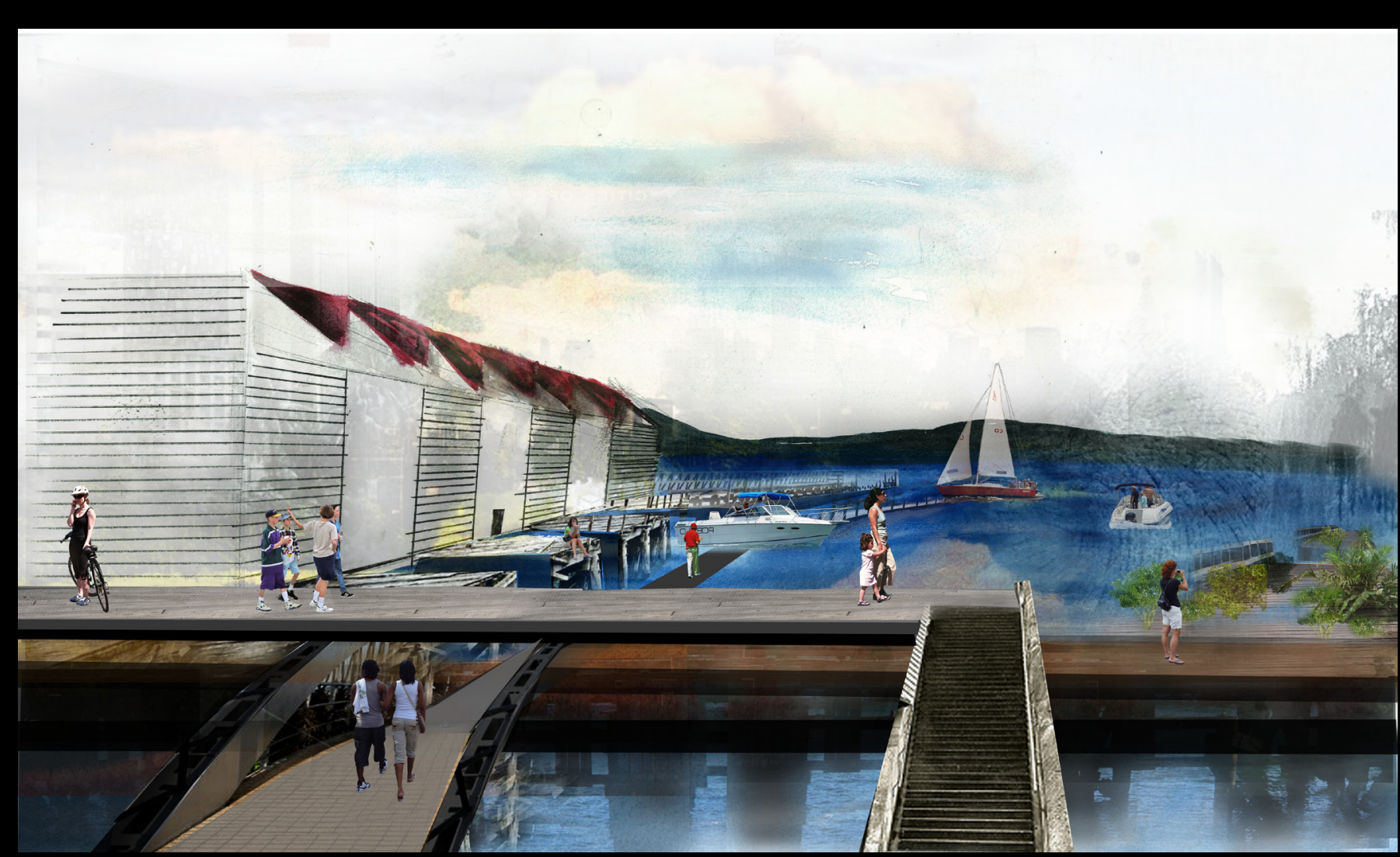


$\because$

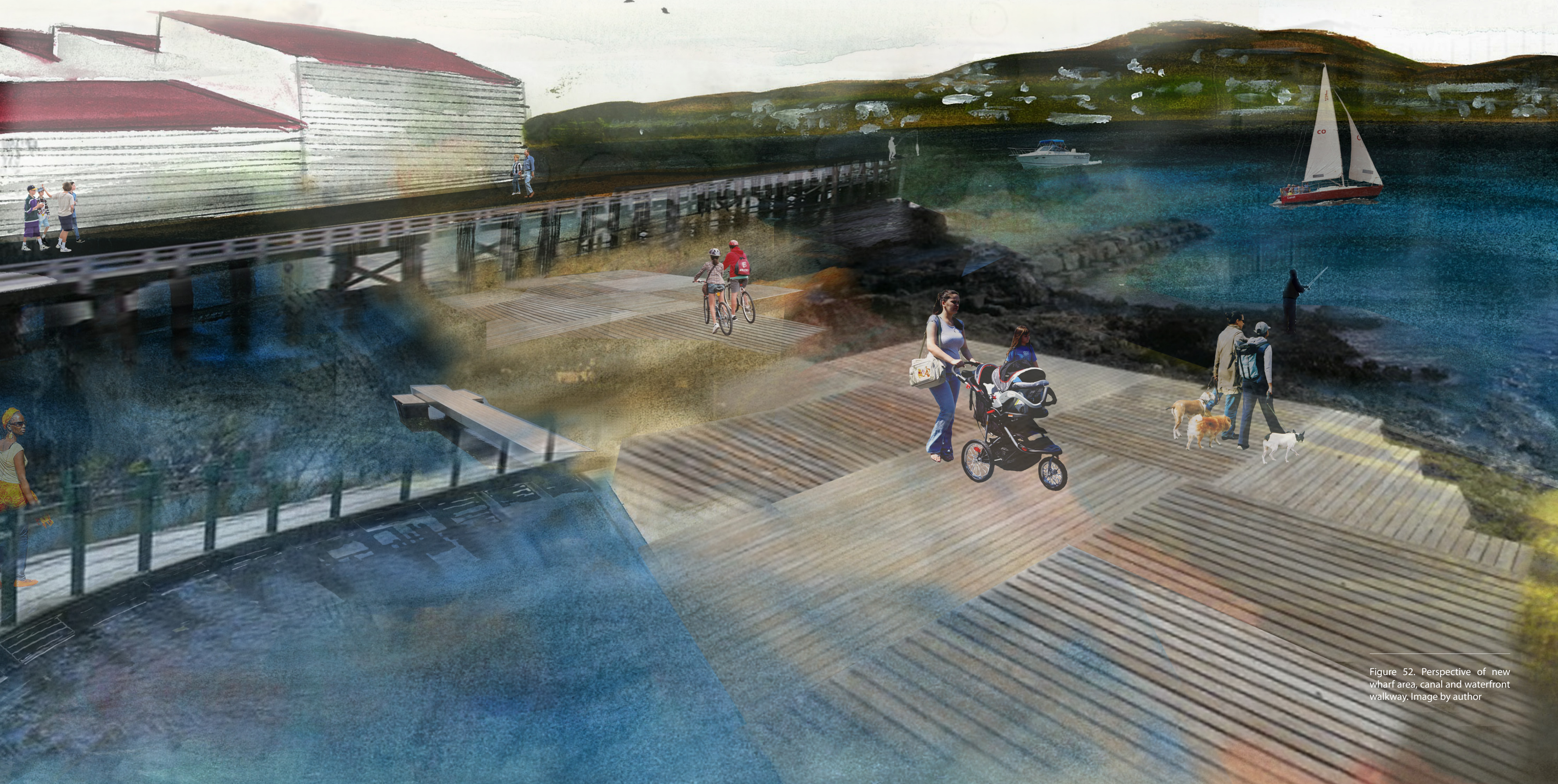




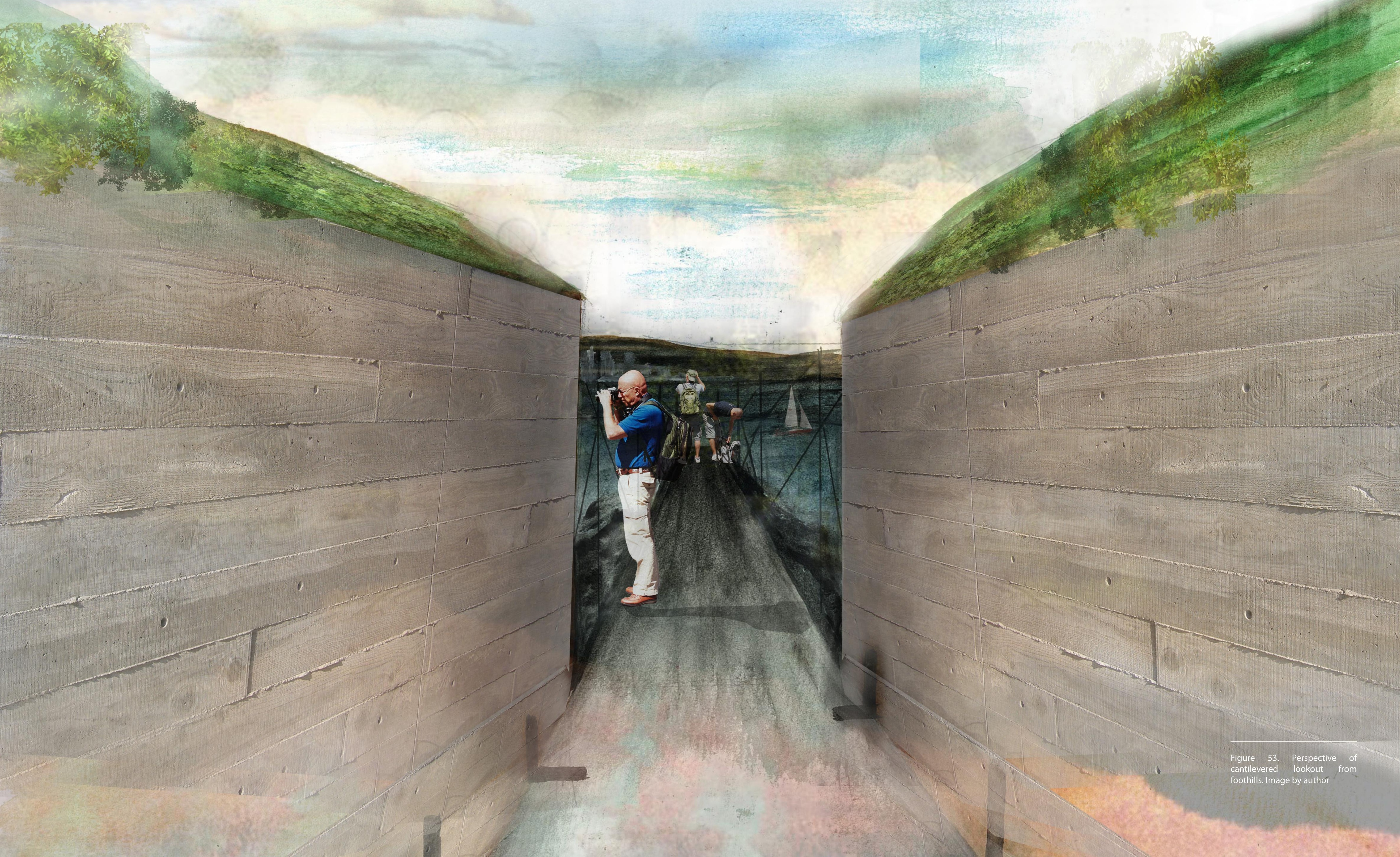




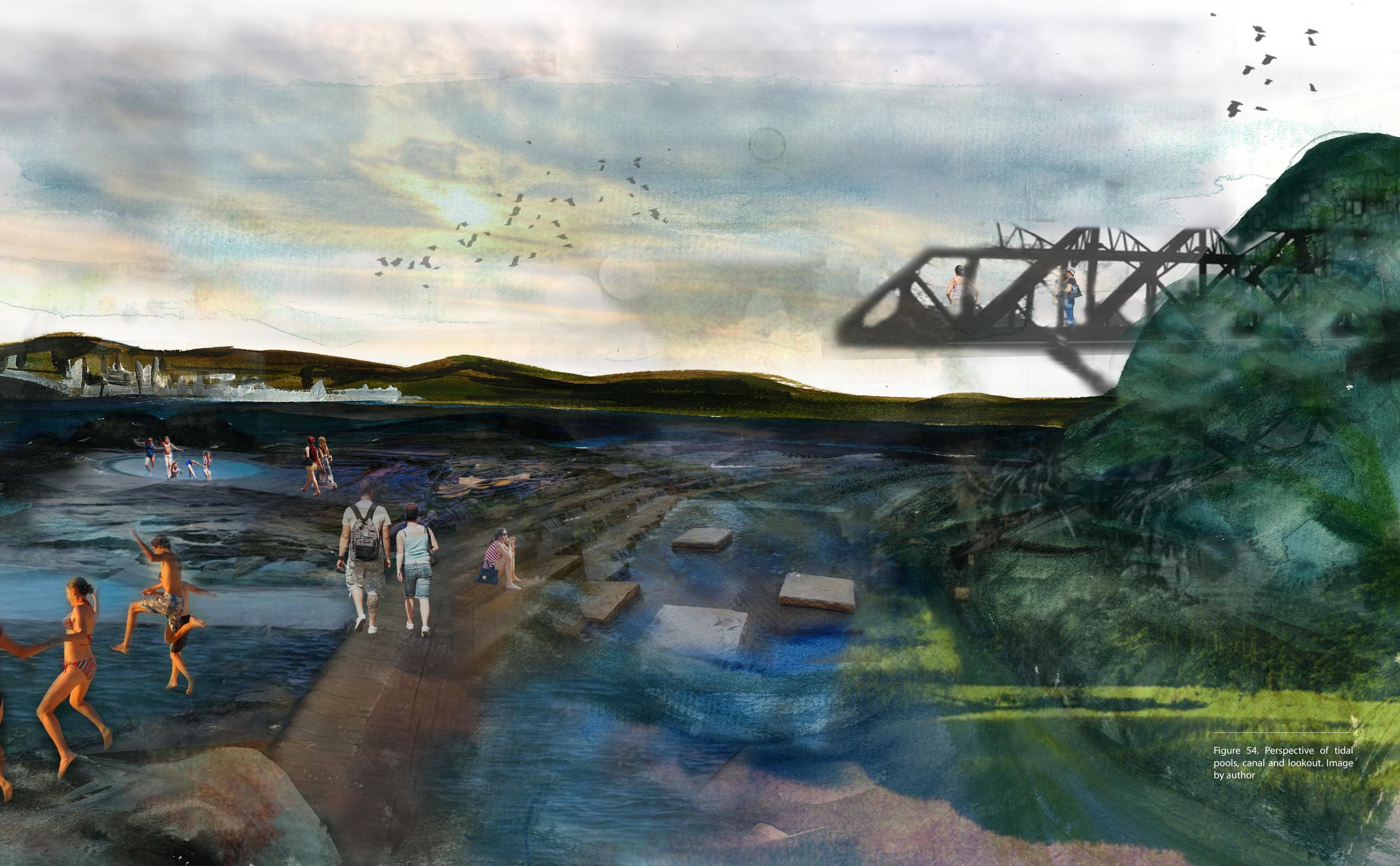




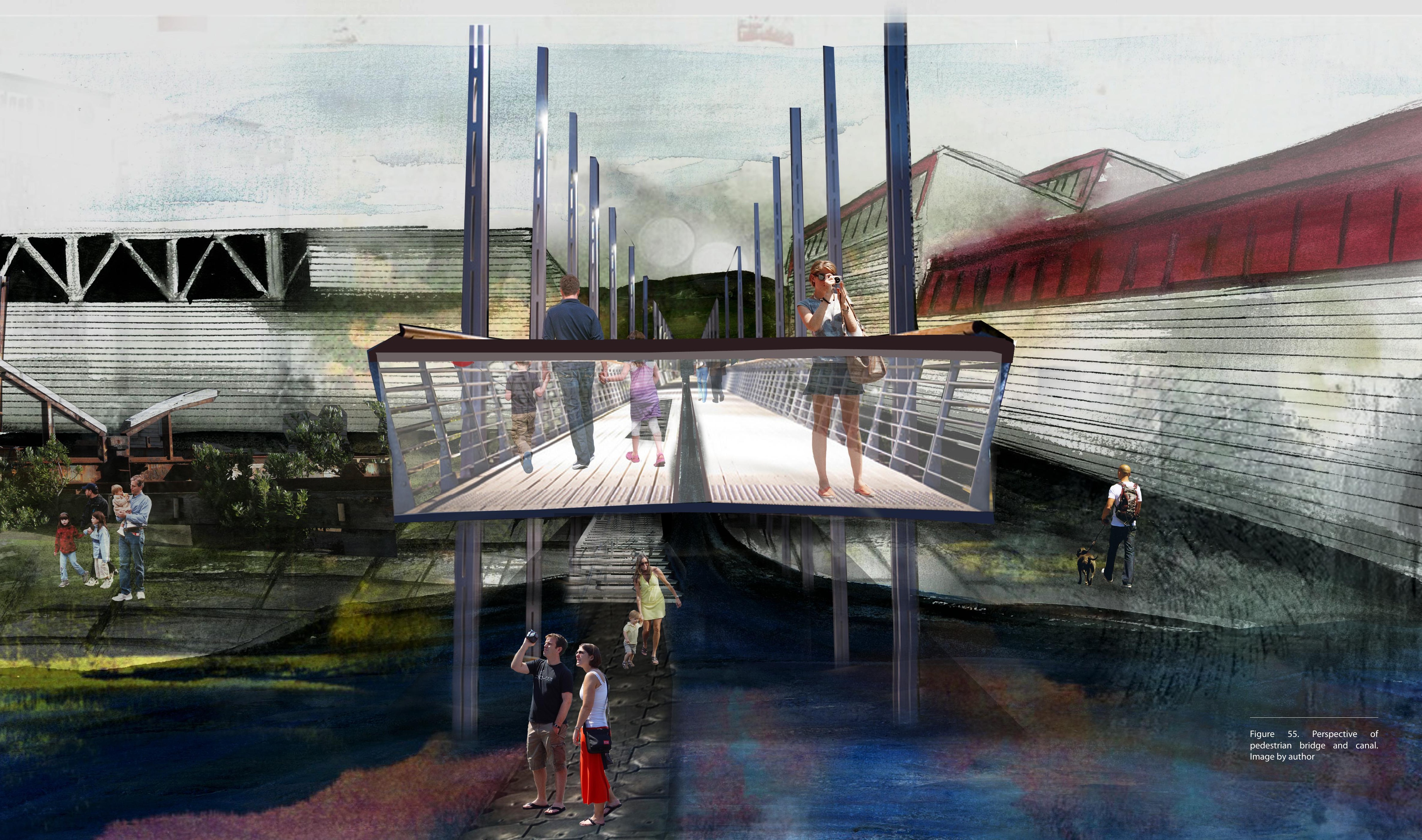


This investigation into the man-made landscape has brought forward concepts that specifically highlight memory within the landscape. The concepts of
identity, remembrance and recreation, have formed conclusions used to create conceptual designs specifically for Shelly Bay.

Reclamation was found to specifically reflect the collective iden on and use, including the built environment. Remembrance and recreation were explored in terms of concepts of memory transferable into the built environment. The investigation of these ideas, combined with the analysis of the two case memory within Shelly Bay.

These design concepts reveal a reflection of the program needed to anchor and reveal memory of the Shelly Bay and Wellington City. An investigation into time and permanence, specifically materiality into time and permanence, specifically materiality and
weathering, will allow these conceptual ideas to become grounded in reality, and at a smaller scale on the site. 
4. Time and Permanence

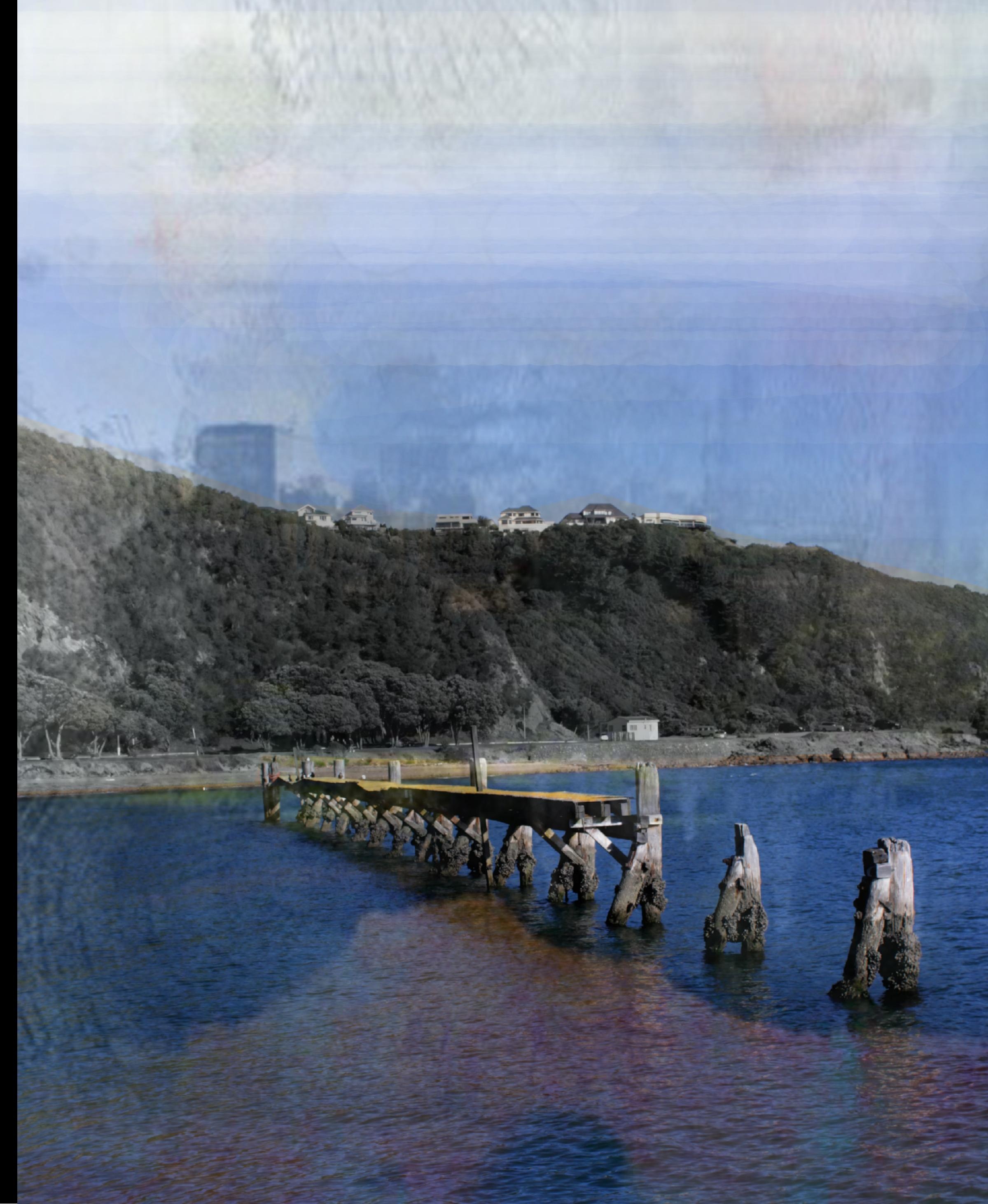




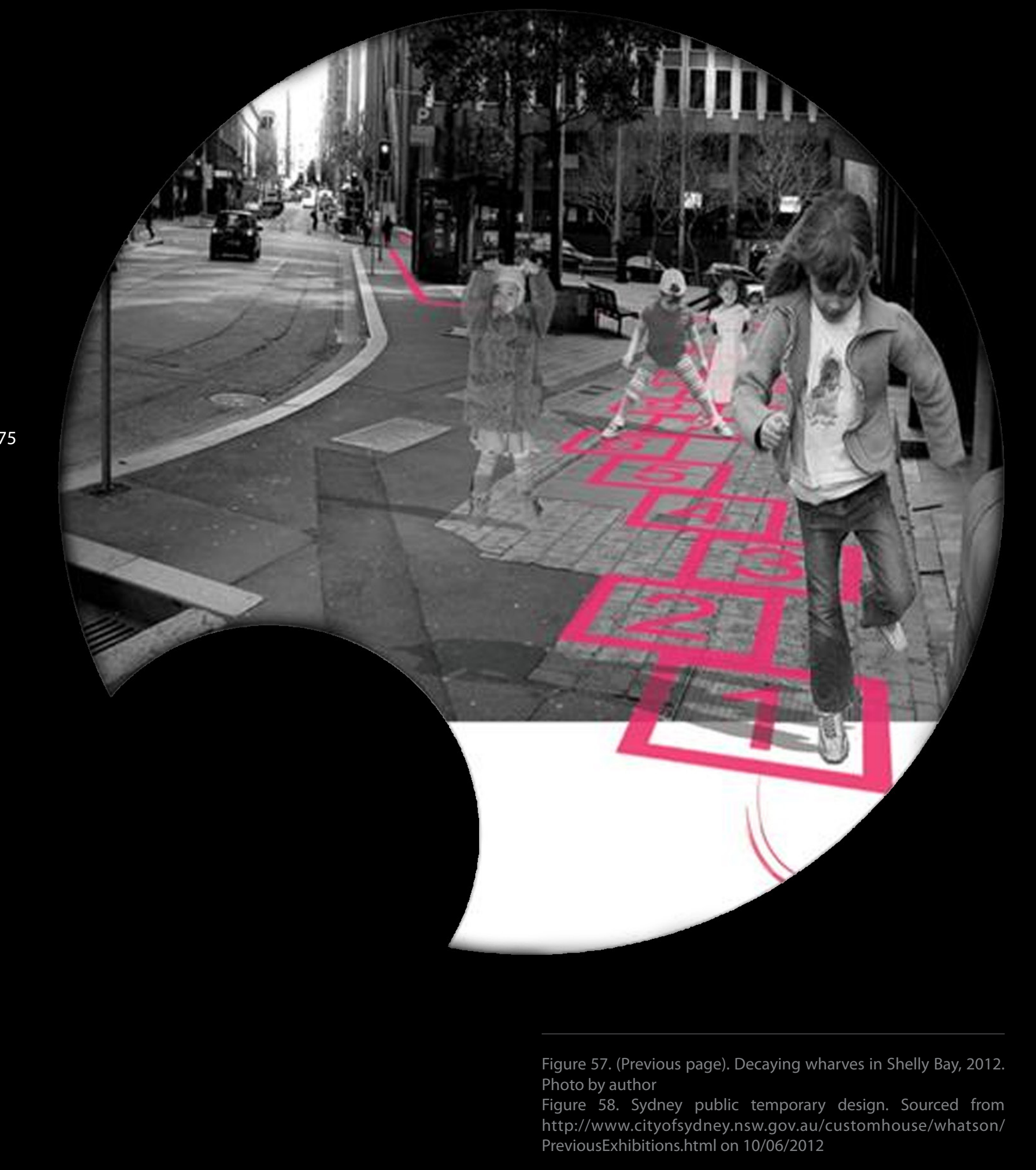

"Temporality: We do not apply the word 'temporality' in its literal sense to spaces and uses but rather use it to refer to such special qualities of the temporary rather than the actual duration of use (Spiegl; Haydn 2006, p24)."

The exploration of memory within this thesis has revealed that temporary designs can be utilised to display memory within the realms of materiality and time.

As it stands, temporary designs and uses have yet to be proven to solve any solutions to vacant and urban voids within the city (Haydn, 2006). However, they have led to a new way of thinking about design may lie within the ability to merge temporary use with permanent designs that adapt and change as the urban environment and social environment changes around it. Within the book 'Temporary Urban Spaces' the authors examine and discuss the ideas surrounding 'temporary use' while excluding a discussion on temporary designs. Is it the spaces which are temporary or the designs that shape them? What is the difference between temporary use and temporary design? Temporary use can refer to the habitation of space, either performing a specific function, or the public using the space for a specific activity. Temporary designs would control the use of the space, through form, materiality and process. How 'temporary' the design is, can either be planned for by the designer in reference to the use of the space and activities that would occur, or through the choice of thering.

Haydn and Robert explore the theories of the Situationists in 'Temporary Urban Spaces' as the terminology of temporary use has its roots in the theoretical models of the group dating from the late 1950s. The key idea of the Situationists was that it was necessary to relate the constructed environment to the social context and to conceive space as a product of social activity (Haydn, 2006). They also suggest the idea of 'roaming' and the aim was for a 'psycho-geographical' exploration to bring out the social aspects of the topography and the affective dimensions of constructed space (Haydn, 2006).
This would be an affective approach to designing with interim uses/temporary uses within landscape architecture, while also enhancing the design of reflects and responds. As the idea of the 'temporary' incurring change, it may also be effective at reflecting the collective memory of both the public and the landscape. Cities have recently been taking part in the temporary use phenomenon, organising events that allow artists and designers to display temporary designs and spaces in the public. This promotes different type of design, and the installations provoke the public to find out more about what is going on around them (figure 58).

Temporary spaces and temporary uses in short provide refection of the space and the people who use it, not be suitable. Temporary designs may be a means of testing more permanent designs "When encouraging temporariness, however it must remain clear that the lasting effects should not be restricted to the microlevel (Haydn, 2006, p59)", This research will explore whether this concept may be applicable to Shelly Bay, using the site as a testing zone or macro design space that may in turn provide interesting developmen plans and temporary designs that can be applied to similar sites around Wellington.

To support the notion of identity earlier explored, locations and designs of temporality portray the relationships and history of a site. The materiality can display this as a projection within the physical surfaces. They are no longer void spaces, lost within expanding urbanism; they are spaces where new projections and representations can be made as intensity and durability of these traces vary, and this may be a way of determining more permanent designs. "Temporary spaces. move first of all on the level of structures of action and interaction of the production use and appropriation of material spaces and, at least as importantly, on the level of systems of spatial representation... Temporality allows ideas to be conceived and experimented over time, no matter how short (Haydn, 2006, p59)." 
4.2 Materiality, Weathering and Trace
The choice of materials, weathering over time, and the traces they leave, are the physical components that may reflect the sites memory. Materials can be used to reflect the history of the site, while also displaying the contextual and climatic elements over time, temporarily or permanently. An investigation into these concepts is a key part of this thesis and determining how to anchor memory upon the site of Shelly Bay.

The breakdown and weathering of materials is inevitable, so landscape architects must choose to what degree, where that failure will be, and when (Kirkwood, 2004). This can be designed into the landscape and the design, through weathering and landscape and the design, through weathering and materiality. If the design is temporal, then traces of it can be marked upon the site or design, creating
another layer of memory in time. This can define 'site' and 'place' through landscape weathering and trace revealing the natural properties of the contextual components to the landscape. Materiality can forge a new identity in the landscape, as it reflects decay and character, contains memory within an object, and archives time within the built environment.

One can question if the landscape materials and elements will continue to function as they were originally intended post-implementation and after the start of the weathering process. Climate, erosion, wate movement, planting and pedestrian use will all affec how the design weathers, "Making the weathering of a material visible within the landscape is a design both artistic and pragmatic" (Kirkwed, 2004, p35). When designing for memory and considering the weathering of materials, perhaps creating a preferred weathering of materials, perhaps creating a preferred should make in this case. Landscape identity, and the memory and transformation of the landscape does not just need to be considered in the past tense. How the natural environment changes can be reflected within the design, and especially within the materiality, weathering and trace. Specific parts of the design can be chosen to reflect the weathering on the site, and this should be considered and incorporated into the design intent, the site program, and how the design adapts and change over time.

According to Kirkwood, there are three types of weathering within the landscap :

- Cyclical - weathering by the natural forces of climate on daily and seasonal basis.

Serial - linear weathering by mechanical damage, loss of material integrity and the actions of clmate. (most commonly found in timer and wood

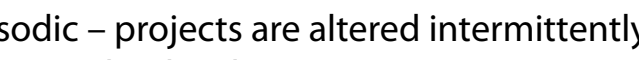
ent, new owners or

authorities such as government maintenance.

Cyclical weathering would be a large factor within the Shelly Bay site. As a coastal site the design will be impacted by salt spray, wind damage, water damage and increasing tide levels. As the development of the design takes place, pedestrian traffic and movemen will also be a factor within the durability of the materiality. Developing the design through a series of steps and understanding the spatial relationships, materials, structure, and form through an ongoing shift in scales. This will give clarification through selection, hierarchy, shape and density of materials (Kirkwood, 2004). How these weather and develop will be based on design intent, program, temporality, an the process of the design implementation.

This is important within the concept of memory, as it allows the processes of the landscape to become part of the man-made landscape, in both the presen the notion of containment is often associated with the idea of memory and hence material object (Rodrig be stored or held within memory through the design and objects within it gives permanence to memory, even if the materials are temporal. Incorporating processes and changes into the design function; program and materials can achieve this 


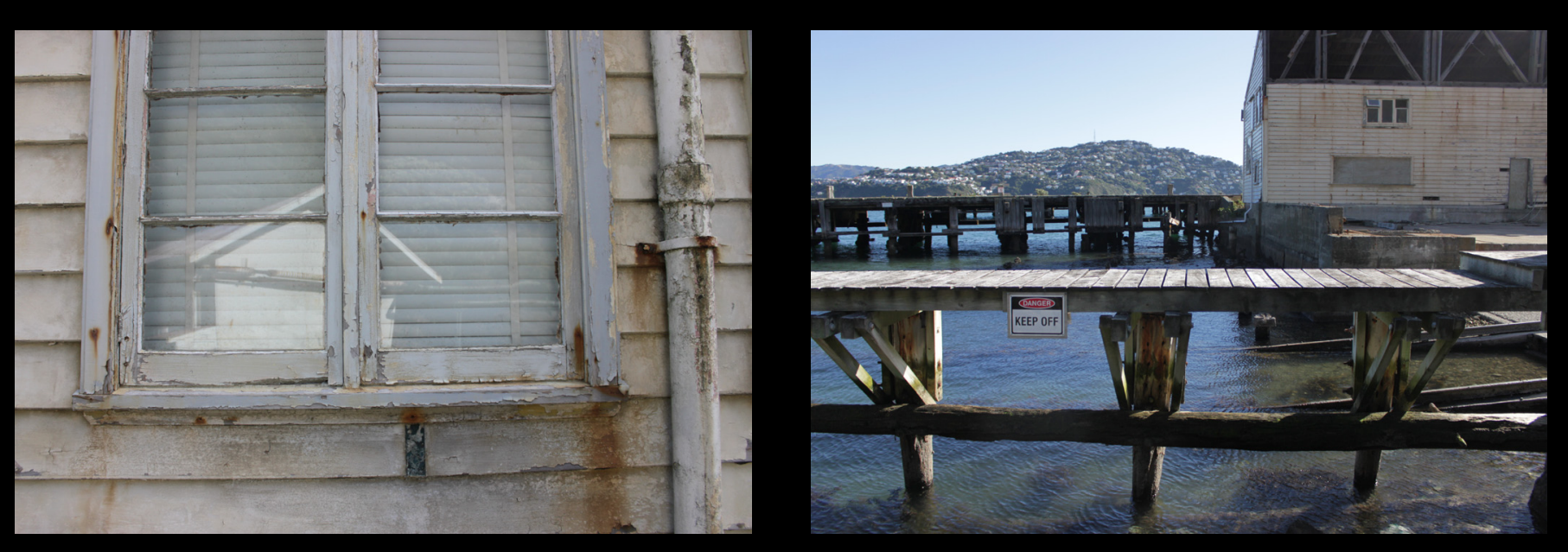

Existing materials on the site can show a designer how materials have withstood the contextual and climatic elements. This showcases the memory and traces of the natul ente. Within especilly Wellington, these affects can be quite significant. The exposed coastal environment of Shelly Bay has exhibited these processes and their impact upon the built environment Site analysis on Shelly Bay for this thesis has formed a basis for a material palette in order to reveal these qualities in the future. The observation of the current state of the site has also shown what materials are temporal and which are permanent. This will be taken into account within the final design. Temporal aspects within the site will be formed; therefore wood will be the main material choice. In more permanent structures, stee and concrete are more permanent materials, however they will weather depending on placement within the site and exposure to the elements.

The images to the left highlight the current state of weathering and degradation of materials and structures in Shelly Bay. Photographic studies and natural elements can dominate the coastal site. This needs to be taken into account within the approach to design A breakdown of the natural and man-made processes occurring on the site, and possibly in the future, will help to achieve a design that is cohesive with the natural environment. It also allows an amoun of control for the designer when choosing materials, forms, and programs. 


\subsection{Process and Change}

Observation, measure, and adaption of the process of materiality, weathering and trace are relevant to the design of memory and landscape architecture. It is also a factor of temporality, especially within the man-made landscape, and can evoke remembrance and recreation. The materiality of landscape elements establishes the form and design ideas. The process of the weathering and durability over time, makes the design intent visible, and displays the character and identity of the landscape (Kirkwood, 2004). The most important and the most difficult part of landscape architecture is the ability to conceive a final design that takes into account all aspects of the process and changes that occur on the site. The abilty to bridge the built idea over time could be ache read by allowing for built idea over fime could be acheved by allowing for process and change to occur, in the design and within their history. evolution and their inherent nature are engaging - a vital part in evoking memory ...the way the russet colour of rusted metal in sunlight can transport one to another place (Wagner; Kirkwood 2004, p34)." The park designed by Hargreaves Associates
represents landscape architecture within the public realm, and addresses the passage and change of a fragile landscape over time (Kirkwood, 2004). The Crissy Field design also addresses the historical natura history of the site, such as the tidal wetland, the cultural history, such as the airfield, while expanding the future recreational public culture to broaden the number of residents and visitors to the area. Materiality and durability over time are also integrated into the design approach, as the design works with, rather than against, the reoccurring process of the tides, wind and microclimate (Kirkwood, 2004). This approach that Hargreaves Associates undertook is very similar to the design outcom will hip to uns. Assessing the fina and details needed to undertake similar design

An interview with Hargreaves Associates referenced

An interview with Hargreaves Associates referenced Architecture, explains another approach to temporary and permanent designs that will be useful within the design experimentation section of this thesis, "Where other designers talk about the difference between temporary and permanent, I would talk about the difference between process-oriented landscapes and landscapes designed as set pieces (Kirkwood, 2004, p156)." The landscapes in this design are processoriented, and are not intended to stay as they were originally built. Instead, they are intended to change, evolve and be shaped by natural forces. Simplistic designs and the best material choices have allowed the man-made elements to be controlled within landscape and cyclical weathering.

As Shelly Bay is a large site, a process-oriented landscape would achieve a more active design. The smaller trigger sites within the larger area, which have individual functions and translations of memory may need to be designed as object driven landscapes but also function within the larger process and overall design intent.
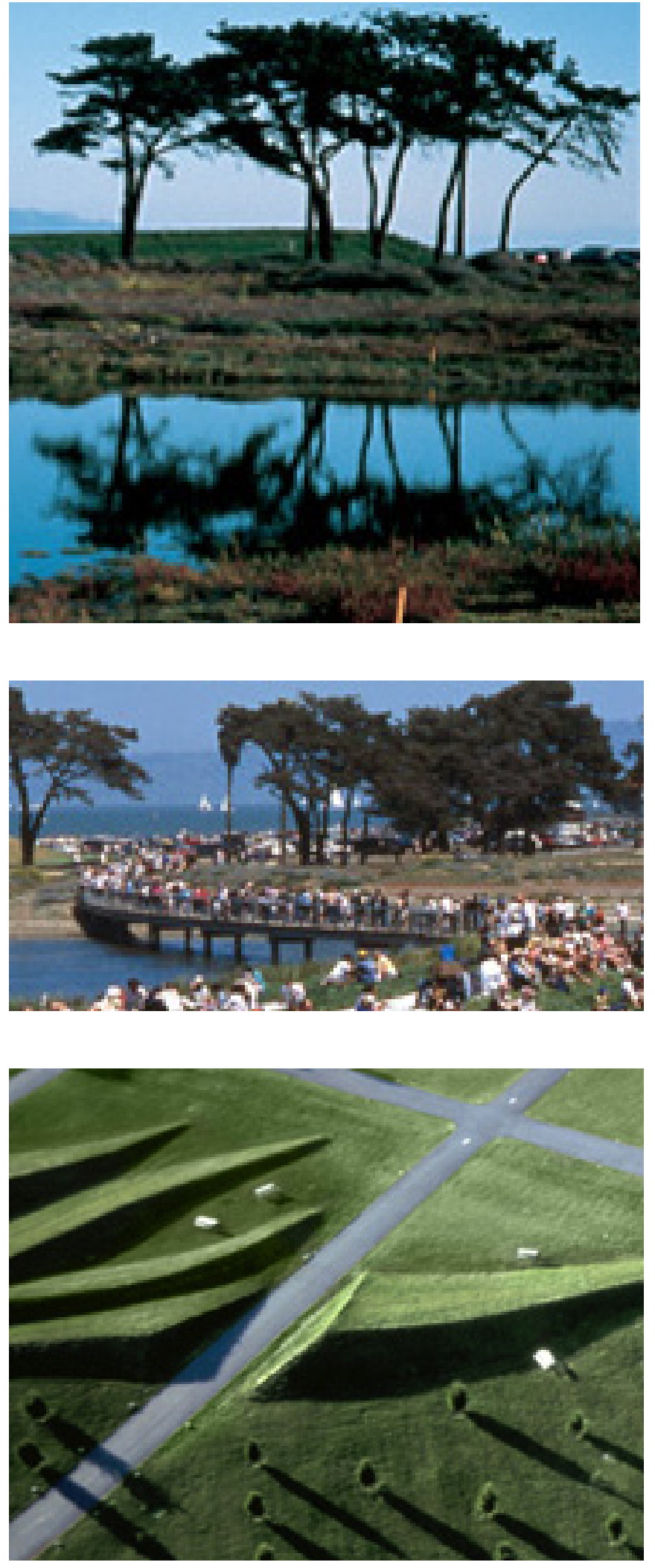

Figure 61. Crissy Field tidal park restoration design by Hargreaves 
The investigation into time and permanence revealed factors of temporary design, materiality, weathering auilt design of memory within Shelly Bay. Existing site conditions and the weathering of materials reveals the climatic affects of the exposed coastal environment This will influence the choice of materials within the trigger sites. Materials will be chosen to withstand the elements structurally, while others will be used to reveal the context and climate of the site through planned exposure and premeditated weathering. The material choices, their placement on site, and their incorporation into the program will create a number of temporary and permanent designs.

Experimentation through design will determine the placement and choice of materials on the site. The process of the site, the materials and the design over

that anchors the historical memories of the site while revealing natural processes and public use over time. 
5. Design Experimentation

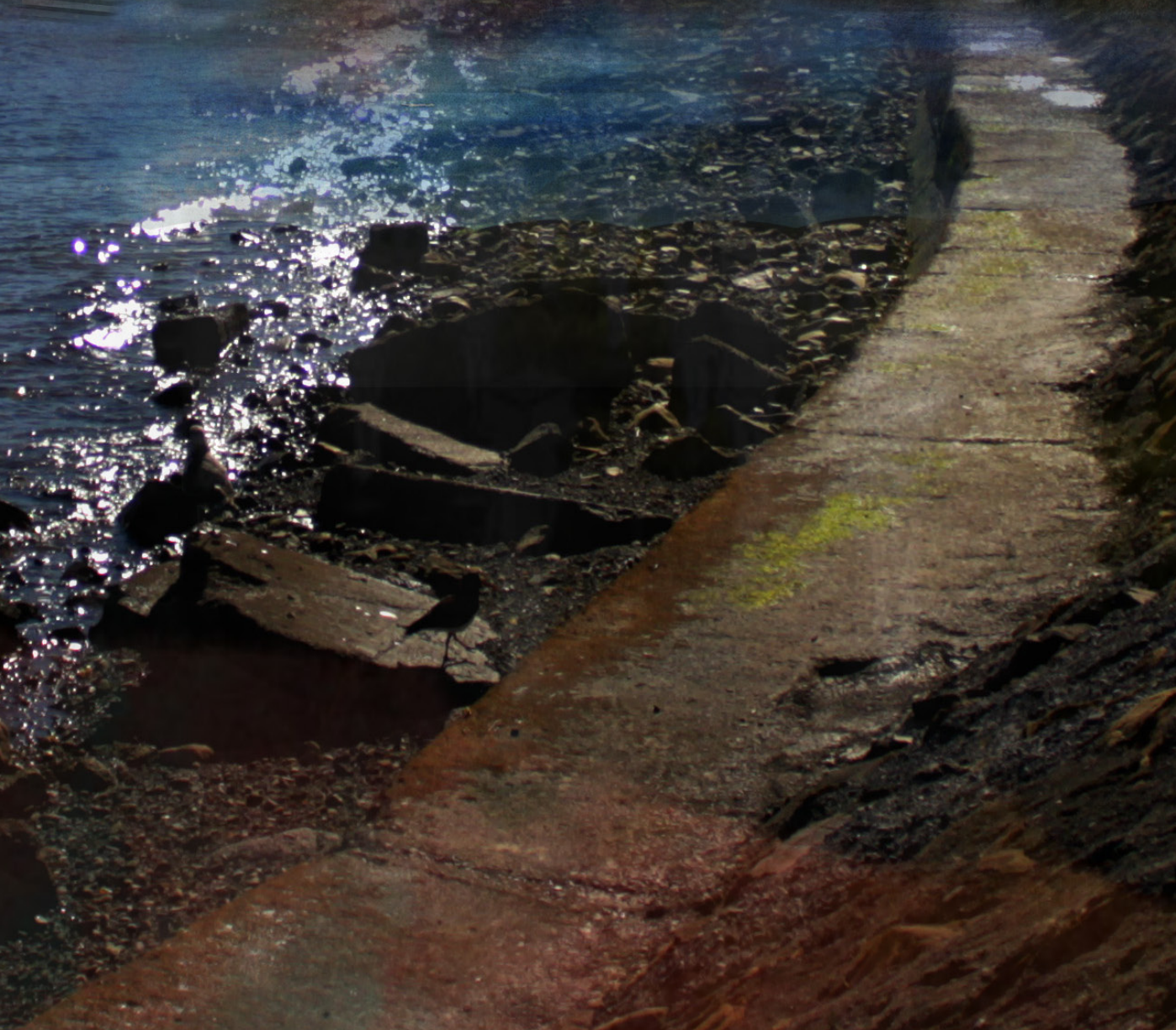




\subsection{Initial Concepts}

Research, conducted through design, into memory within the city (scales of design, permanence, ign options upon the site of Shelly B

The site analysis of Shelly Bay revealed historical edge conditions to the site that have been formed through natural processes and by the occupation of different groups upon the site. Man-made interventions created topographical changes to Shelly Bay that now form the collective memory of the site, while past occupations have been lost in this progression of time. The conclusion formed from this research was to create a design that anchors the historical memory of 87 Design Option One will explore if it is possible to doing so, this will open up opportunities to highlight historical cultural sites and possibly activate them into the present public use of Shelly Bay. By exploring the concept of recreation, the design will focus on contrasting the different land formations over time. This will challenge the impact that man-made infrastructure has had upon the memory of the landscape.

Design Option Two will explore the concept of bridging the historical memory of the site with a present day design. The concept of 'bridging' the history of land transformations will not challenge the impact of the man-made landscape, but accept it as a part of the memory and process of the site. This concept will aim to highlight the historical memory of the site in a

Both design concepts will explore the idea of an 'Ecomusee.' A memorial to the history of the site will e created. However, the concept of a memorial will be explored in a new way. The design will act as an and future occupation.

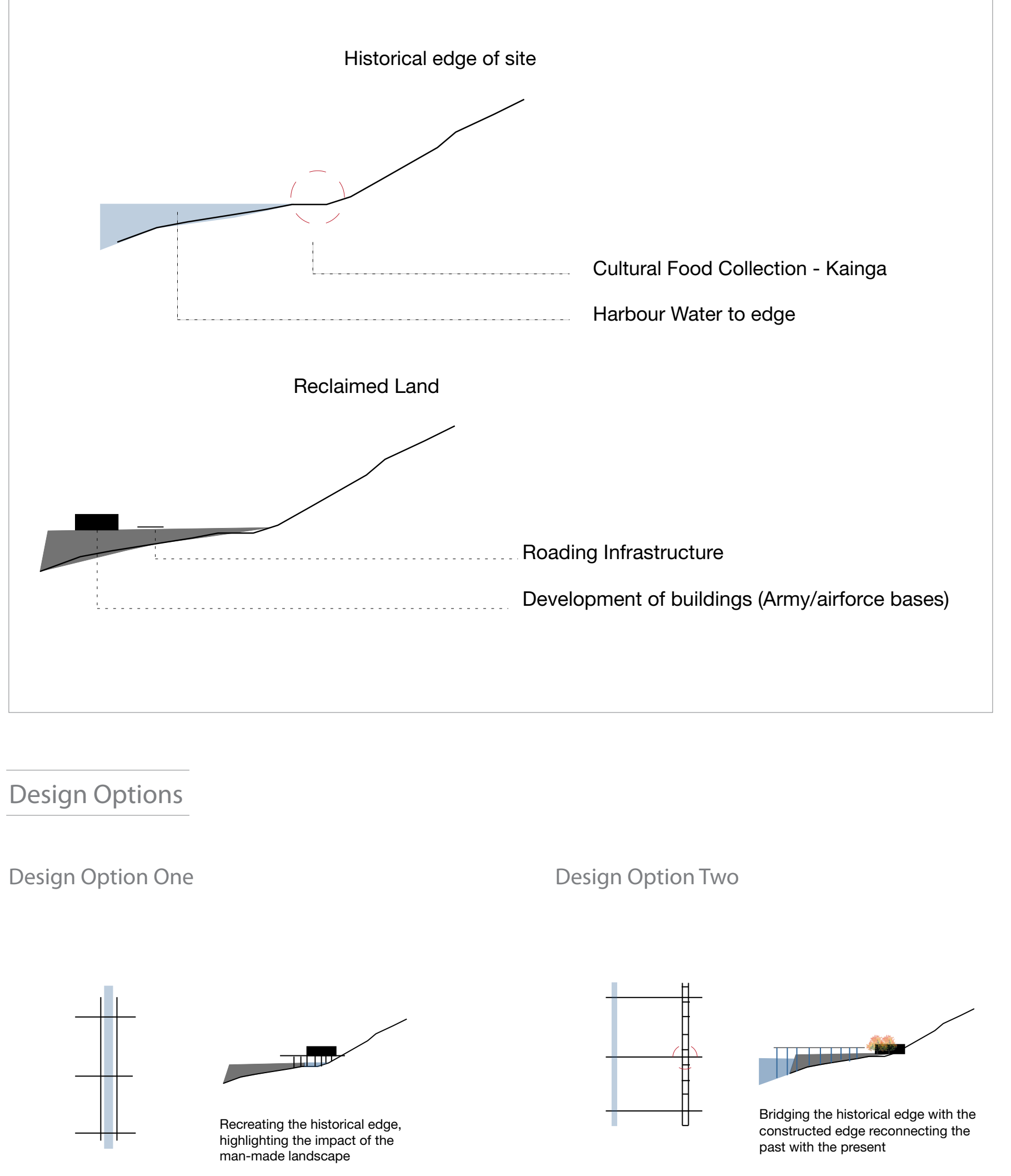


"These museums were thus perceived as a kind of substantive collective regional memory that would constantly nourish and renew remembrance" (Hauser, 2006, p821).

To constitute the collective memory of an entire area combining the creation of industrial heritoge sites with the development of a cultural landscape that is simultaneously old and new, an 'Ecomusee' could be utilised. This thesis has discovered that memory can be manifested through the experience of degradation and change. This design allows access to memories through a journey of the site.

The program that is used to create an'Ecomusee'simply consists of a central exhibition site in combination with antenna sites. The central exhibition site is the larger design intervention. This intervention should display the memory and history of the site while activating the area for present use. The antenna sites draw on relationships and connections, capturing and main pran of the which is suggested by Huser can be Ths program with New Zeeland culture and history.

Antenna Site

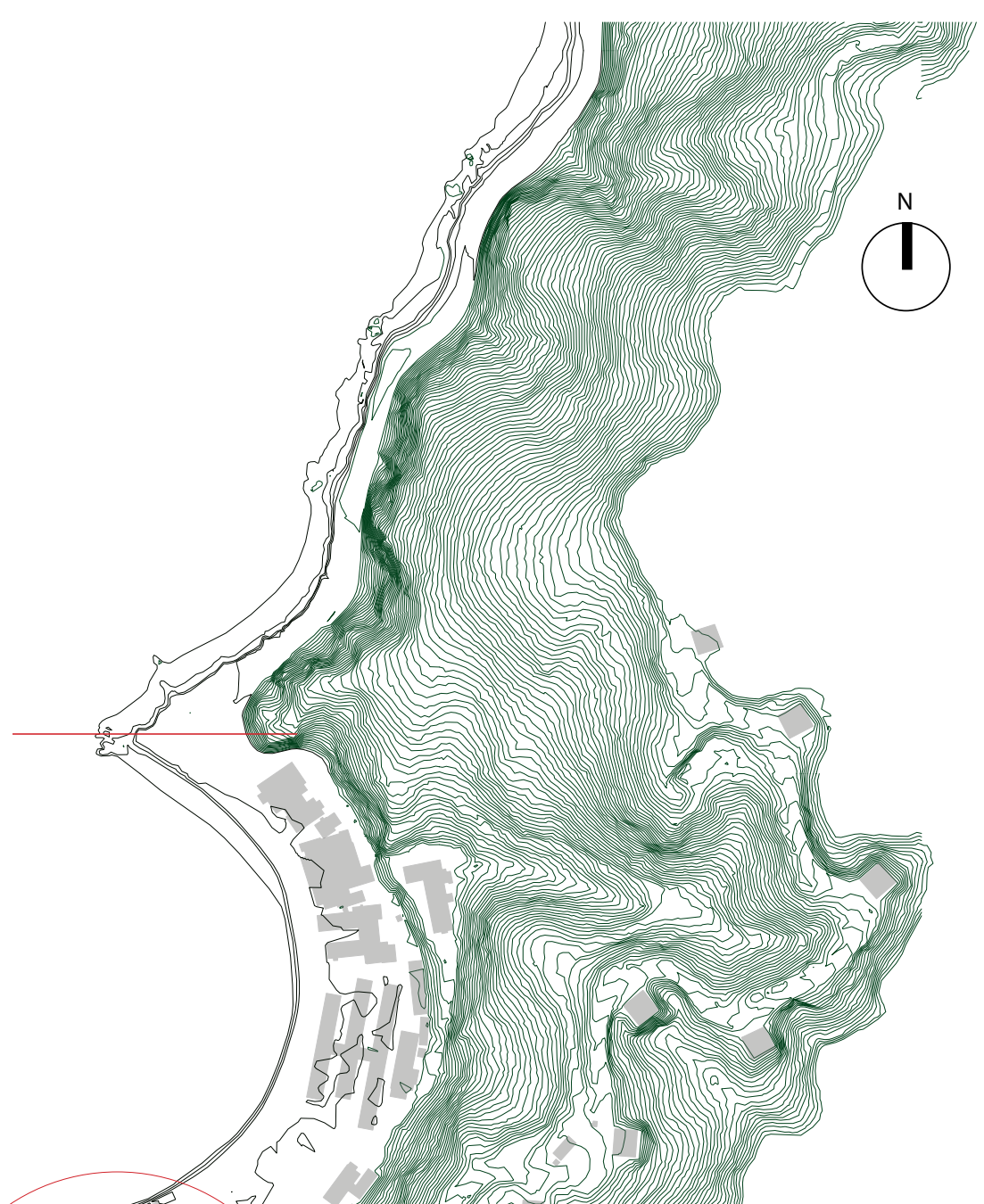

Antenna Site

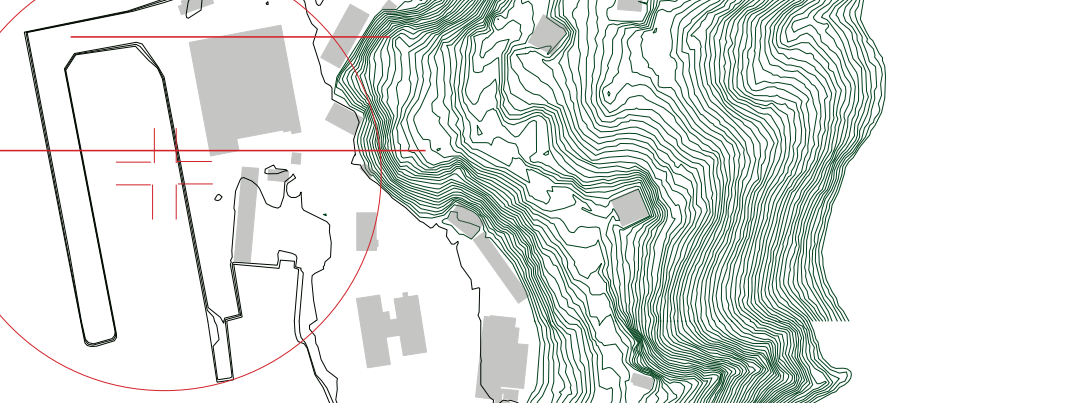

90 
The design program is an archive of the site. The memory of the occupation of the site, the
appropriation of land, the man-made landscape, and
the degradation of the site will be the main points of reflection. This allows for a collective memory to be formed within the landscape, while still providing designs at a personal scale, for public interaction and interpretation.

The underlying theme of the archive, that links the antenna sites together and reflects this site particularly, is the appropriation of the landscape. The three interventions aim to reflect the appropriation and change that has occurred through man-made

The central archive has been proposed to bridge the decaying wharves, the former 'kainga' (food collection) site with the foothils. This highlights the three typologies of the site (harbour, reclaimed land site. The antenna sites will bridge the land typologies. The designs will aim to highlight a number of other aspects of the historical environment while activating the large open space for the public of Wellington.

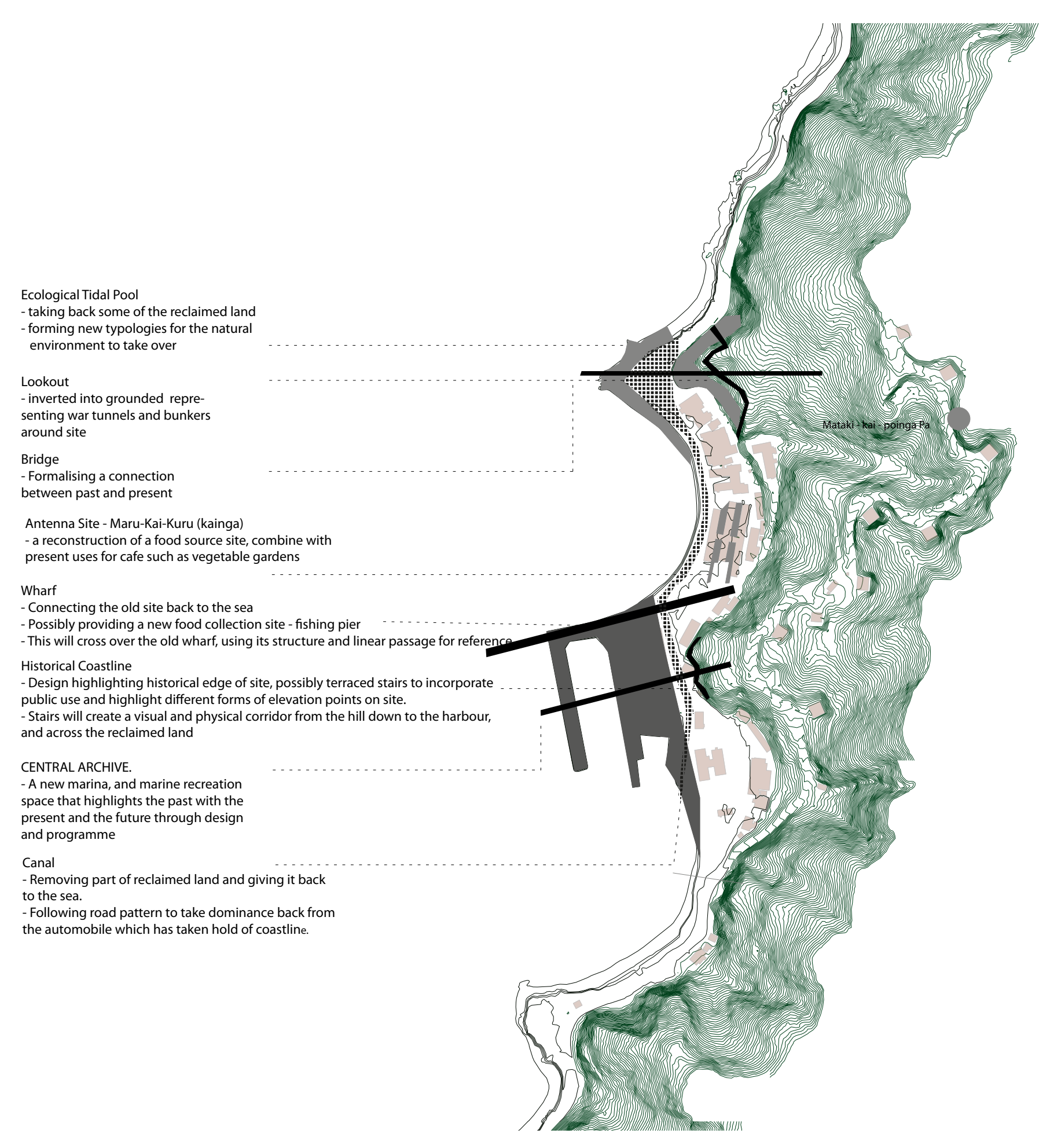


The concept of developing an 'Ecomusee' to constitute the collective memory of Shelly Bay led to the can also be thought of as 'trigger sites', an adaption on Hauser's antenna sites. Their form, materiality, contex and program are intended to trigger collective and individual memories. The sites will also trigger a new activated public space within Wellington City.

Trigger Site A is designed to reveal a connection between the industrial wharf, naval heritage and a new harbour marina. A pedestrian bridge could activate this site by connecting it back to the foothills and to a new residential housing area.

Site B will highlight the number of signs and traces

identified through the site analysis chapter. A new historical coastline with the foothills The structure will crente a new activated fenr wh current cafe with the historical food collection site.

Site $C$ will investigate the natural typologies that currently existon the site and the surrounding Miram Peninsula. These reflect the current collective identity of Wellington. This identity refers to the typology in relation to the urban environment. Wellington is known for this type of landform, its coast being dominated by a rocky shoreline. The design will reflect these ideas through the integration of tidal pools and a lookout. These will connect yet contrast each othe as they are inserted into the rocky coast and the steep

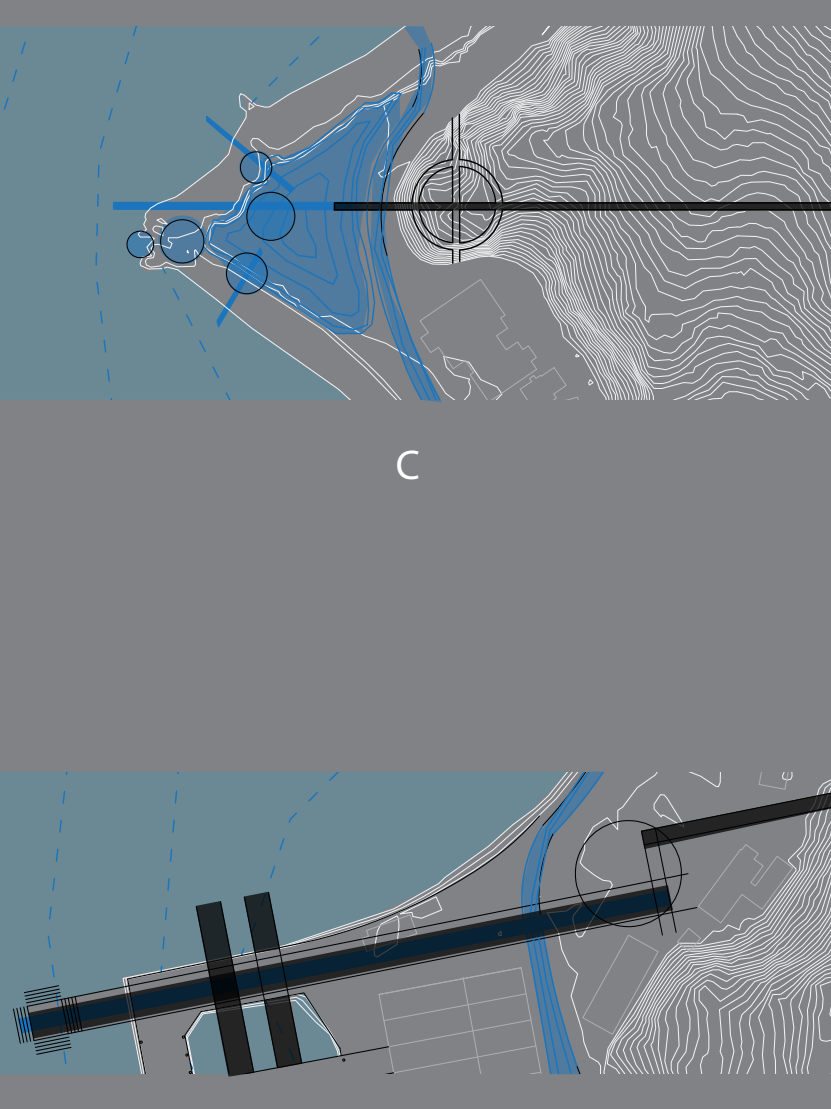

B

7.4
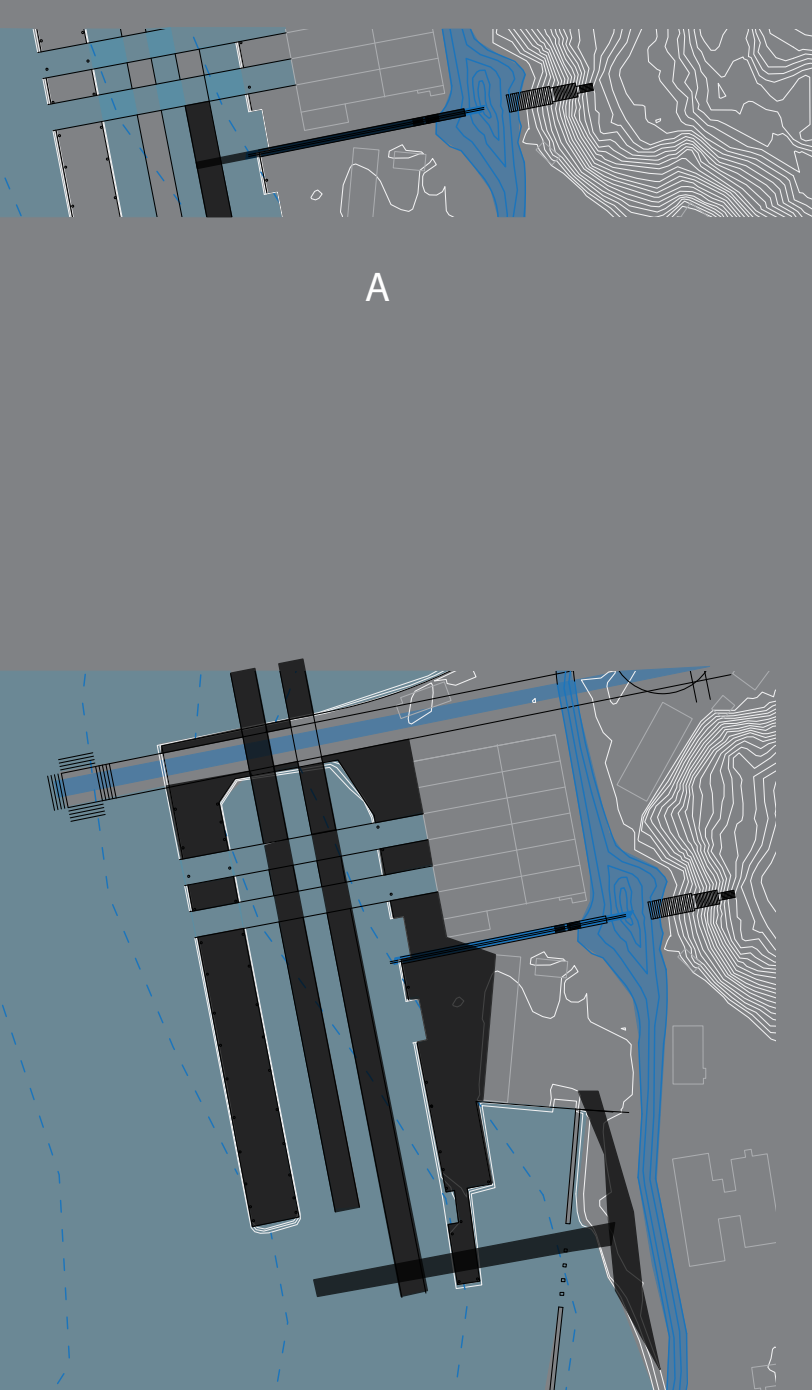

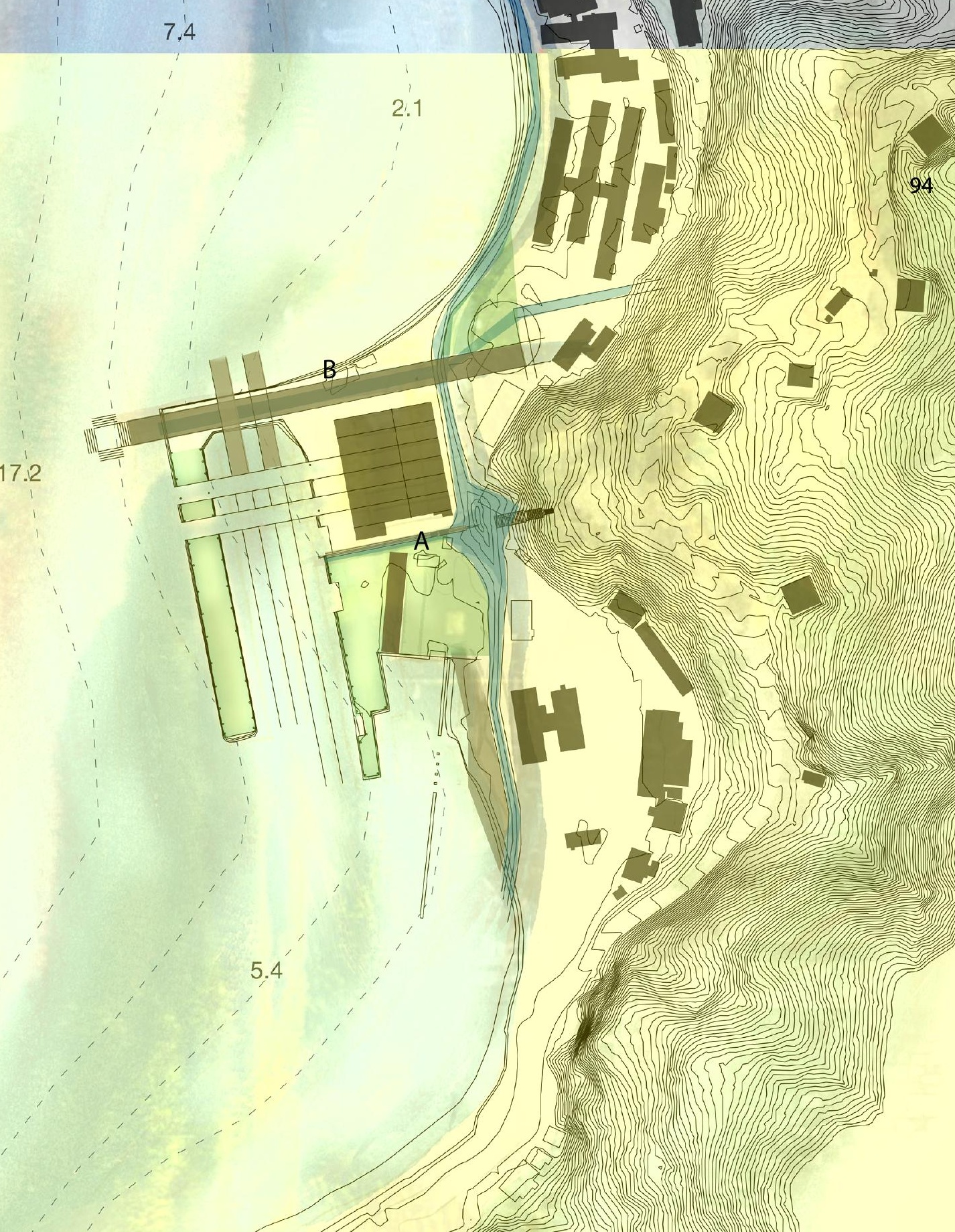


5.2 Developed Design

Option One

This design option shows an exploration of the site through the recreation of memory. The main concept draws on Wellington's collective typology memory idea of the man-made landscepe and its dominance over natural typologies.

The image to the right displays a possible masterplan of the site. The masterplan shows a man-made cana cutting along the edge of the reclaimed land and foothills. This canal is the connecting relationship between the three trigger sites.

The spatial layout and trigger sites will be explained in the following images.

95

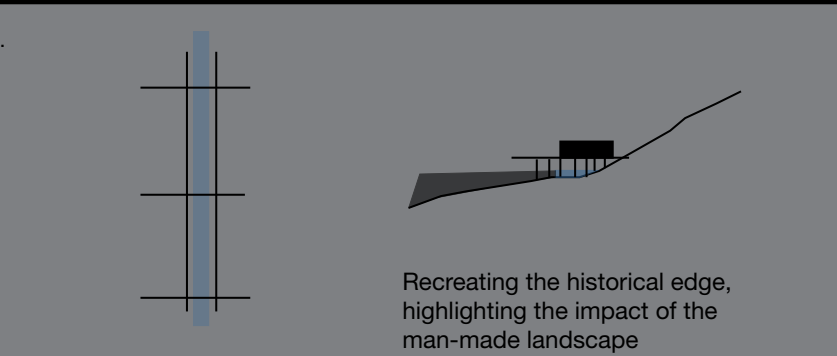

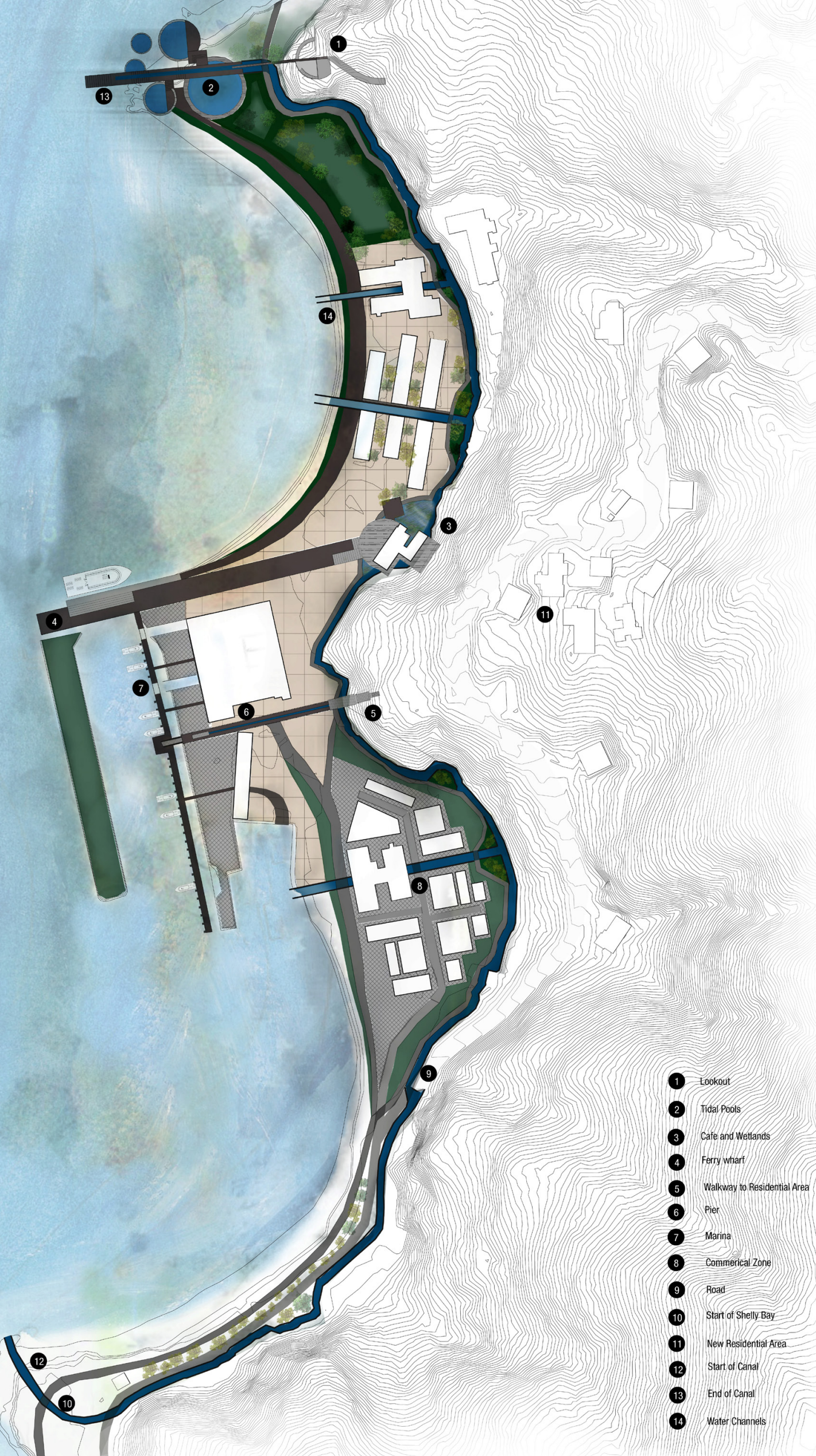


Open - Space Diagram

The open-space diagram highlights available areas for parallel programs to occur within the trigger sites in
Shelly Bay. Areas that are available for pocket parks and large parks are located. Spaces for commercia areas that may active Shely bay in the future have been identied. The con secting physical relationships cor the spaces is the dor through the site.

Hydrology Diagram

hydrology diagram indicates the layout and function of the canalin relation to the trigger sites and the harbour. The start and end of the canal signals the Shyscal start and end or Shelly Bay. Water Channels (1)

\section{Connectivity Diagram}

The land-use diagram indicates how each of the existing buildings will be incorporated into the masterplan program of the site. The diagram also highlights the relationships between the buildings, the commercial spaces, the residential areas and the trigger sites. The residential area is shown on the foothils where there are currently unused air force base houses. It is proposed that a new residentid space will help to activate the site for the future.
The connectivity diagram indicates the access into Shelly Bay as well as the vehicle access and pedestrian Walkways connecting each of the spaces. Vehicle ccess has been removed from the nor bay, creating a pedestrian friendly environment. The main road has been redirected to the existing road up the foothills, and reconnected with the coastal road after the last trigger site. This design moves will take dominance away from the vehicle and provide more access and connection to the water for pedestrians. down from the re-directed road.
Hydrology Diagram

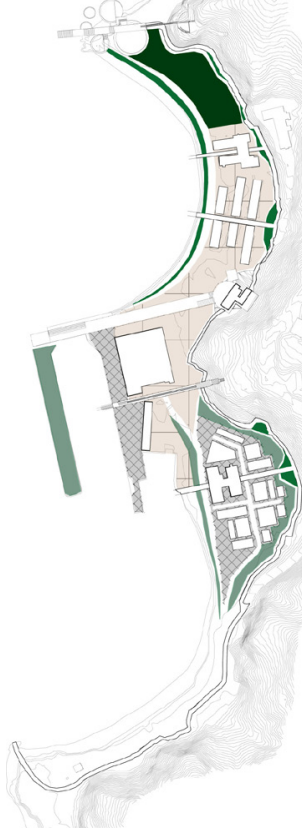

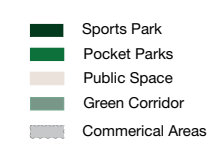

Figure 70. Image by author

Land-Use Diagram

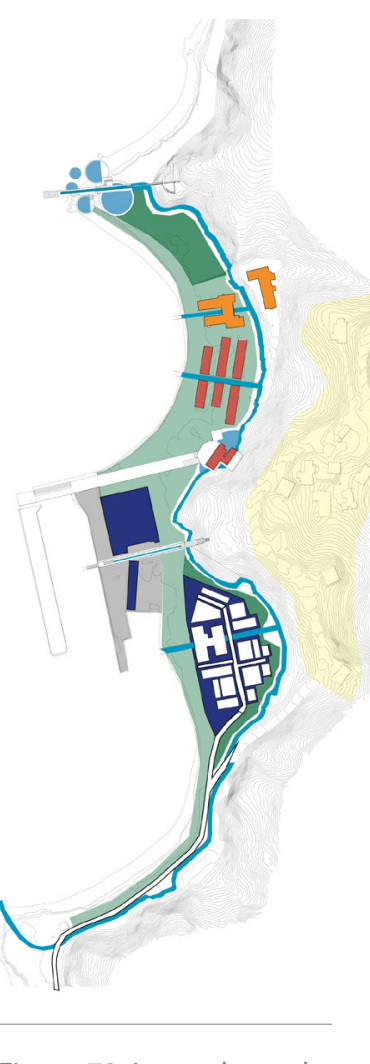

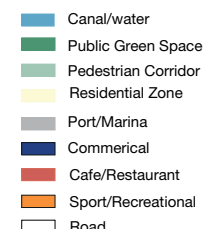

Connectivity Diagram

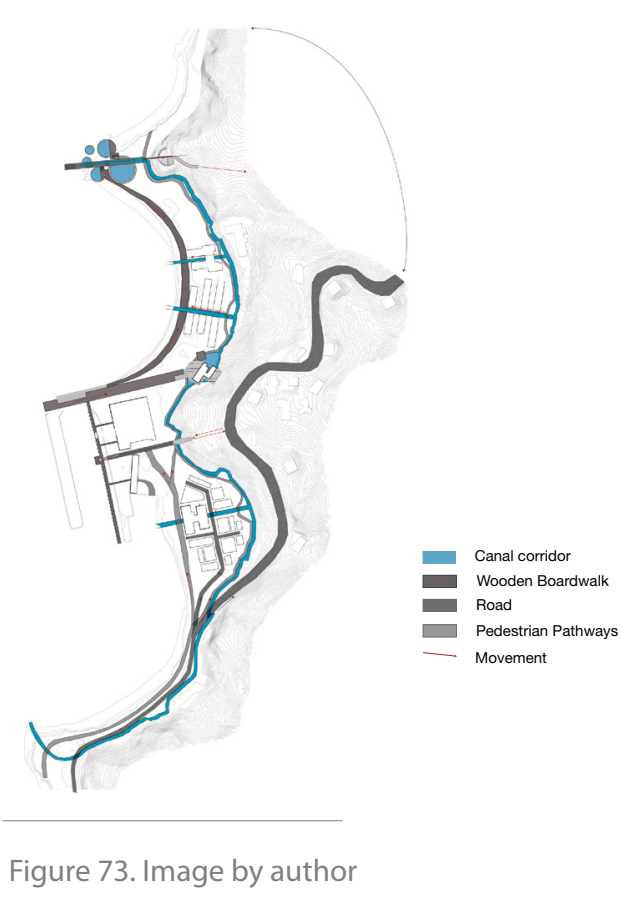



the man-made landscape and its affect on the natural environment and typologies. 
The design of site A investigates the possible future relationship of a waterfront marina and a residential The design of a raised pedestrian walkway connects these two spaces.

The walkway raises users above the reclaimed land, creating a journey from the foothills down into the harbour. The height of the walkway brings users through the tops of the existing buildings within the decaying wharves. It is designed to create an experience of recollection while highlighting the man-made occupation and changes of Shelly Bay.

The form and materials mimic the time period of the existing buildings and wharves. The walkway will degrade over time, breaking the relationship with the of the site by the navy and air force and the resultion re the ste by the navy and air force, and the resulting marking the line between the land typologies.

Section A shows the relationship between the walkway and the canal. Both of these interventions are reflecting and recreating the historical coastline yet using the spaces to activate the site in a new way for the public of Wellington.

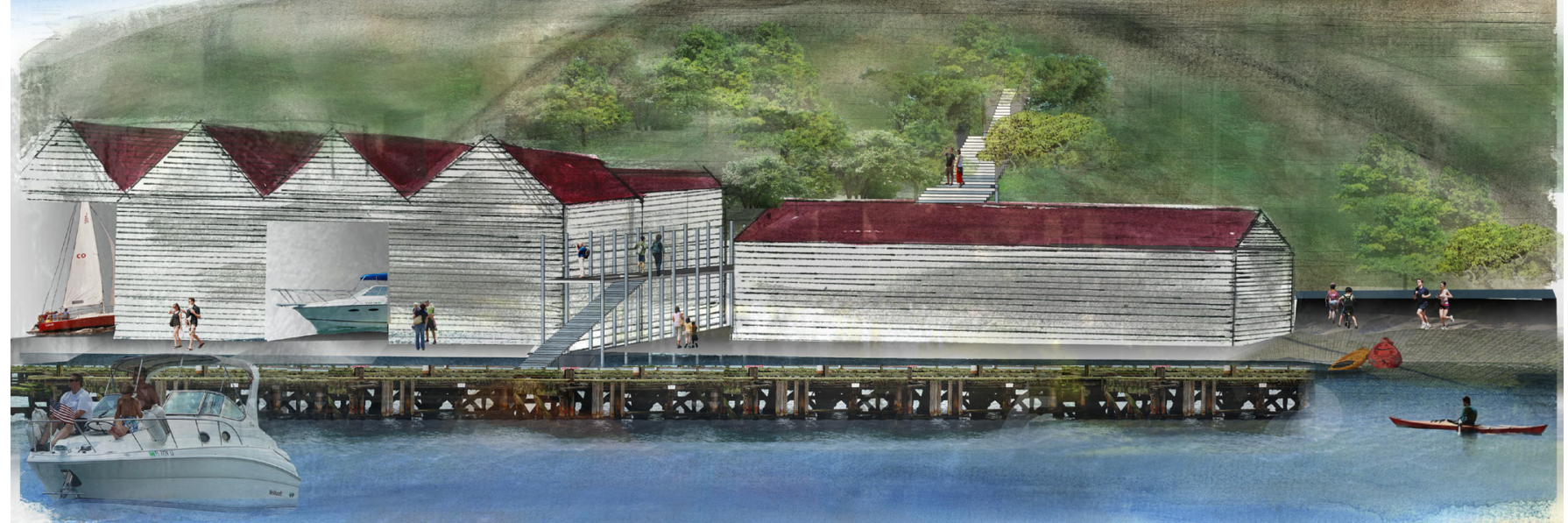

102

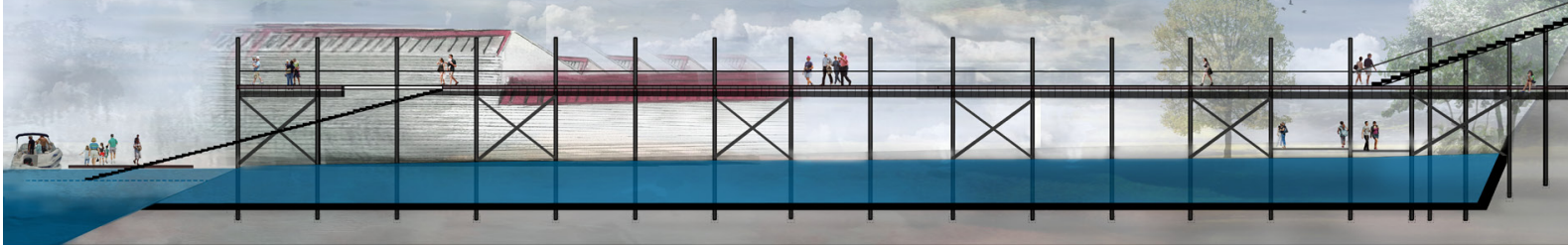

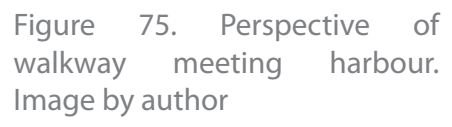



Site B investigates visible and nonphysical signs of the appropriation of the landscape. The decaying wharves
reflect the military use of Shelly Bay, while the present Chocolate Fish Cafe sits upon the former kainga site of the Maru-Kai-Kuru village. An opportunity was presented from the discovery of these layers of memory to create a design that elevates the past while activating the site for the future.

A new wharf has been created to connect the degrading wharves, the reclaimed land and the foothills. The new wharf will replace a part of the old wharf, pulling the structure back along a raised boardwalk that ends at the existing chocolate fish cafe. The decision to raise the care off the ground created a space for the canal to flow beneath and reflect the 103 past cultural food collection site. In the past, this site marks this time in history.

The implementation of a ferry wharf will activate Shelly Bay within the wider site of Wellington City By providing an alternative approach to access the site is predicted that the public and tourists will be more encouraged to visit Shelly Bay. The new wharf will be a grounded concrete structure, reflecting contemporary materials. The boardwalk is designed to resemble site A and provide a consistent material palette across the site.

Presently the Chocolate Fish Cafe is one of the only businesses activating Shelly Bay. It is known for supplying a range of seafood delicacies. The new wharf provides a new fishing and shellfish collection site, providing for the current business whitereflecting

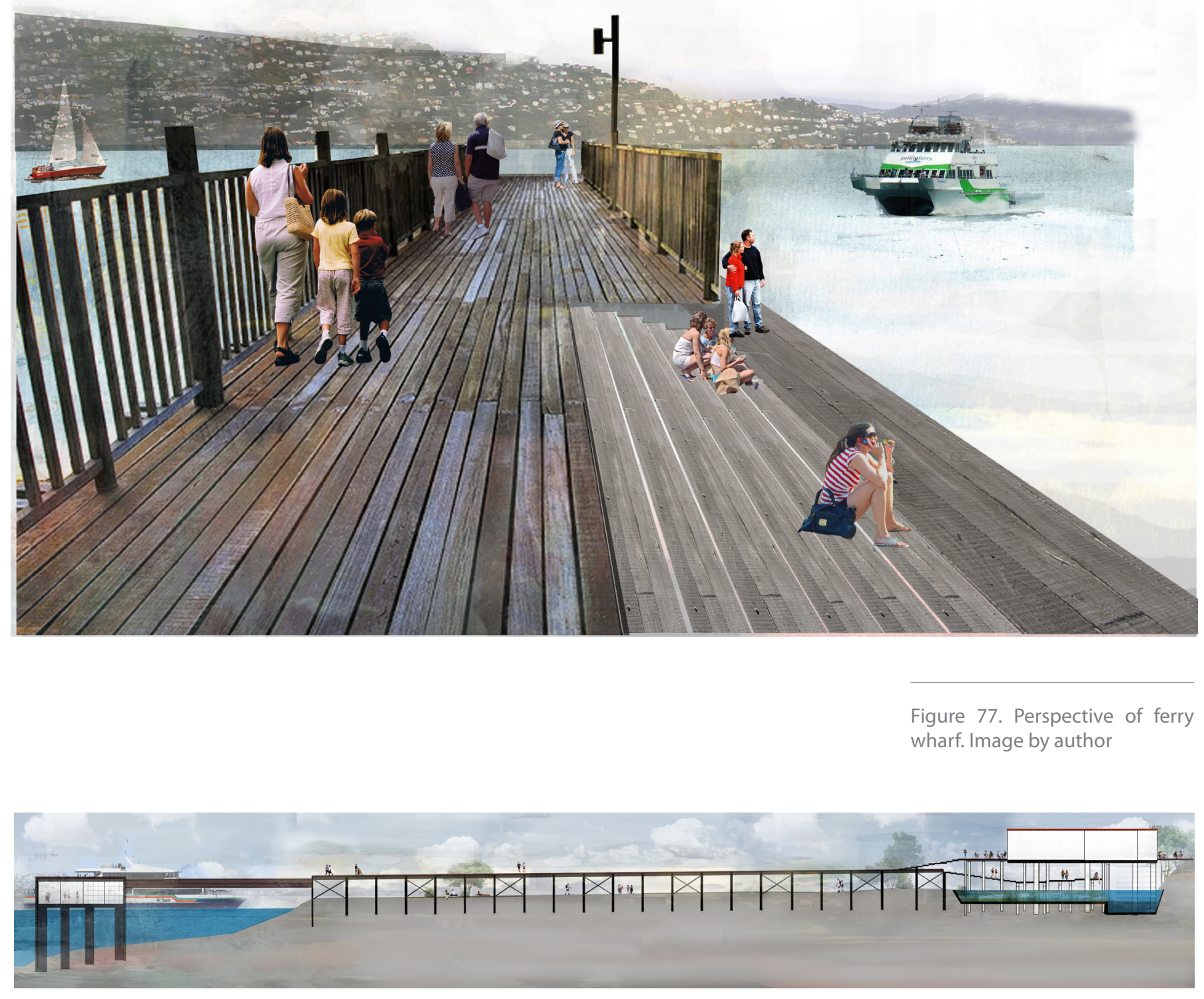



The design of site $C$ highlights two important aspects
of the site; the rocky coastline and impending sea of the site; the rocky coastline and impending sea
level changes, and the context of Shelly Bay within Wellington's urban development.

The tidal pools are circular concrete structures inserted into the rocky coast at the final point of Shelly Bay. Designed to initially appear as man-made structures, over time the sea will overtake these pools. The area where the design is inserted is an extremely exposed site. This will allow users to experience a range of climatic environments that characterise Shelly Bay and Wellington City, for example wind and salt spray. Situated at different levels and different sizes, the tidal pools respond to the natural and manmade landscapes formed on Shelly Bay. A connecting 105 wooden pathway leads users down into the water. This in the foothills.

The lookout has been designed to reflect the military occupation of the site. The form of the design resembles a number of war bunkers that currently reside in the foothills of the Miramar Peninsula. The lookout is a concrete structure that provides a cantilevered platform viewing Wellington's waterfront and industrial port. There is an interior and exterio side to the lookout. The southern interior wing is inserted into the ground. A circular concrete wall is slitted, providing small glimpses of Wellington City from inside the structure. The northern wing is a semicircular concrete walkway floating above the ground. This provides a view while being immersed in the surrounding vegetation and exposed to the natural elements. The design of the lookout has a number of contrasting elements that evoke differen
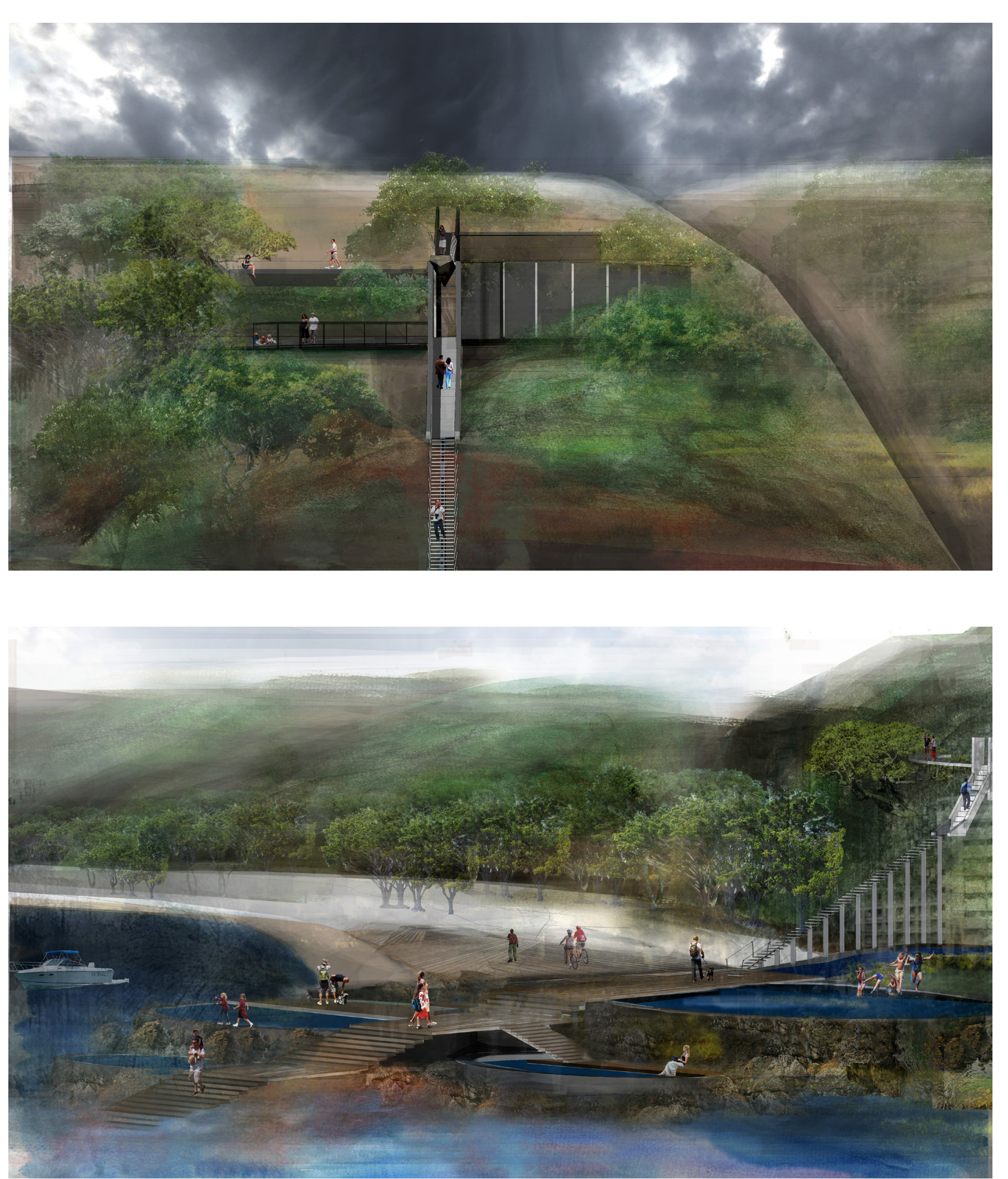
Design Option One explores the possibility of recreating the historical coastal edge of the site. In doing so it has opened up opportunities to highlight
historical cultural sites and possibly activate them historical cultural sites and possibly activate them the concept of recreation, the design focuses on contrasting the different land formations over time. This has challenged the impact that man-made infrastructure has had upon the memory of the landscape.

However, there are a number of problems that have arisen from this design option

- The canal may be perceived as a negative reflection of reclamation. The act of reclamation created flat space that en. Thed Shelly Bay to become a site that

- The material choices and analysis of degradation of each trigger site needs to be developed. This will 作 the future program and use of Shelly Bay

- This design caters mostly to the collective memory of Shelly Bay. Details in the design and spaces need to be developed to reflect individual memories.

Access to the whole site needs to be reconsidered. This has been restricted by the design of the canal.

To successfully anchor memory upon the site of Shelly Bay, while also providing a new design and program that activated the site within the expanding urban development of Wellington City, these problems need to be addressed. 
Option Two

Design Option Two will explore if it is possible to recreate the historical coastal edge of the site. The historical cultural sites while activating them into the present public use of Shelly Bay. The exploration of this concept, recreation, will allow the design to focus on contrasting the different land formation over time. This will challenge the impact that manmade infrastructure has had upon the memory of a landscape.

Changes made to the trigger sites and masterplan will reflect the analysis of design option one. The design of the canal has been removed, resolving issues surrounding access to site and service access to buildings. The three trigger sites have also been 9 developed to amplify the history and memory they conside and to engage with the climaty has been reof the site over time.

The masterplan (figure 81) shows the development of the site layout and interactive spaces. Existing buildings have been retained and incorporated into the program of the site as commercial areas and multiuse buildings. The key to the masterplan highlights the different spaces and connecting walkways.

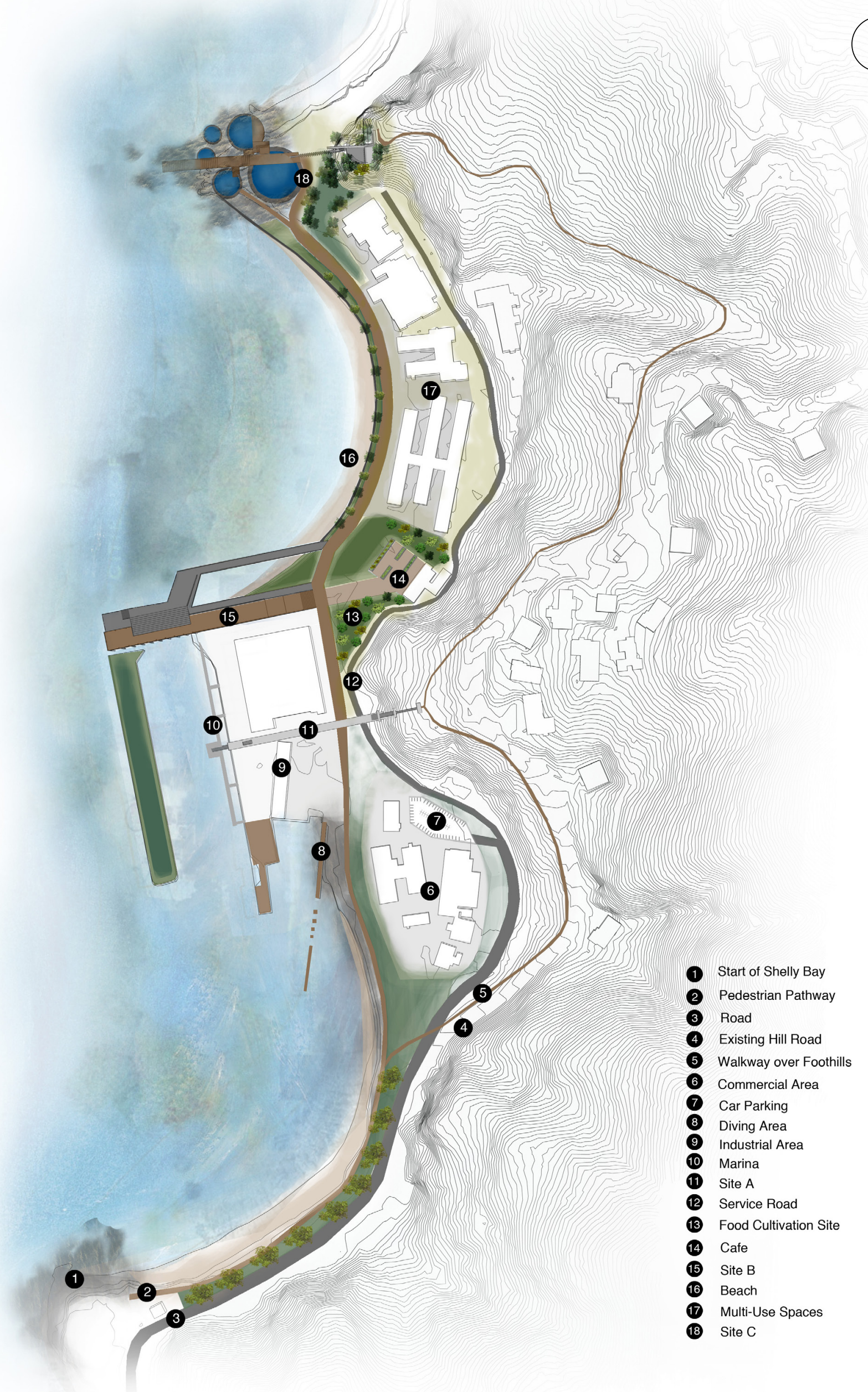



This image (figure 82) shows changes made to the sites access ways from analysis of design option
This has resulted from the removal of the canal.

Developments include:

- A service road to the northern end of Shelly Bay.

- Car parking for the commercial areas.

- A pedestrian walkway along the foothills connecting the three trigger sites as well as the residential area. - The main road diverts up the foothills to the new residential space.

111 - A pedestrian walkway spans the length of Shelly Bay gger sites. The aim of these developments is to create a more
accessible and usable site for the public and future business operators on the site.

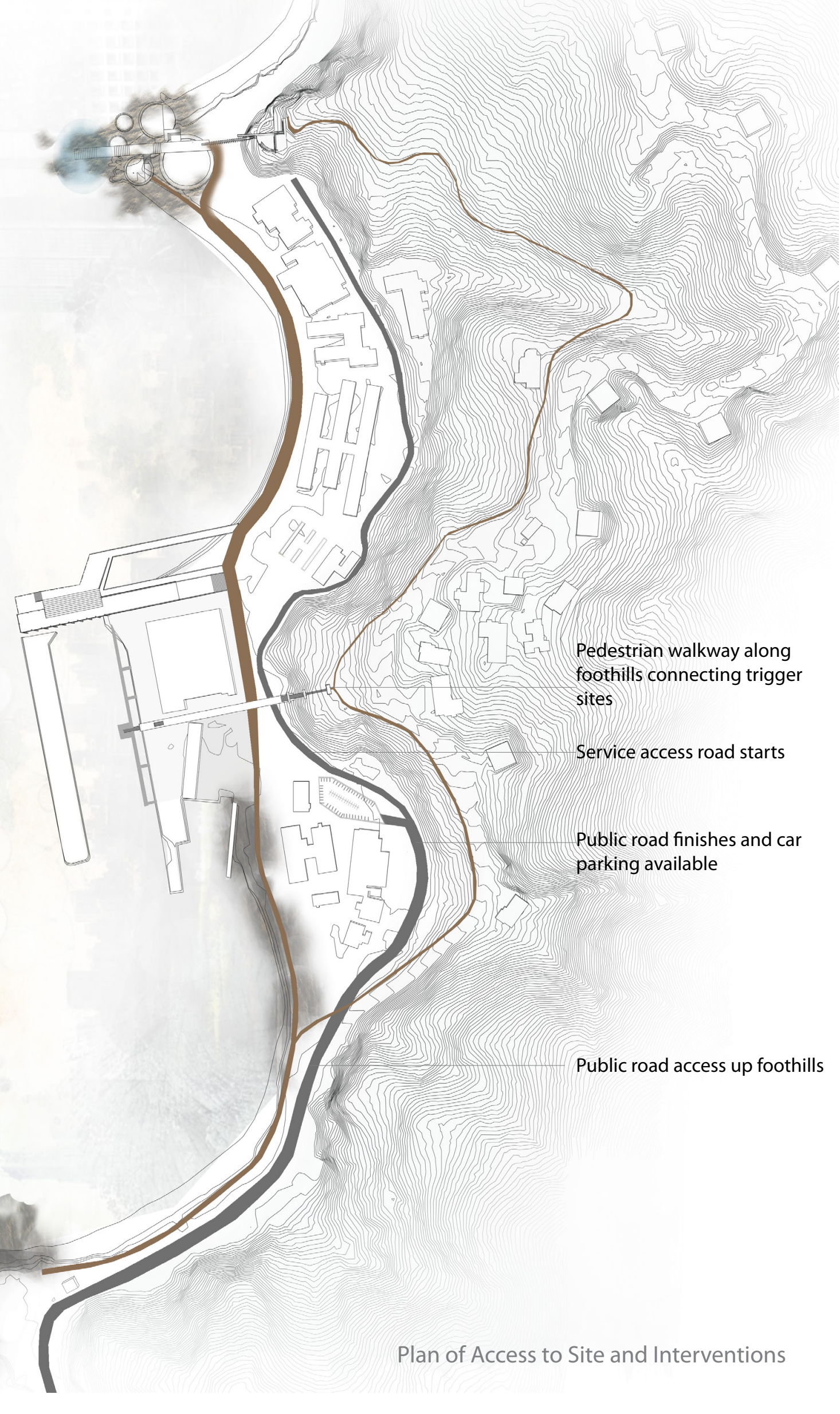


Connecting the new suburb to the waters edge. - Lifting pedestrians above the reclaimed land, allowing a sense of the different typologies in the landscape

The lightweight steel structure looks back to the

industrial naval and boat-building yard, while also

portraying a very man-made material.

113
- A new ferry wharf to activate the site

fork

the cafe

-This aspect is looking back towards the historical Maori

Thing collection site and the newds the historical Maori

activating the Shelly Bay area.

- The new wharf takes over part of the old wharf area

creating a new connection to the land

-The wharf acts as an anchor while also activating the site. - The untreated concrete poles and structure create a very grounded appearance in the water.

-The main wooden fishing wharf on top is a reflection of the crumbling wharves around it.

- It is designed to weather over time and reveal the concrete structure beneath it.
- The lookout is grounded within the topography of the landscape. Made out of a solid concrete structure, the lookout is oriented towards Wellington City and the impending urban expansion. -The lookout is also paying homage to the past war bunkers and army occupation of the site within it's form.

- The tidal pools are integrated into the rocky coastline.

- The pools are designed to be taken over by the sea and the rising waters over time.

- The wooden boardwalk descends into the water.

- It eventually becomes engufed by the harbour and will weather and disintegrate over time as the natural landscape takes over.

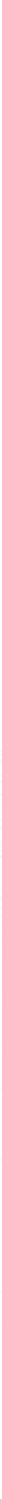



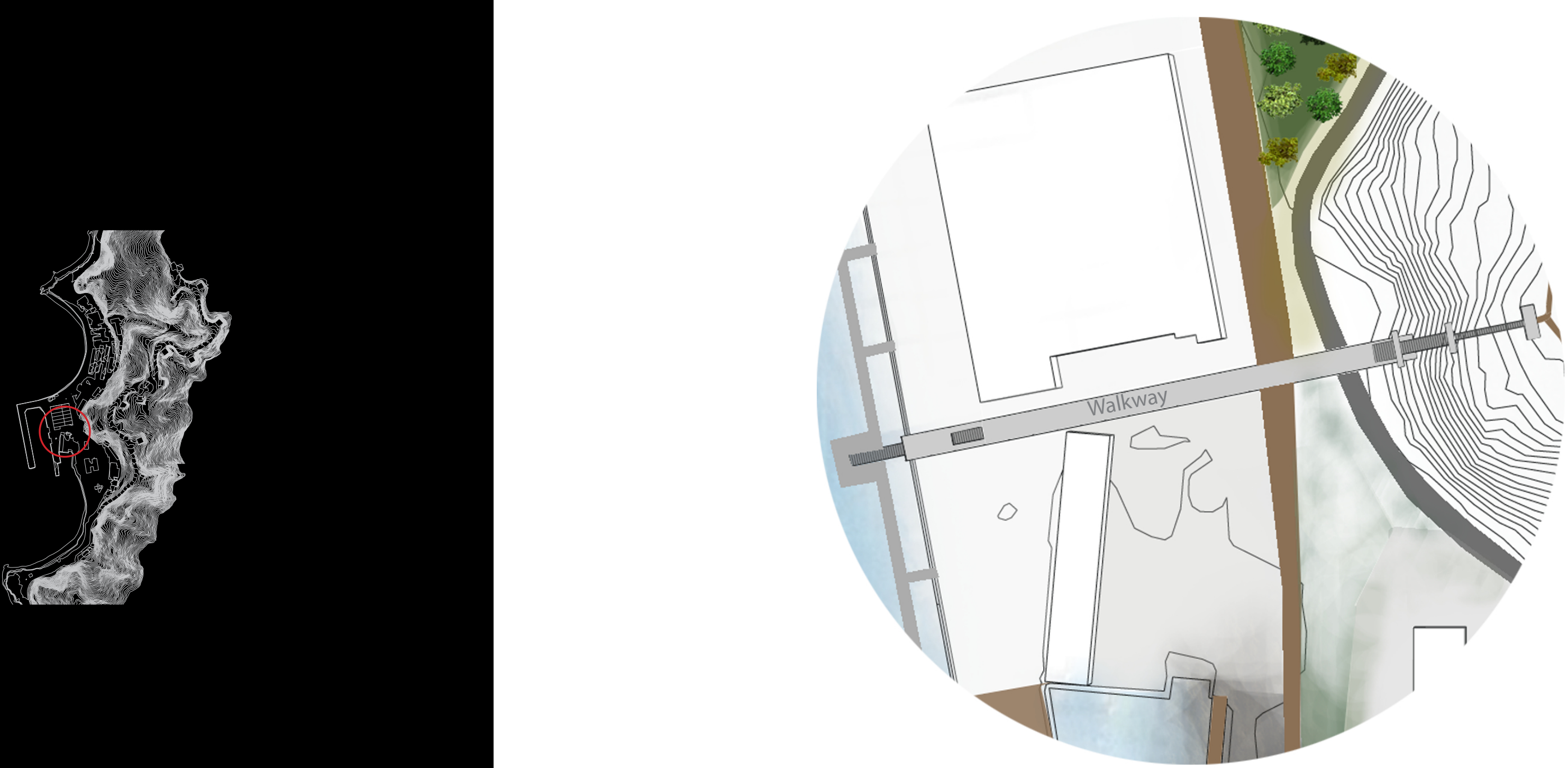

116 


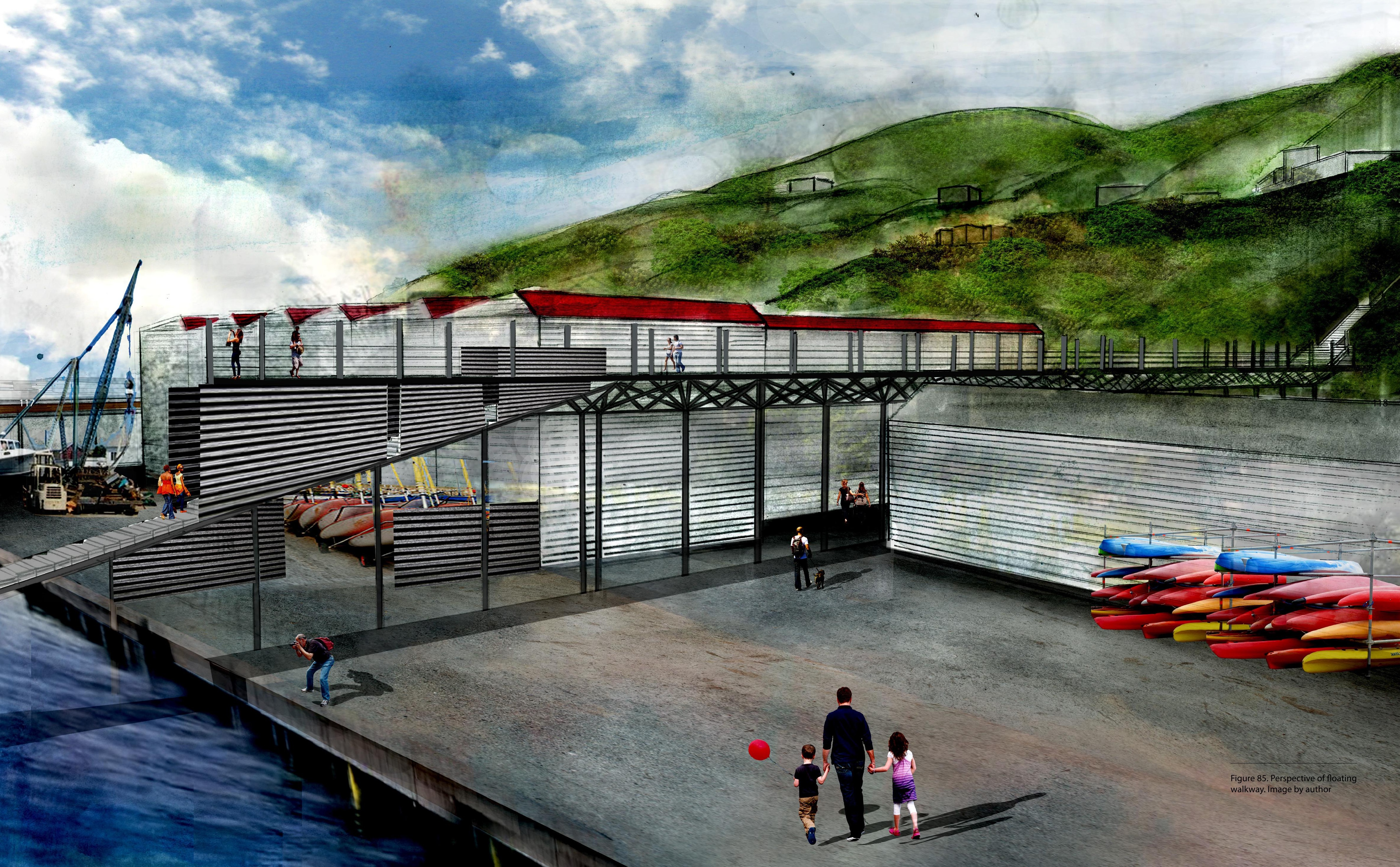


The design intention behind the walkway bridge is to connect the foothills with the harbour. It also leads the pedestrian to the new spaces outlined in the masterplan (residential area, commercial area, marina).

The chosen materiality reflects the historical aspect of the site, for example the navy boat yard. This has been achieved by using stainless steel as the main structura material. This material also reflects the concept of a man-made landscape and the durability and changes that will occur upon this materil with in the coasta

The context of the site creates a harsh affect upon materials and buildings. Stainless steel allows for a 119 longer lasting design, therefore a lasting connection steel chosen, \#316L, weathers more slowly in coastal environments. An unfinished stainless steel is also proposed, giving it an intentional distressed look that reflects and commemorates the history of the site.

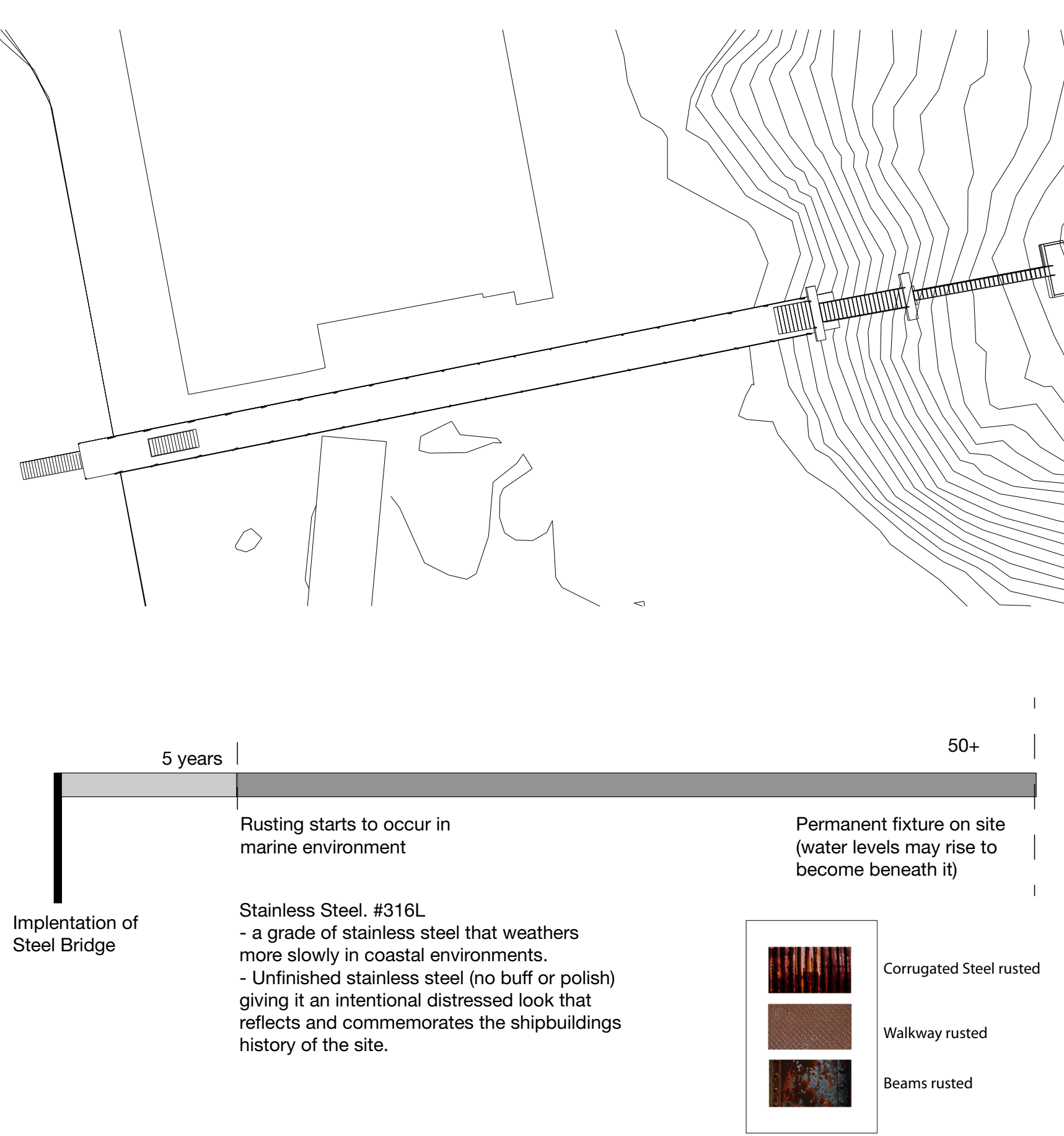


The materiality used within the structure of the design highlights the design intent of the floating walkway.

The structure is interconnected

The steel railings and poles connect to the spine structure.

This connection allows for a more lightweight structure that is strong enough to support pedestrian traffic.

This is important as it creates the feeling of a floating walkway from the foothills, across the

reclaimed land, down into the harbour.

Details, such as the wire rope handrail and textured

walkway, help to reinforce the industrial aspect of the site.

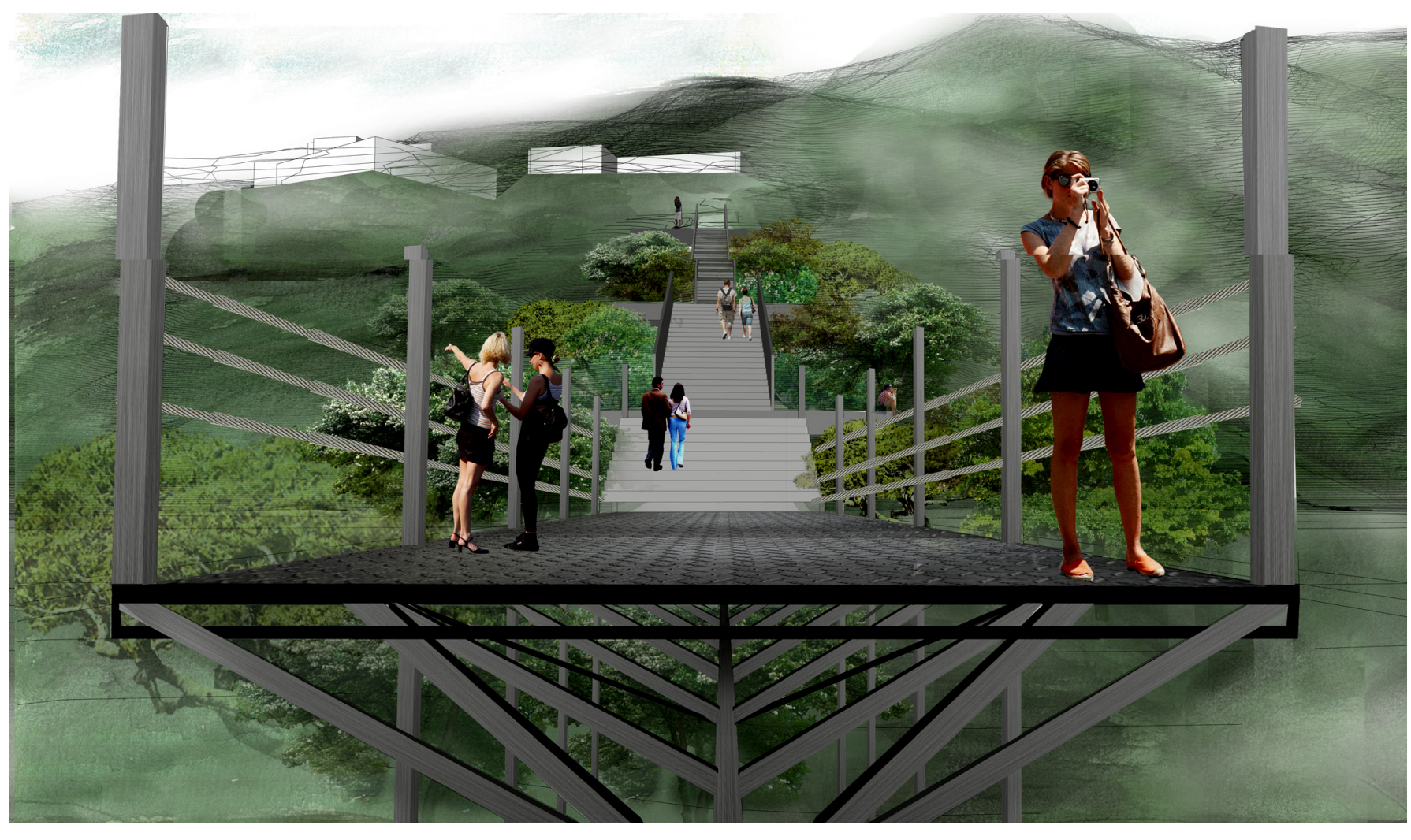

Figure 88. Sectional perspective
of bridge. Image by author 
Material has been used in different forms to reflect a new aspect of the pedestrian journey.

- Corrugated steel has been used to link the walkway with the linear wooden boards of the existing timber buildings.

The descent from the bridge down to the harbour edge is enclosed within the corrugated steel.

This creates an acoustic and visual effect as the

Water is framed within the descent.
Reflections and sounds will bounce within the

narrow staircase as it floats down into the harbour.

Cut out windows allowglimpses of the surrounding

area during the descent. This technique is used within the other two sites creating a forma connection between them.

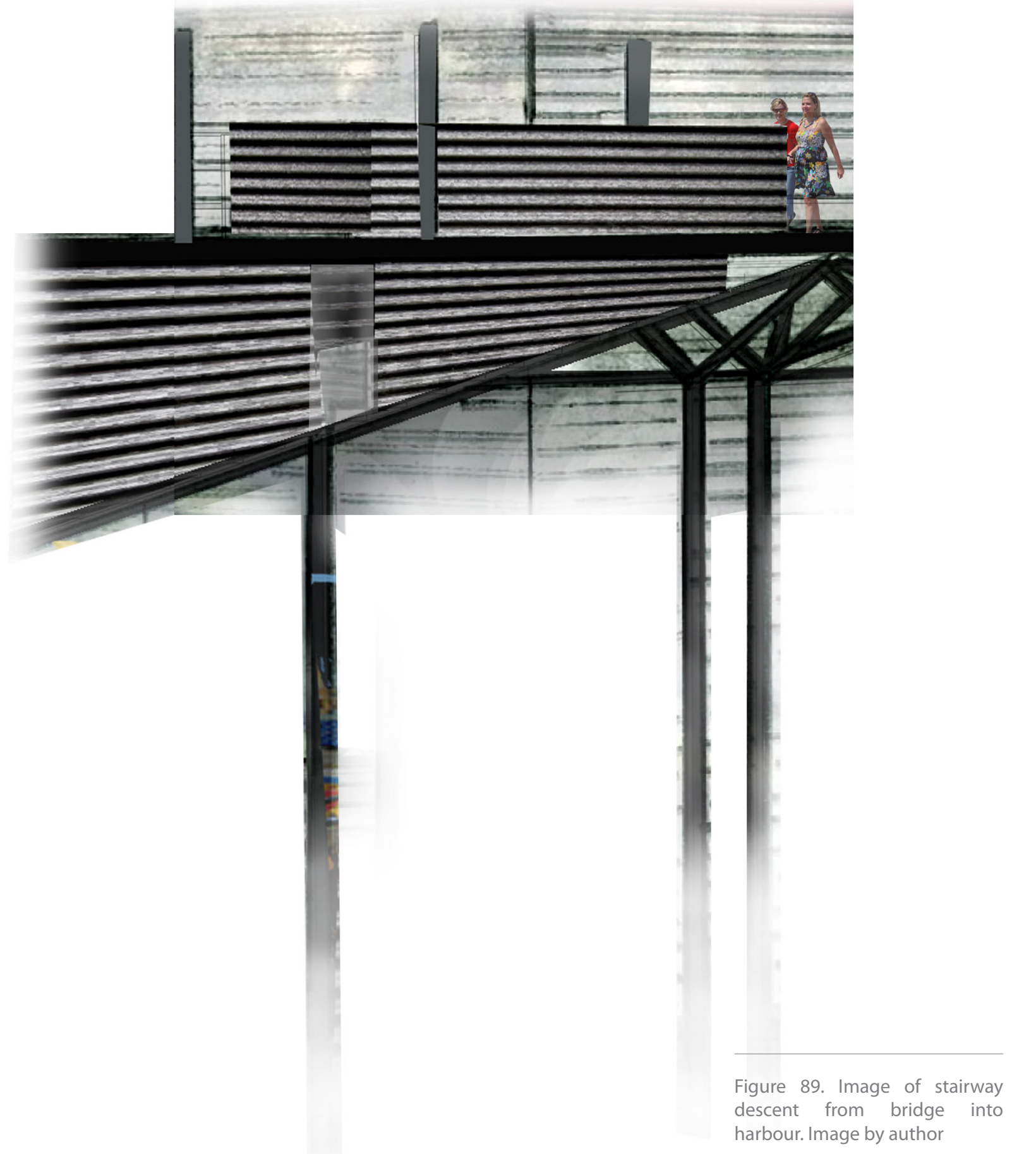


The ascent is highlighted from the floating walkway up into the Shelly Bay foothills (figure 90).

The existing vegetation is used to create an enclosed ascent into the foothills.

The stairway into the vegetation contrasts the

openness of the raised pedestrian bridge.

The width of the stairway decreases with the ascent, accentuating this contrast.

Three platforms have been created along the ascent. These allow users to view the site below them and create rest stops.

The plow steel

stepped on The soundbox connects the stainay

into the foothills acoustically with the stairway

descent into the harbour.

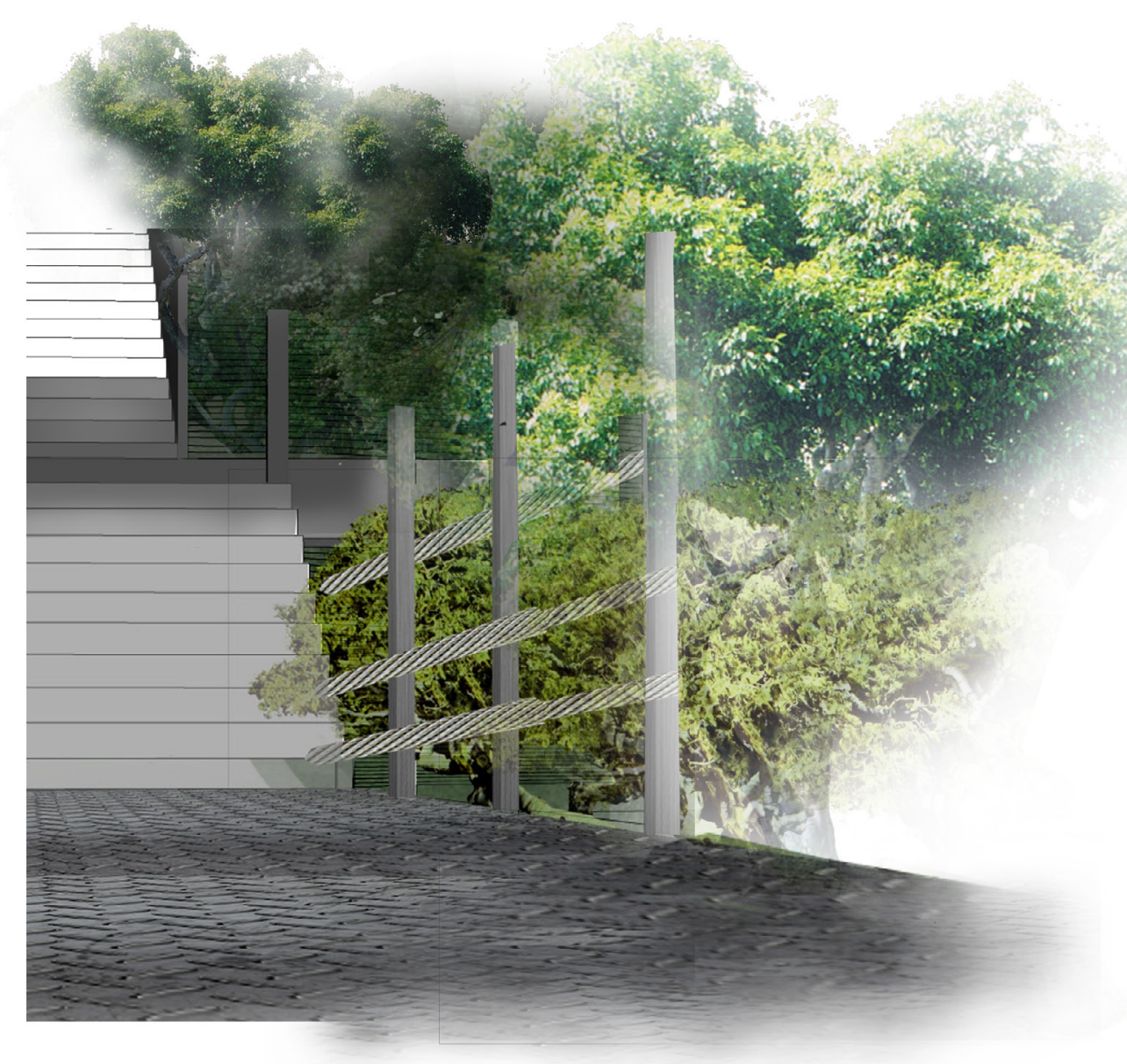

126 


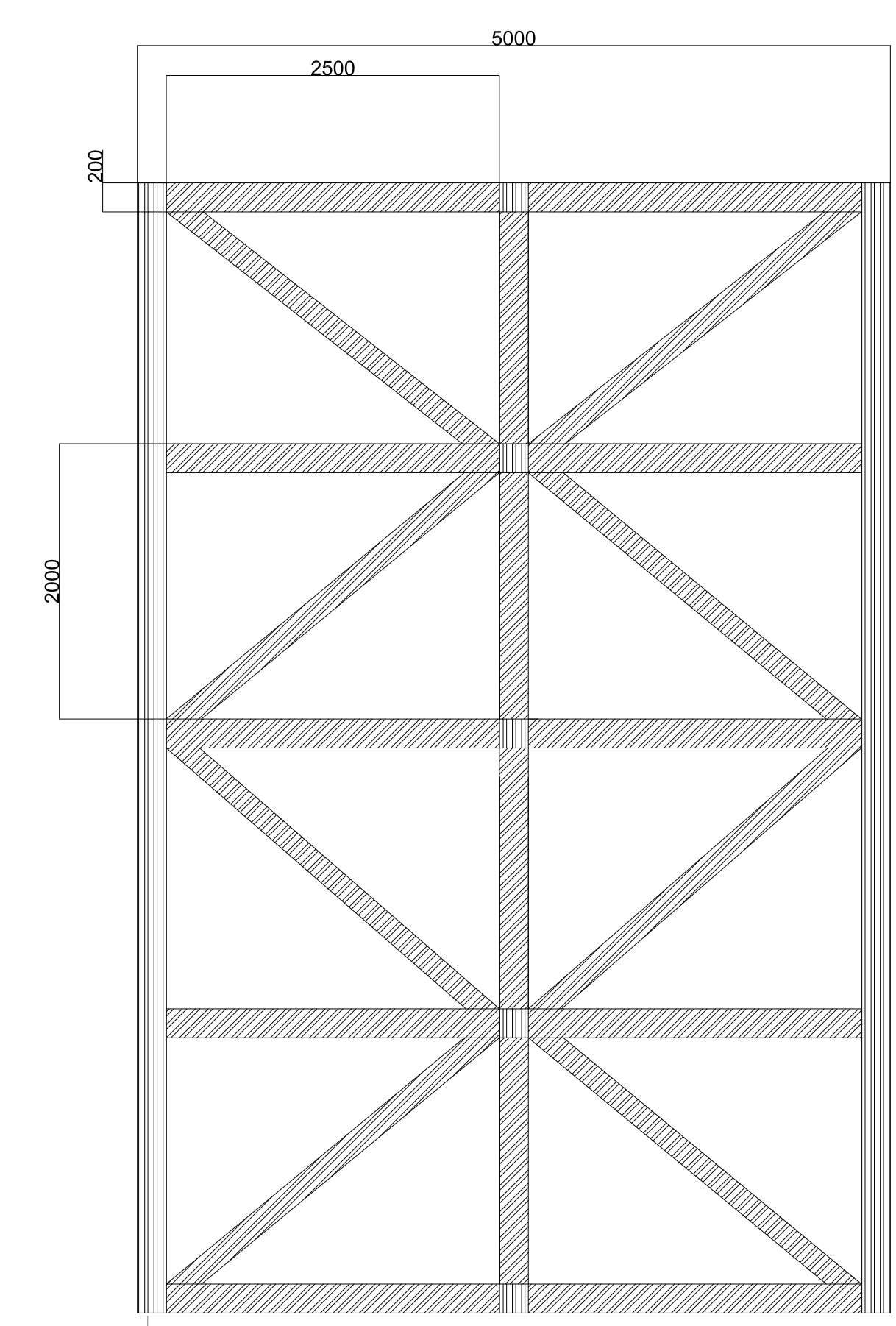




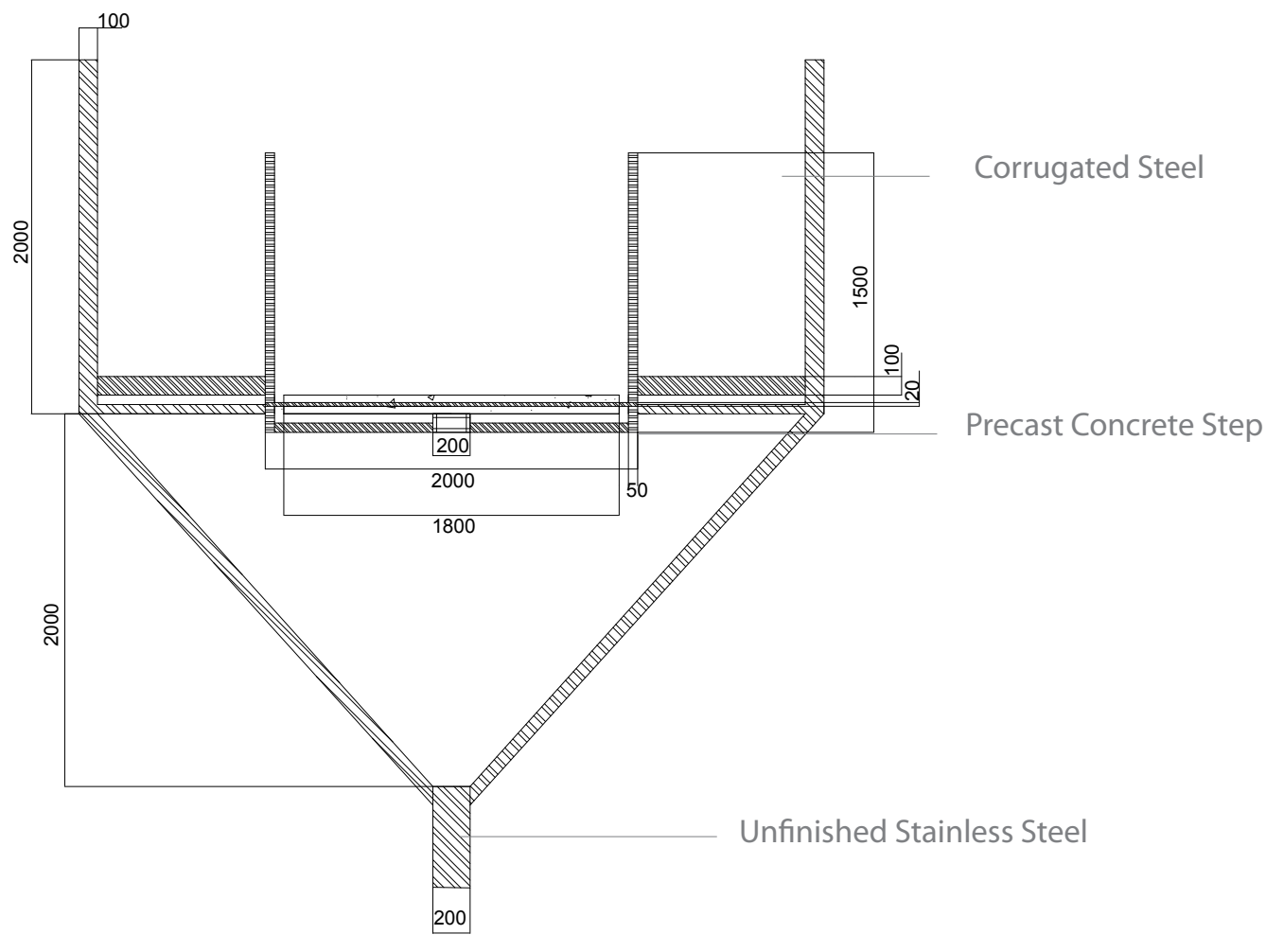

Figure 92. Section of bridge and

stairs descent into harbour

.

All size, dimension and

engineer's specification

130

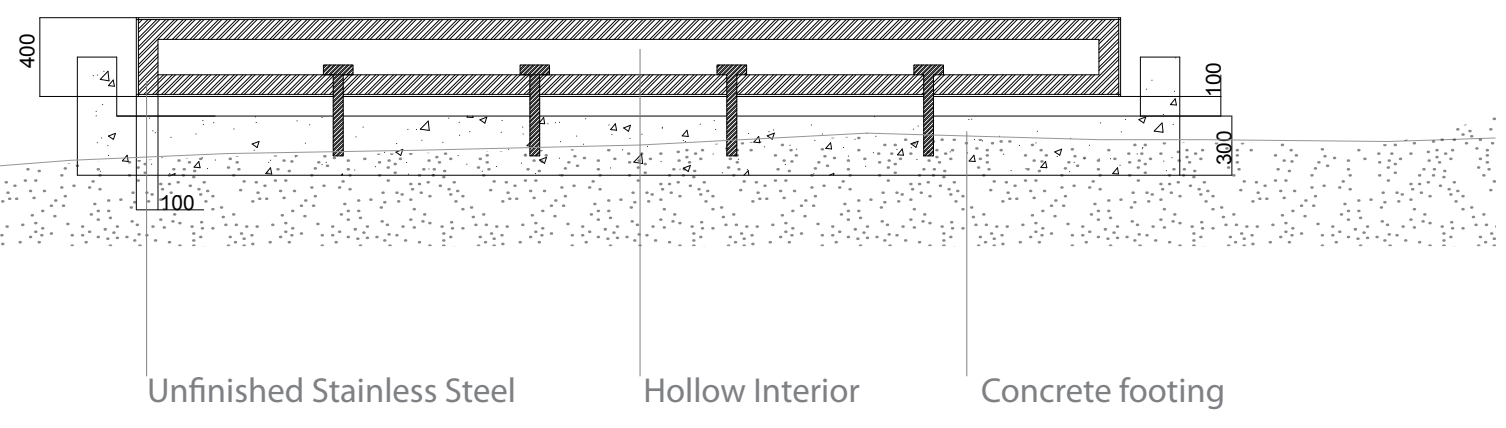

Figure 93. Section of platform in 1.50

connectors to structura

engineer's specification 

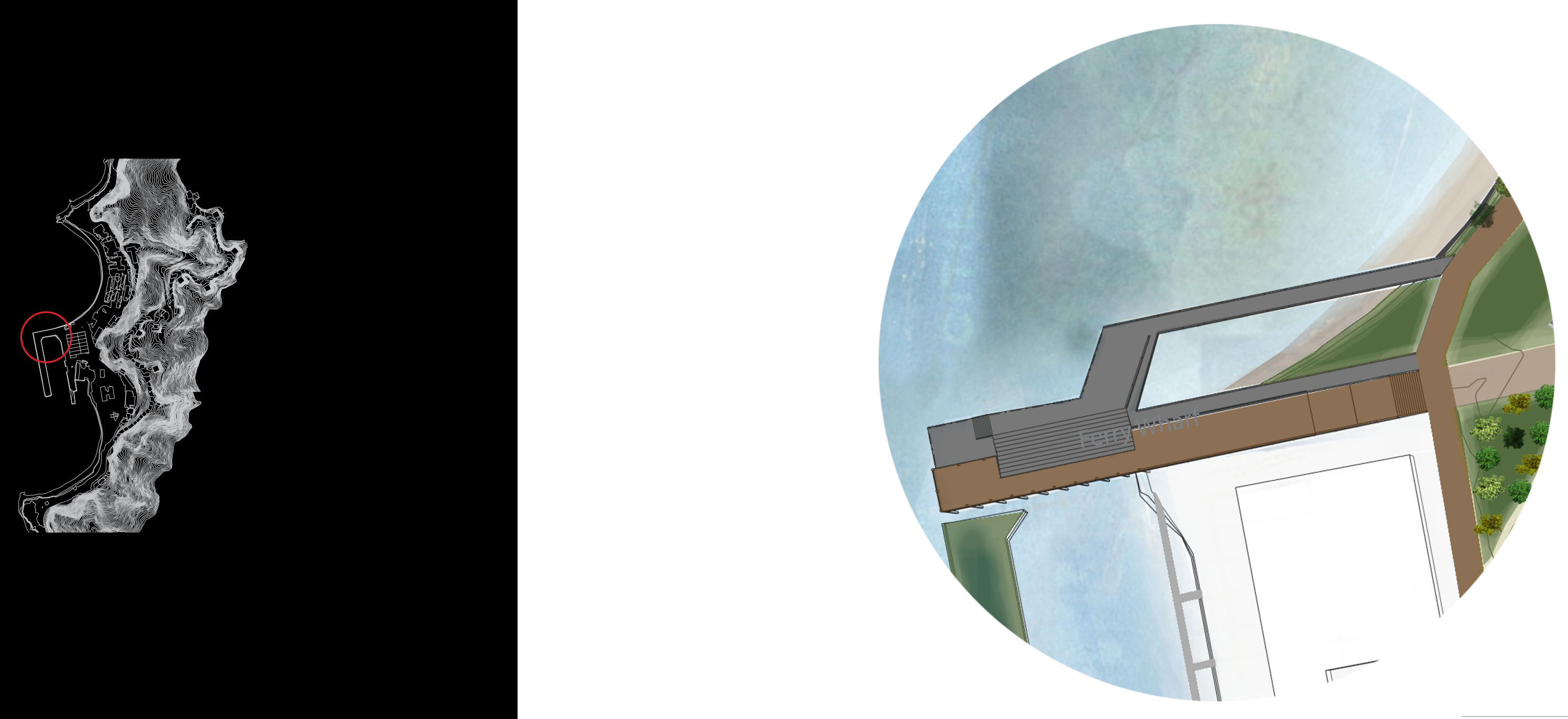

132

Figure 94. Site plan of Ferr
Wharf and Market Space. Not to scale. Image by author 

The design intent behind the ferry wharf is to create discussed in chapter four; Time and Permanence. The concrete structure allows for a resilient material within the marine environment. As a man-made material it also contrasts the current decaying wharves on the site. Grooves in the concrete poles will allow for shellfish and algae growth to occur, displaying the context and ecological conditions of the site. It wil also act as a guide for rising sea levels over time.

The raised boardwalk, which replaces a part of the old wharf, has a timber top layer. The aim is to link the old wharf materials with the new design. It also allows for degradation over time. After the timber degrades, the conct 135 be usable as a walkway.

The wharf also integrates a ferry port and market The winto the site. A ferry port will allow for activation of the site through tourism and public recreation. A sheltered market space will allow the site to create an economic growth. This is important with the integration of a residential site on the foothills and can be integrated with new cafes and restaurants in the area.

Currently the Chocolate Fish Cafe sits at the foot of the hills. It resides on a historical Maori kainga (food) site. The new design pulls the harbour and foothills together, linking the historical typologies with the past and present uses of the site.

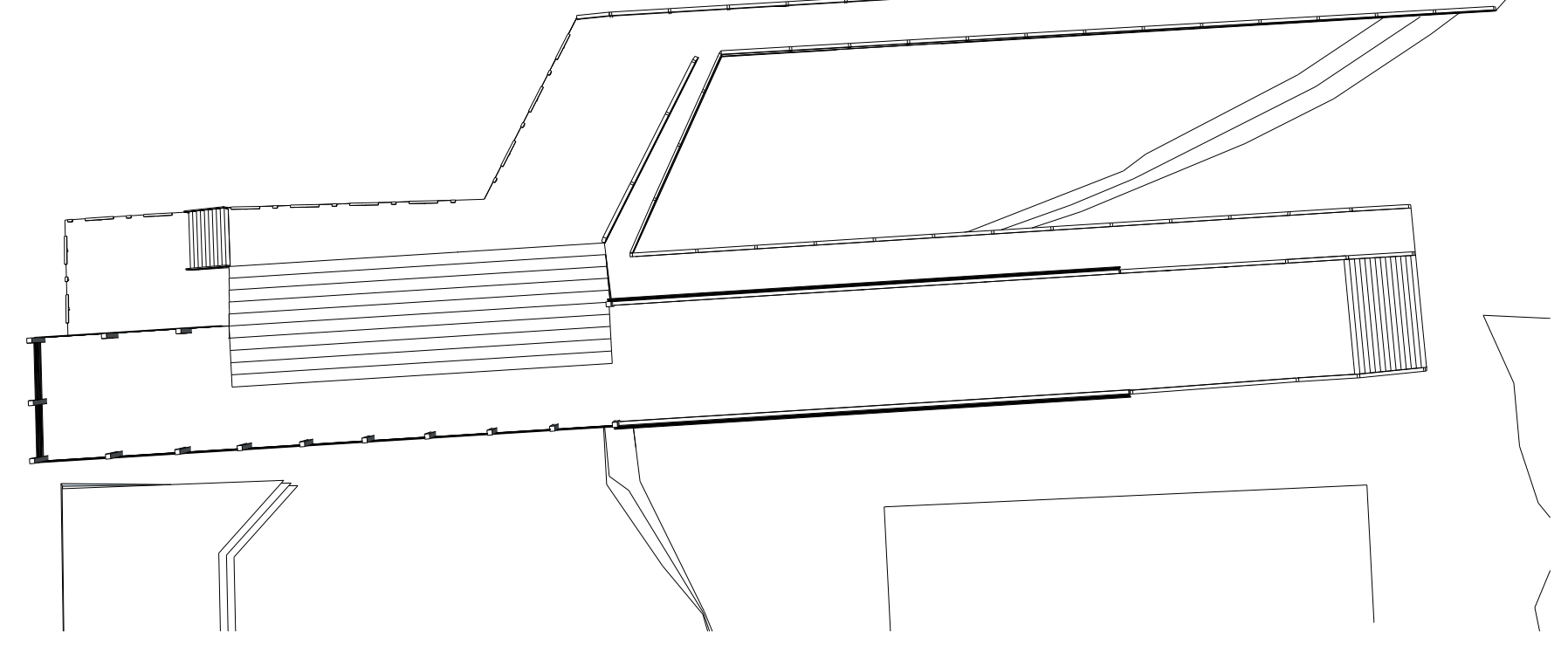

Figure 96. Plan of site B. Origina 1.50 @ A0. Image by author
Figure 97. Material timeline

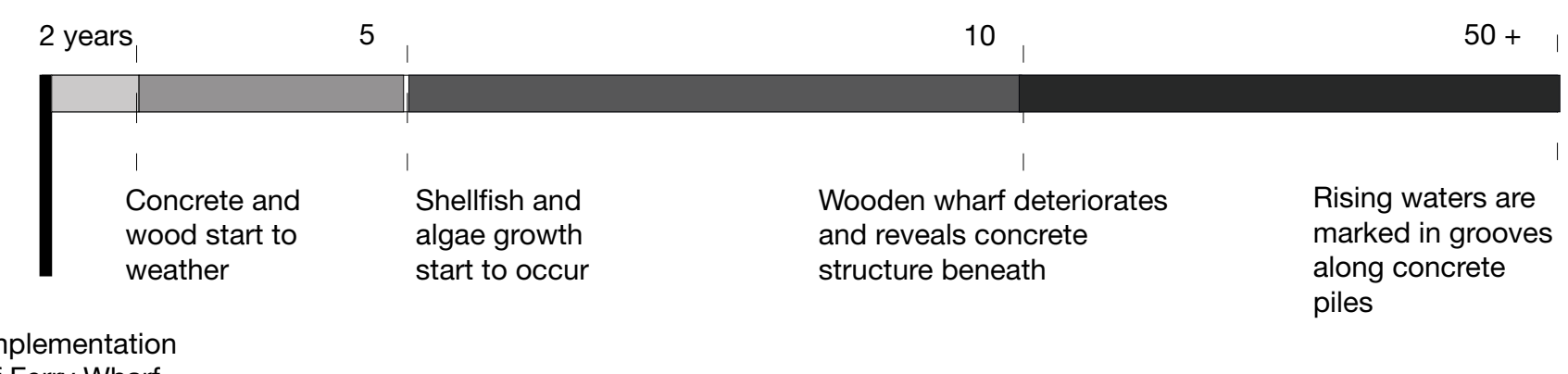
Implementation
of Ferry Wharf 
The market space functions within the ferry wharf through the design of multi-levels and interior

- The lower level of the boardwalk is designed to allow markets and other retail stores to temporarily or permanently set up.

This is a sheltered multi- use space that will help to

activate Shelly Bay in the present and in the future.

The access between the interior and exterior is not

restricted and is gained through cut out sections along the walkway.

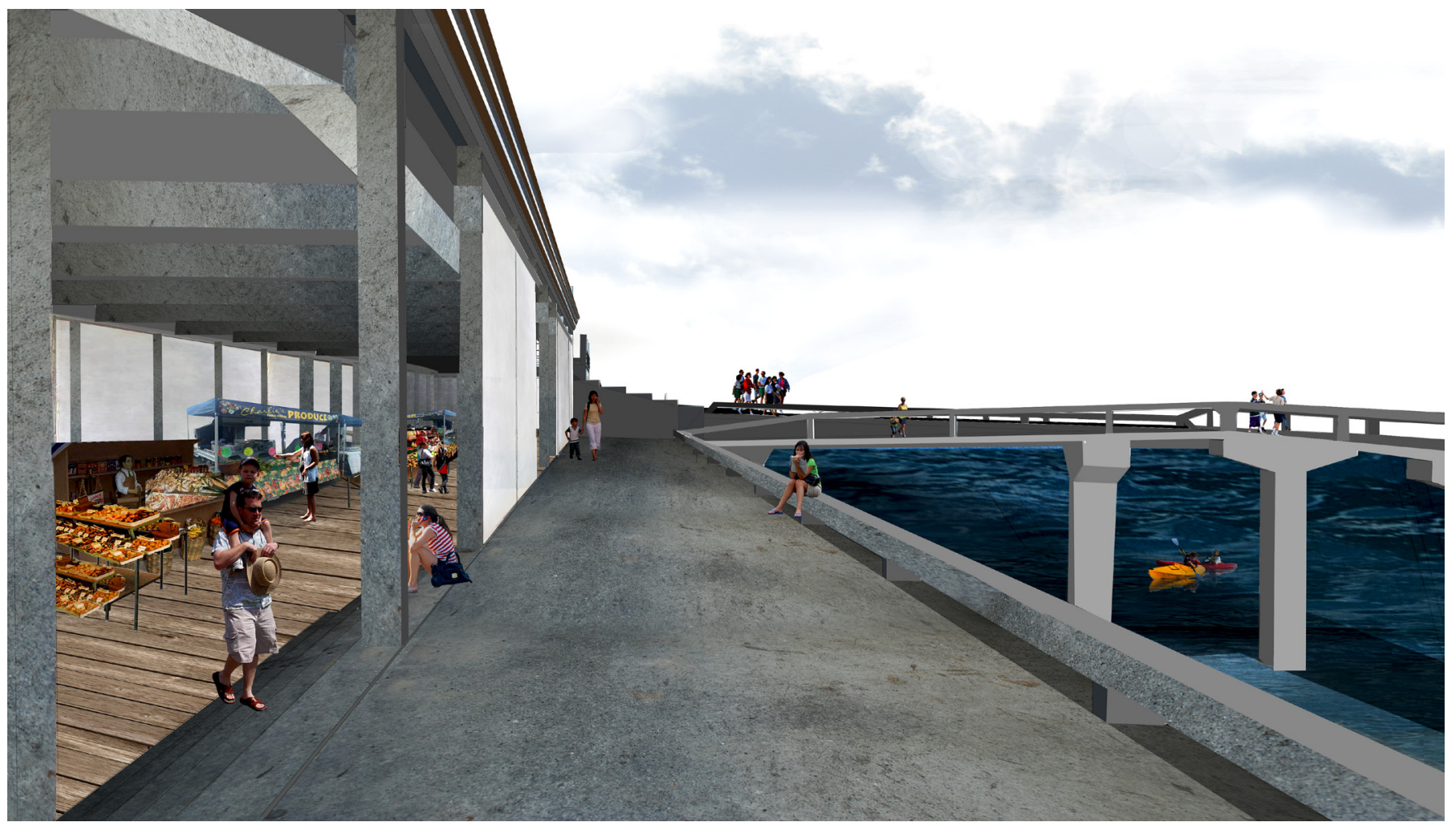



Different levels and angles have been created to to occur.
provide

The form is designed to create different types of spaces for recreational activities to take place, for example fishing, markets and boat docking.

The change in levels represents the change in

typography of the site historically, while also

creating interesting spaces for the public.

The different angles of the wharf replicate the

angles of the current degrading wharves,

The wharf has been designed as a ferry port and a boat docking area, providing different levels for boats to dock.

列

139 this space such as kayaking.

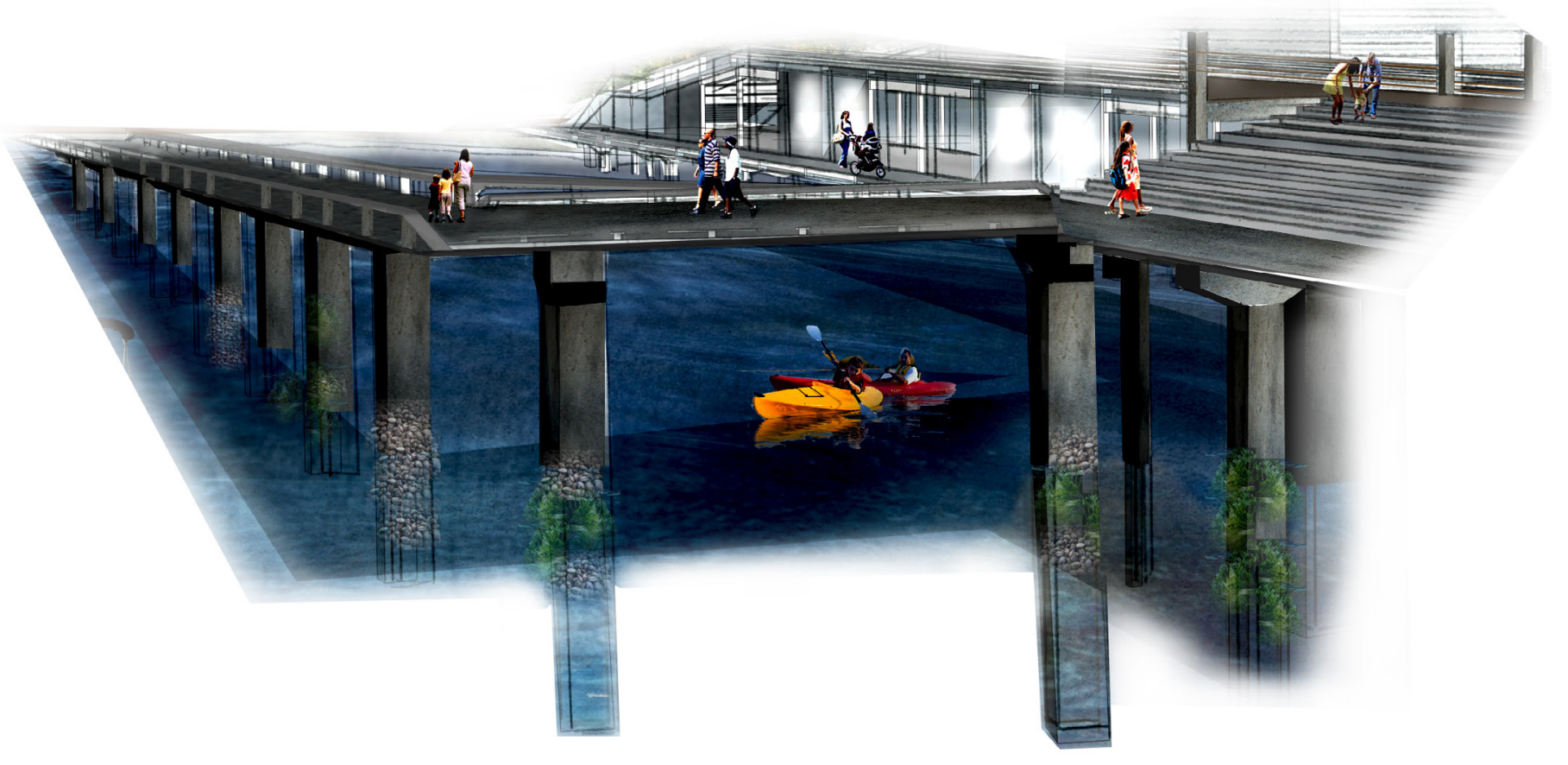

140 Figure 99. Perspective of ferry
port and wharf levels. Image by
author 

This image illustrates how changes in the climate associated activities.

The historical dredging of the bay, combined with the length of the wharf, creates an ideal fishing environment for the public and residents. This could also contribute to the proposed market space.

The materials used (concrete and timber) will weather in different ways within this environment. The concrete will withstand these conditions but will reflect the climate on its exterior. The timber will eventually decay, reflecting the current condition of the historical wharves and buildings. The height of the wharf and boardwalk allows for waterlevel hanges and rough weather condition

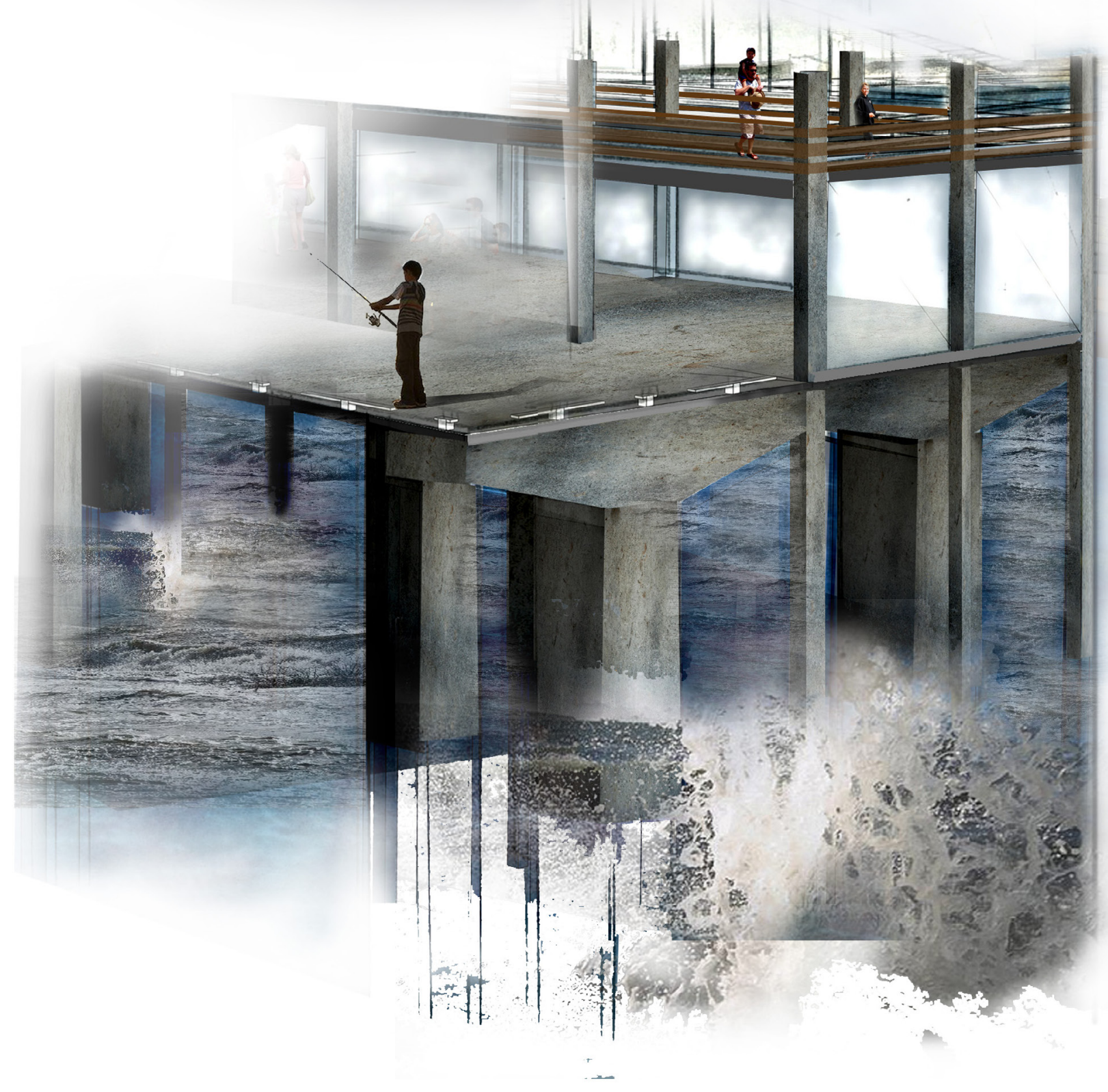

142 


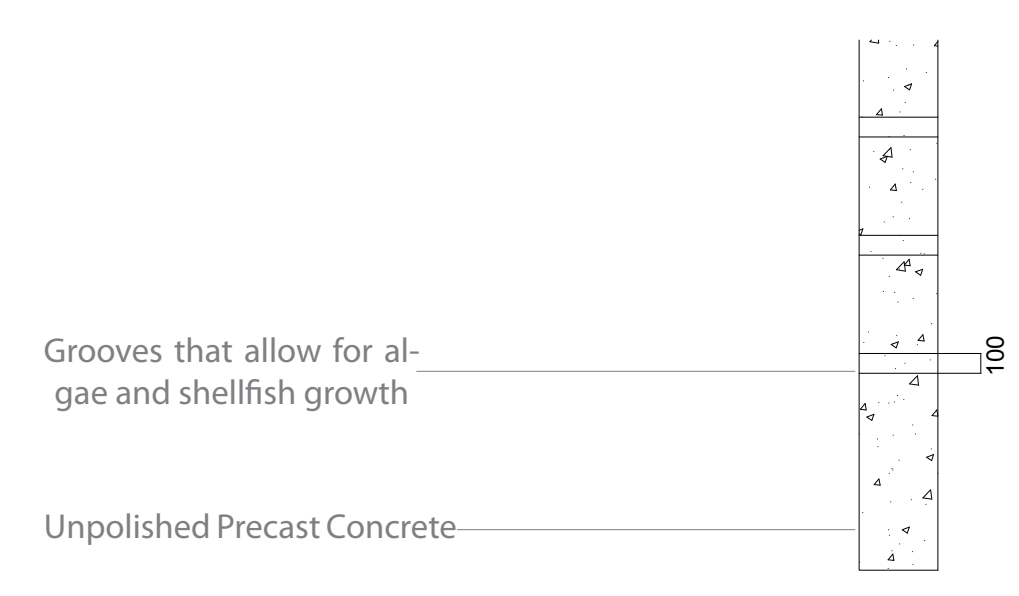
Figure 101. Elevation of concrete
piles @ 1:50. Image by author 


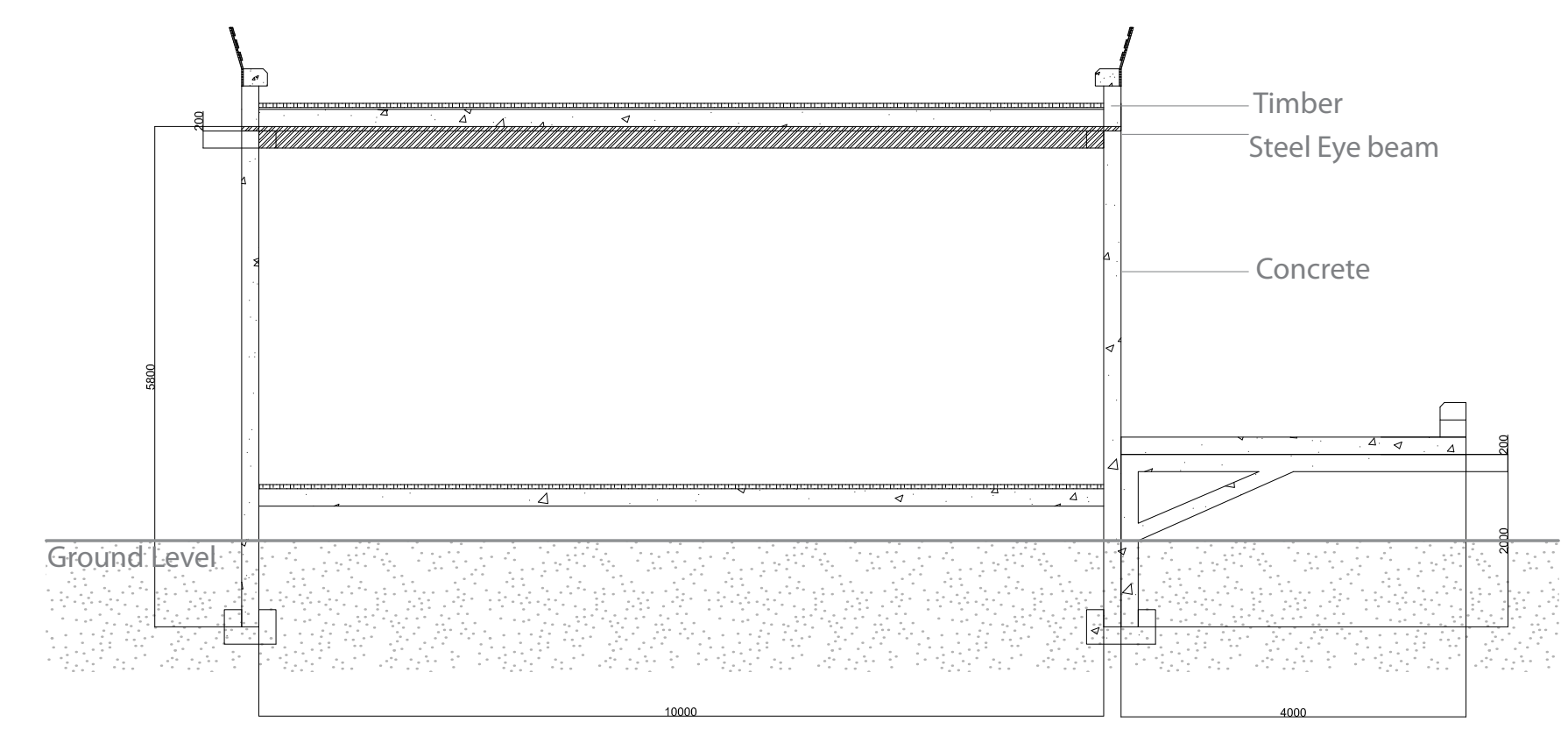

Figure 103. Cross-section of
wharf levels and market space

wharf levels and market space
interior @ 1:100. Image by author

All size, dimension and

connectors to structura

146

ngineer's specification

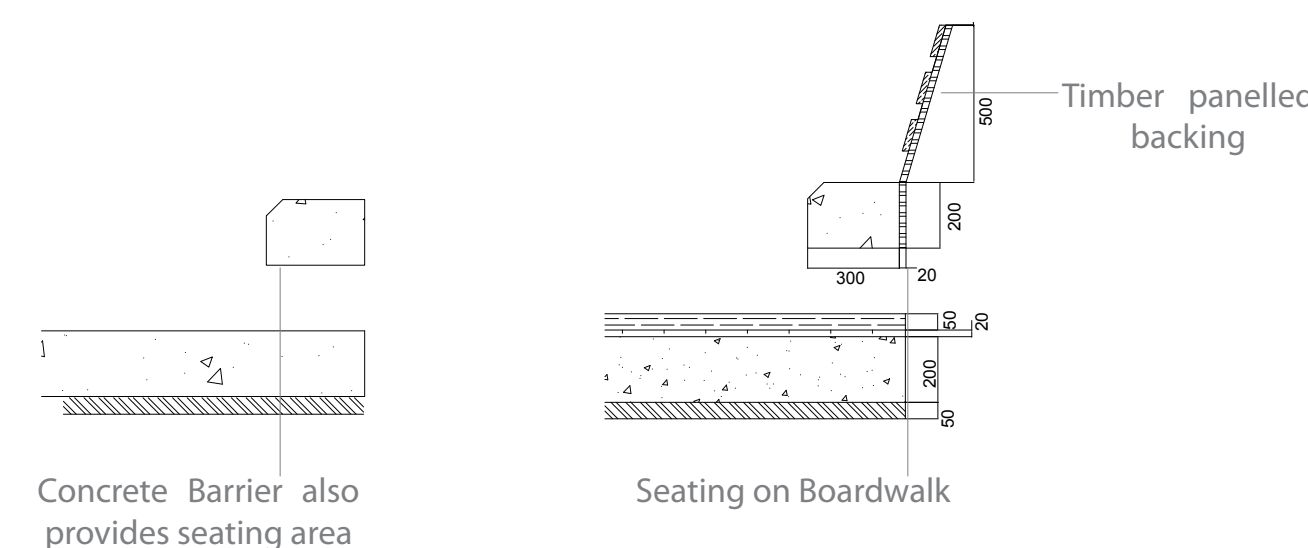

Figure 104. Sections of seating

auth

All size, dimension and

All size, dimension an
connectors to structura

engineer's specification 

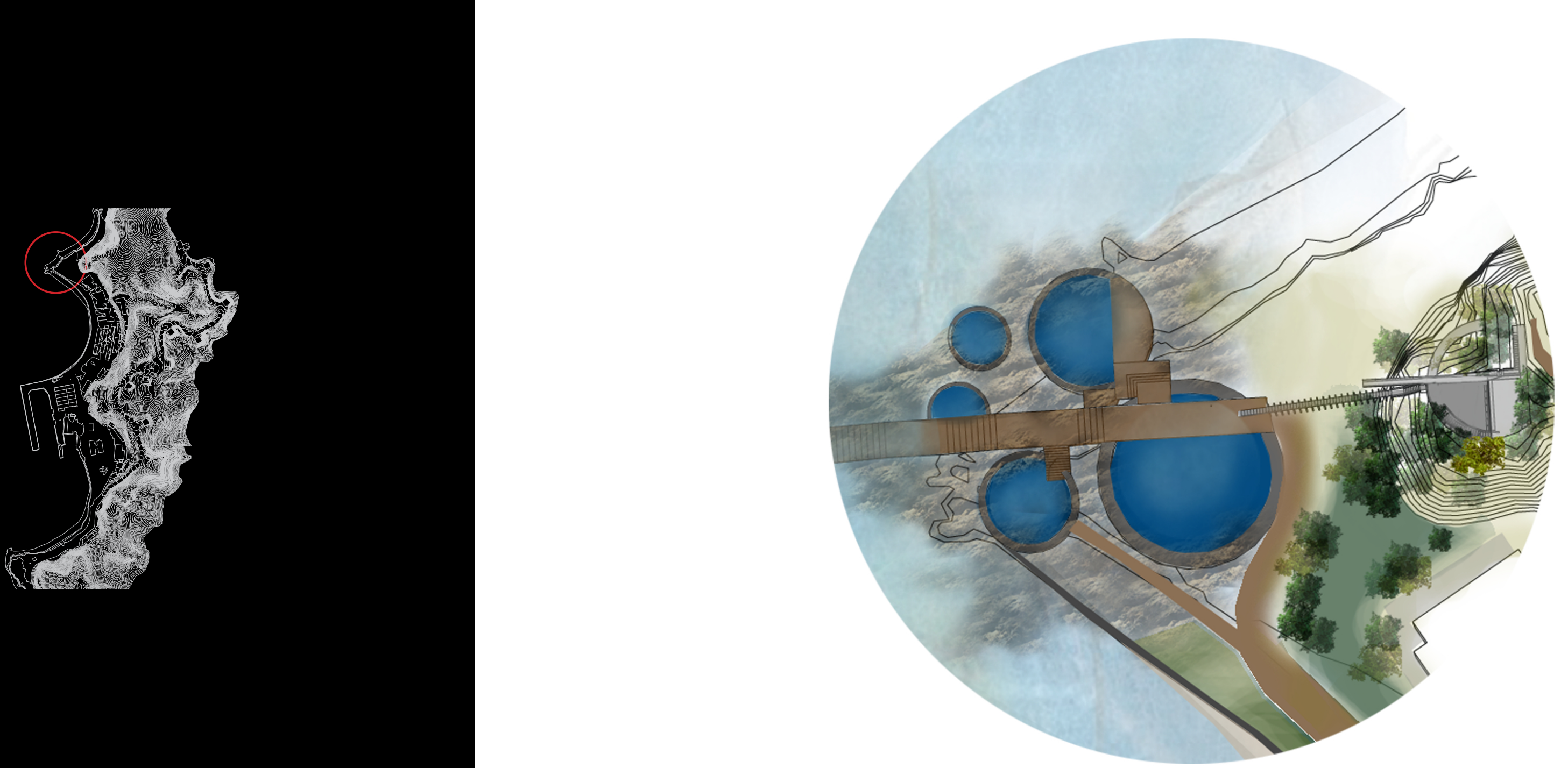

Figure 105. Site plan of lookout and tidal pools. Not to scale,

148 

Lookout

Materiality and Form

The design intent of the lookout is a response to the military history of the site combined with the typology of the site. The intention is to bring users up into the oothills and view Wellington City and the surrounding fuburbs. This renforces Shelly Bays context and its

Both the lookout and tidal pools are perfect circular concrete forms. This reinforces the idea of a concrete forms. This tinforces the idea of a man-made the lookout has been sunken into the foothill, with parts of it becoming engulfed by the landscape. This portrays natures survival over man-made structures. It also allows for different spaces and levels to be created within the lookout.

151 The southern side is almost completely sunk into the foothill, creating a sheltered space with interio qualities. The northern edge responds to the exposed climate of the site. A narrow semicircular walkway brings users across the edge of the hill and into the vegetation. This allows for views of the harbour and the city. A cantilevered walkway, which responds to the same angle as the tidal pools boardwalk, floats over the reclaimed land and allows for even more pectacular views.

A staircase connects the lookout to the tidal pools and boardwalk This is designed to rosemble the salse aualities as site $A$ : lightweight fooating and resame This structure is made from stainless it is painted to resemble timber and the steps are it is painted to resemble timber, and the steps are
concrete to connect the qualities of the pools and the ookout.

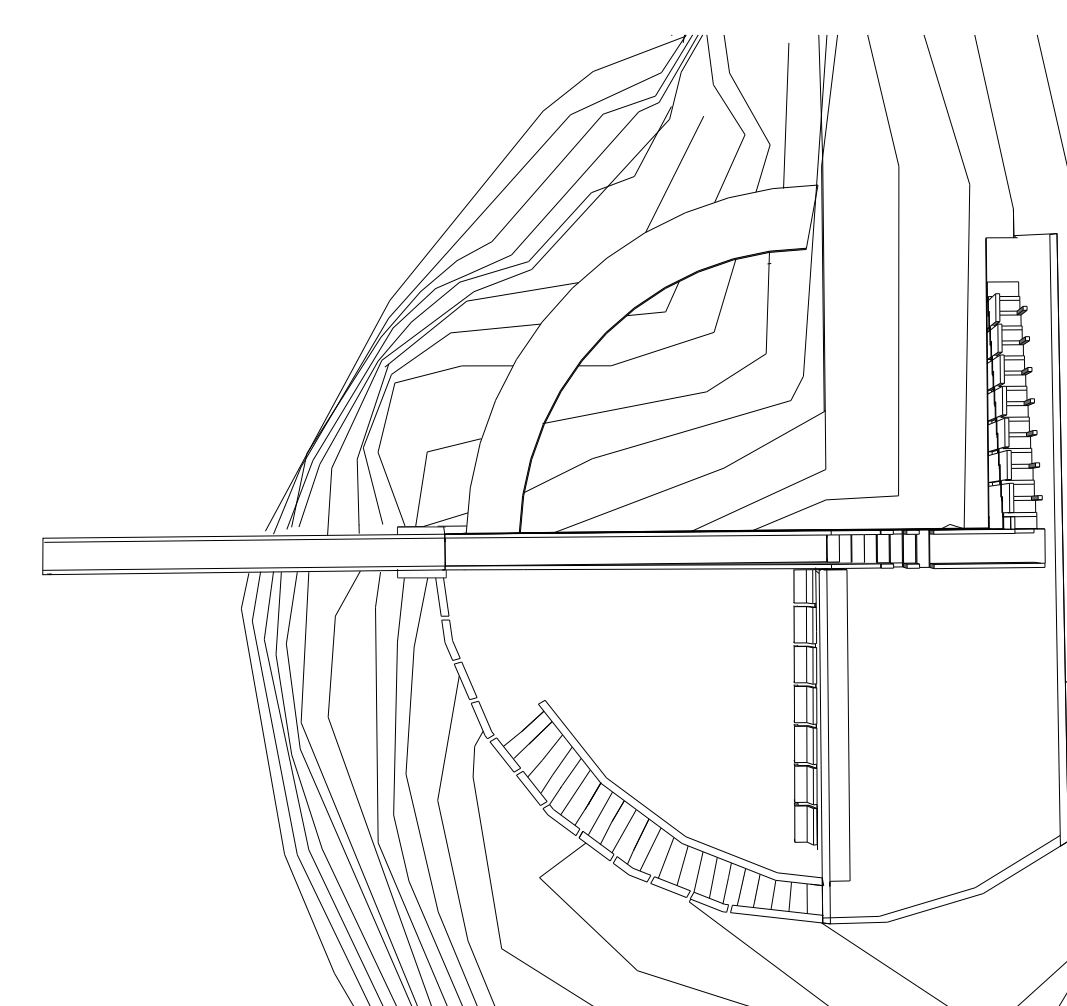

152

10

$50+$

Concrete starts to weather (slower than pools as it is spray) Implementation
of Lookout start to fill with vegetation Structure becomes
engulfed in landscape as vegeation and 
In the ascent and entry into the lookout, the angle of

interior leading to a number of rooms and levels.

The sunken steep concrete staircase creates a feeling of expectation when ascending into the structure.

Low ceilings and narrow corridors emphasise the

idea of the structure sinking into the foothills.

The form of the lookout is designed to resemble

the old military bunkers that scatter the Miramar

Peninsula.

The different spaces and levels provide an intrigue and investigation of the structure for the user.

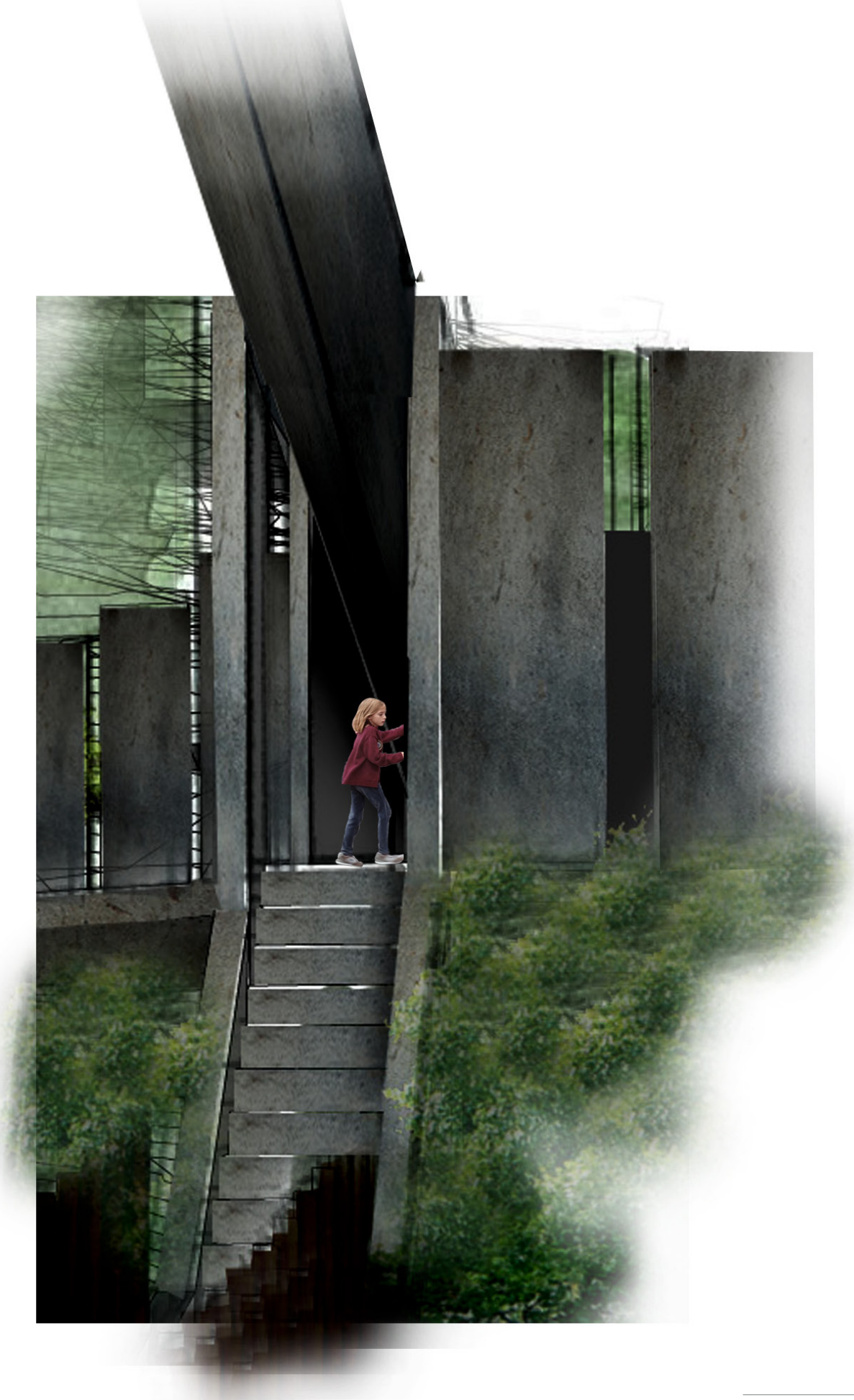

154 
In the south the structure has been sunken into the hils respoch the sto the existing typology and

The southern wing is not sheltered from above but the closed in concrete walls and low floor leve create a feeling of shelter. The semi-circular outer wall has been designed cutouts are a similar technique used across al trigger sites, linking the designs together.

The concrete cuts also allow for vegetation to

impose upon the interior of the lookout. Over time, the structure will appear less dominating and more integrated into the landscape.

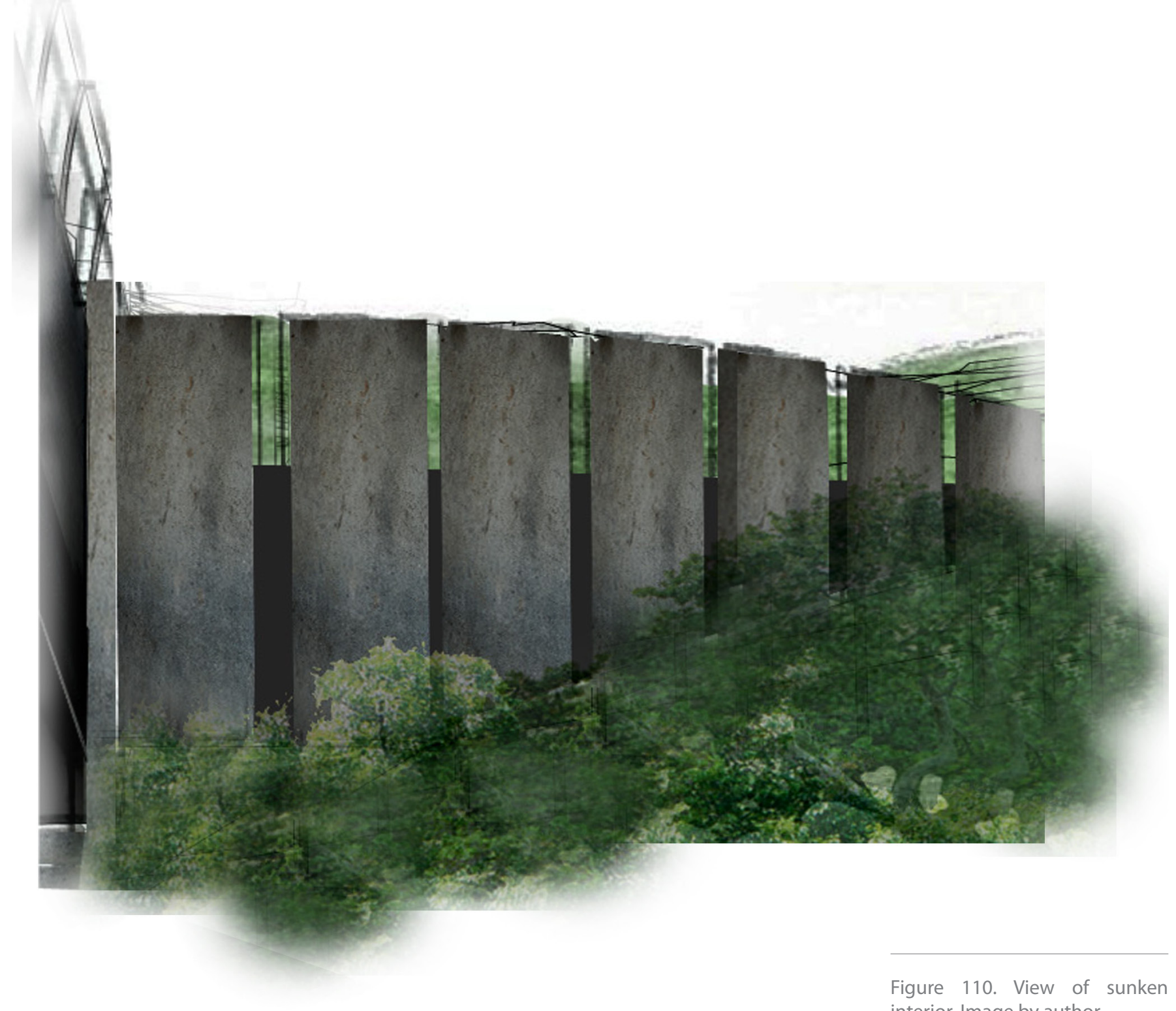


The open exterior wing of the lookout reveals a semiedge of the hill, into the natural vegetation.

- The concrete walkway appears to be floating above the vegetation and contours of the hill.

The platform is exposed to the elements of the site, while providing a full view of the harbour and

city.
The platform connects the user to the staircase which leads to the cantilevered walkway This side of the structurs

This side of the structure allows the vegetation and views to dominate the design, with little mansouthern wing.

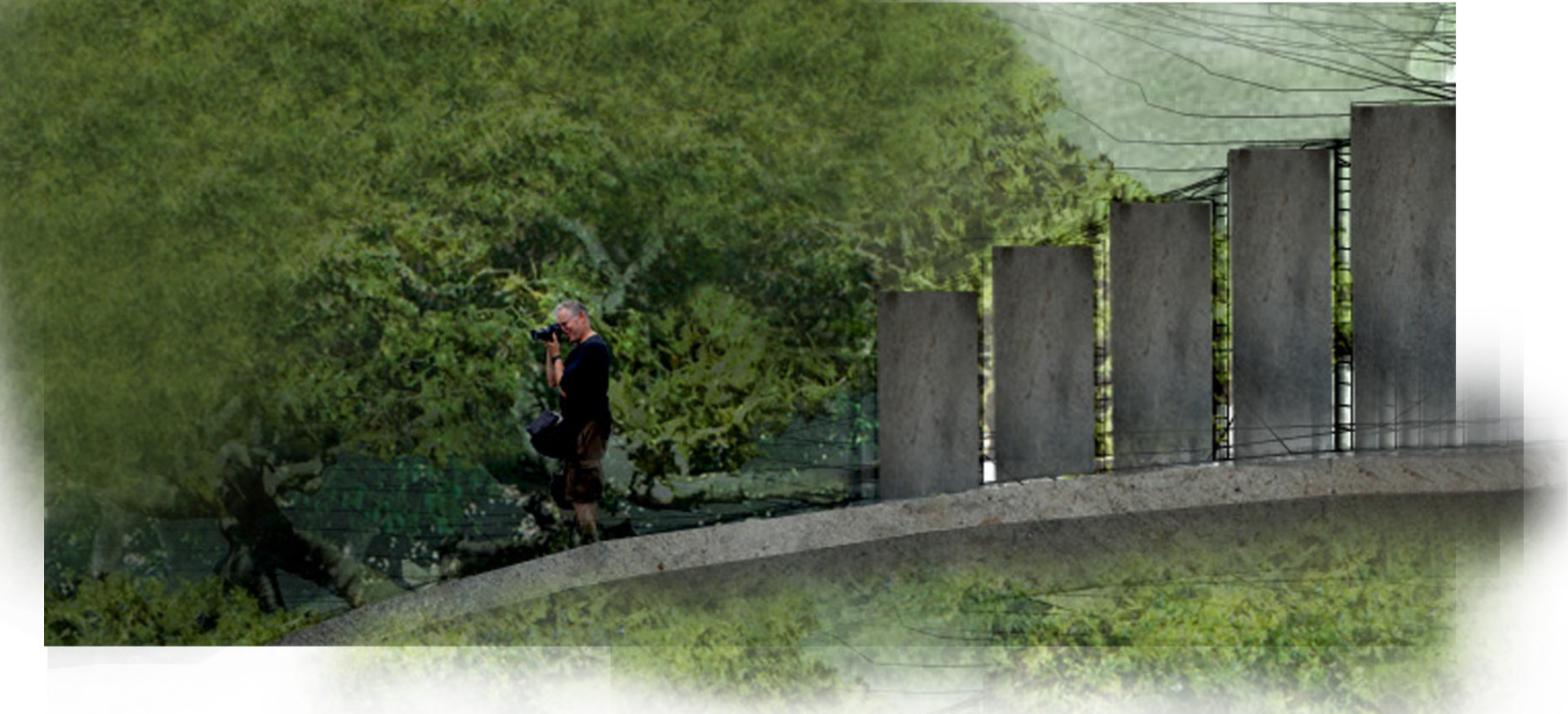

Figure 111. View of norther
wing exterior. Image by author 
The structure of the connecting walkway highlights 作 enclosure of the vegetation upon it.

The stainless steel walkway structure is lightweight, creating a spine like appearance as it connects the ecological tidal pools with the bunker lookout.

the boardwalk below, and allows it to become

integrated into the foothill vegetation.

The narrow staircase and high beams enclose

the walkway while still allowing views along the journey. 


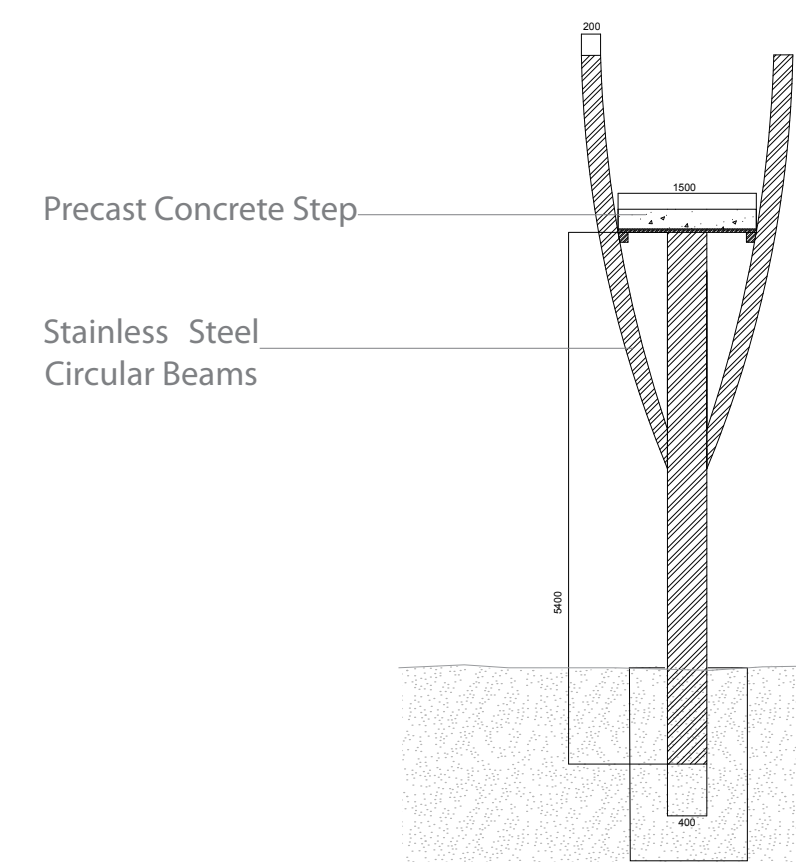

161 Elevation of Concrete Cutout Structure

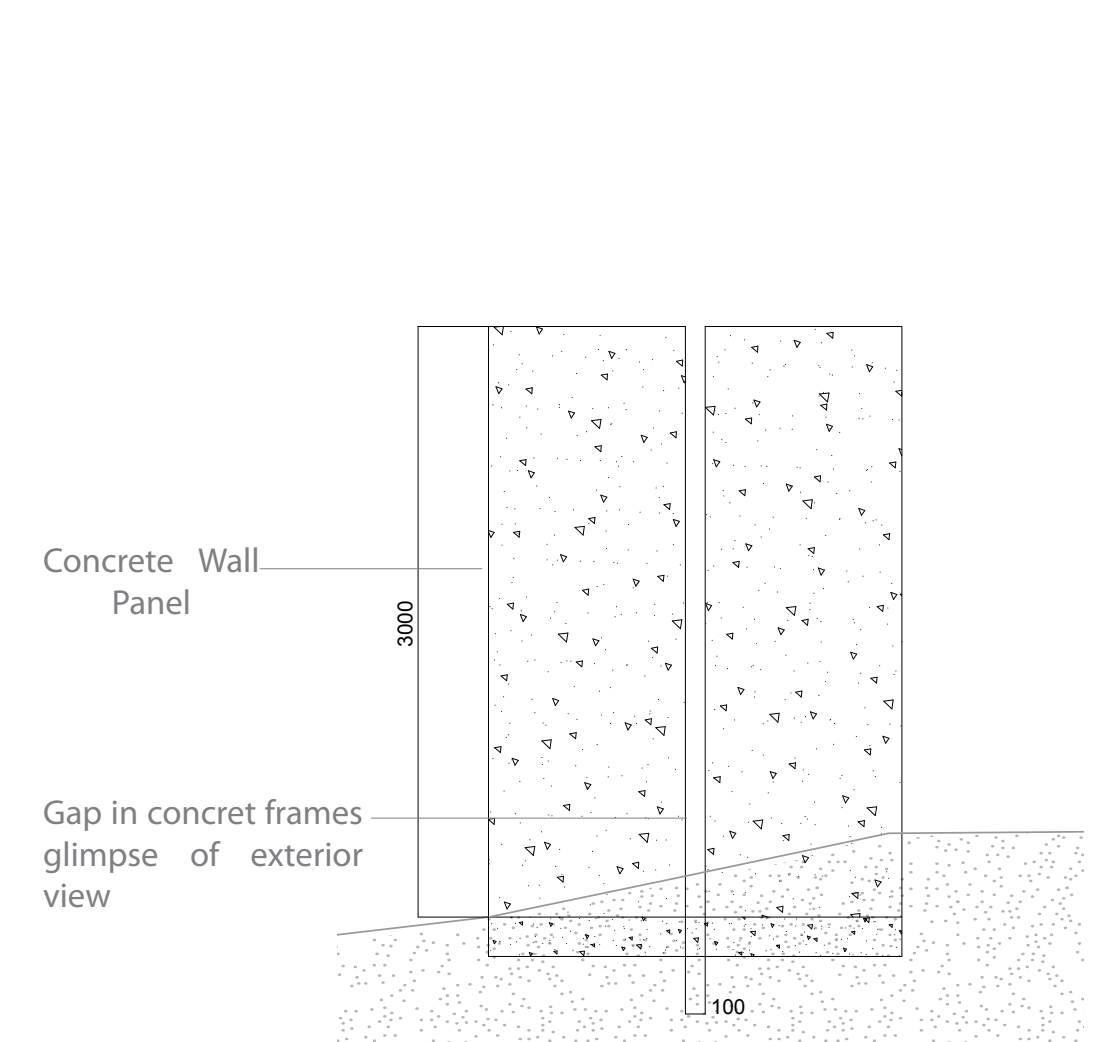

Figure 113. Section of raised

All size, dimension and connectors to structura

Figure 114. Elevation of concrete cutout structure @ 1:100. Image connectors to structura 


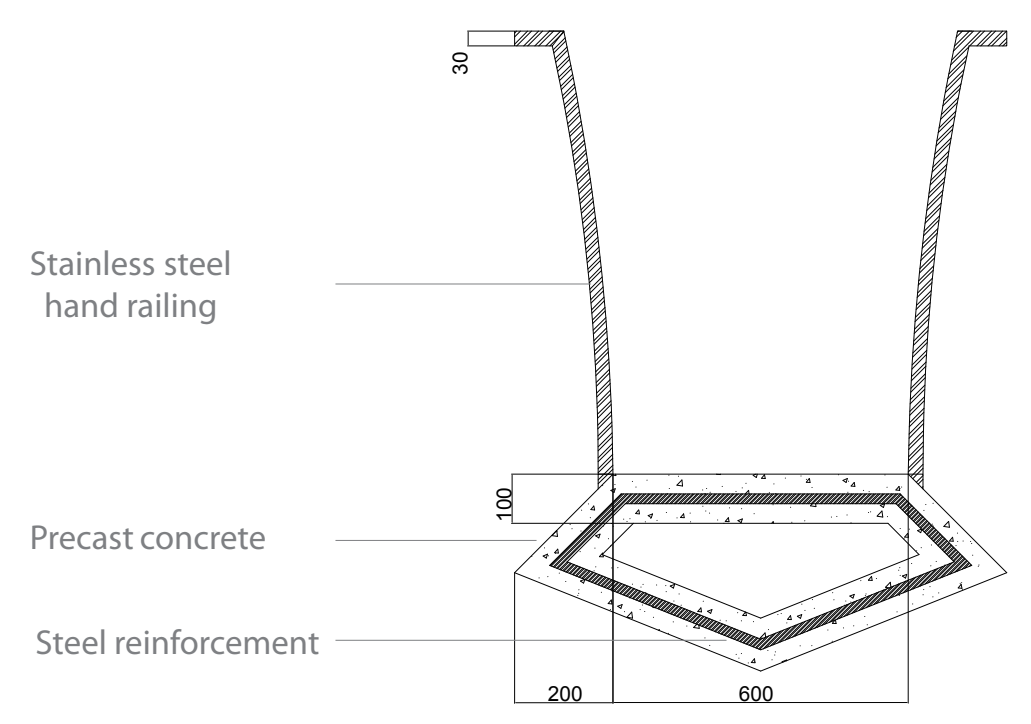

Figure 115. Cross-section of
cantilevered walkway @ 1:20. mage by author

All size, dimension and

onnectors to structural

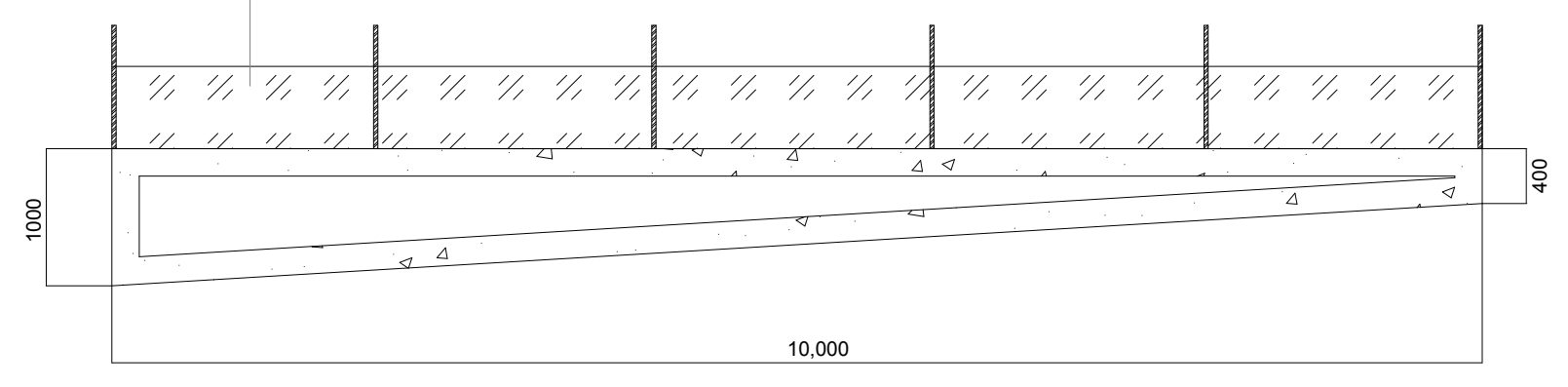

Figure 116. Section of cantileve

All size, dimension and

connectors to structural
engineer's specification 
$=-4,-3 x^{2}+x^{2}$

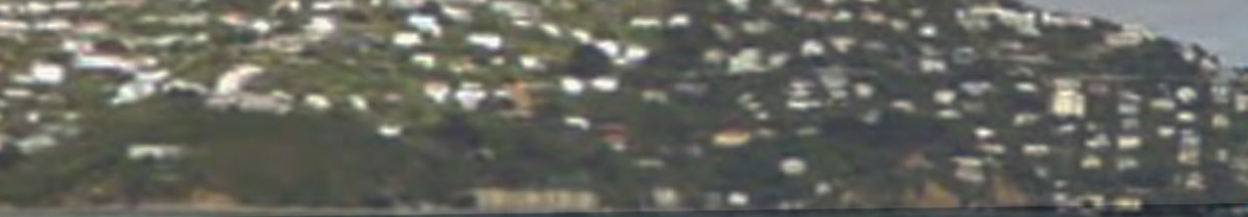

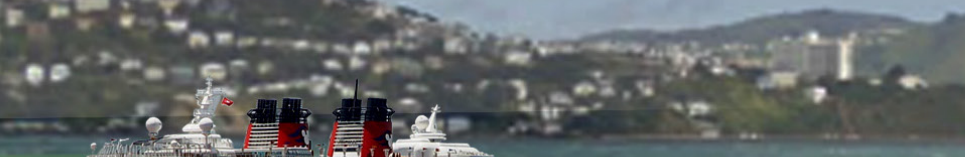
ntipe

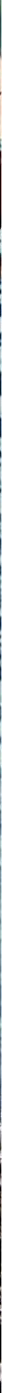


Tidal Pools

Form and Materiality

The tidal pools have been designed as circular concrete structures ennecting them in form and materiality to the lookout above. However the design intent addresses a different aspect of Shelly Bay; the rocky coastline and water ecology within Wellington's harbour.

The pools have been designed to sink into the reclaimed land, appearing as man-made structures along the natural coastline. Channels connect the pools with each other, and allow water to flow in and out. A wooden boardwalk allows access for the public. This timber walkway connects aesthetically with the current degrading wharves on site, following the same angle and width.

${ }_{167}$ Over time, the surrounding environment will overtake the design. The tidal pools will become integrated into the landscape as the water erodes their form, and water levels will also mark the pass. is of time the harbour takes over the coast and tidal pools. The wooden boardwalk will decay and eventually erode replicating the historical materials of the site Access and use of the design will change and adapt as this process takes place.

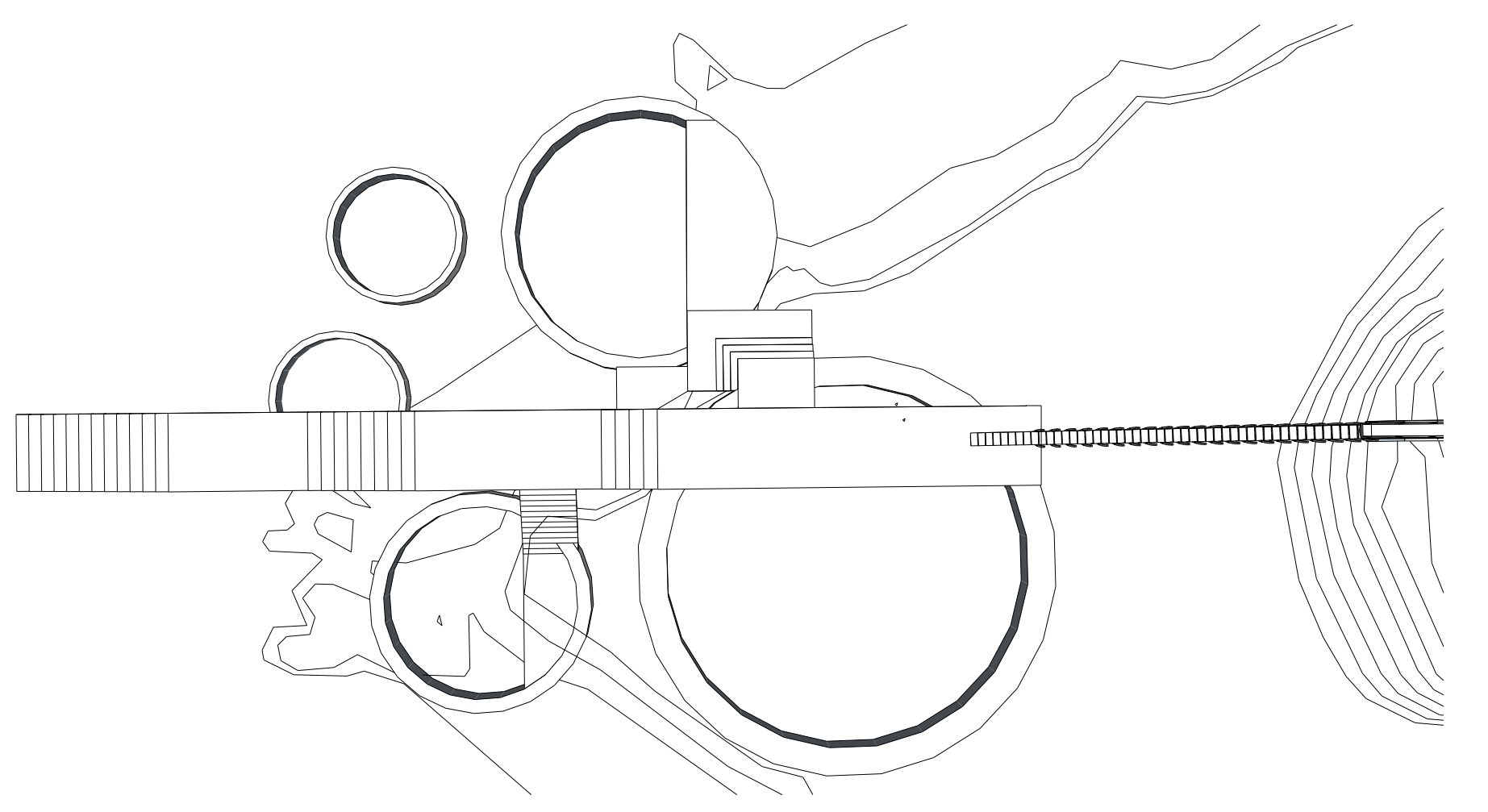

168

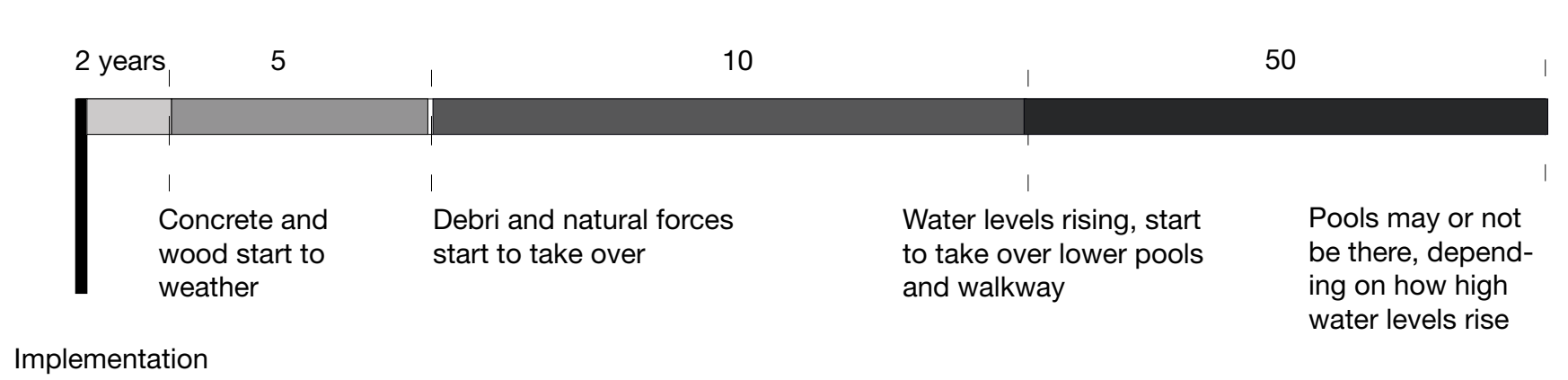



The context and natural forces impacting upon the site, the design, and the materis is illustrated here
(figure 120).

- The site is an exposed coastal environment. The site for the tidal pools is even more exposed as it is built upon a rocky point with no sheltering foothills.

ts the pools

and boardwalk in normal climatic situations. However, in rough conditions, the water and salt spray will impact upon the design and public use of the site.

Within a stormy environment, drift wood, seaweed and other materials will be pushed into the pools, furcher incorporating them into the natura

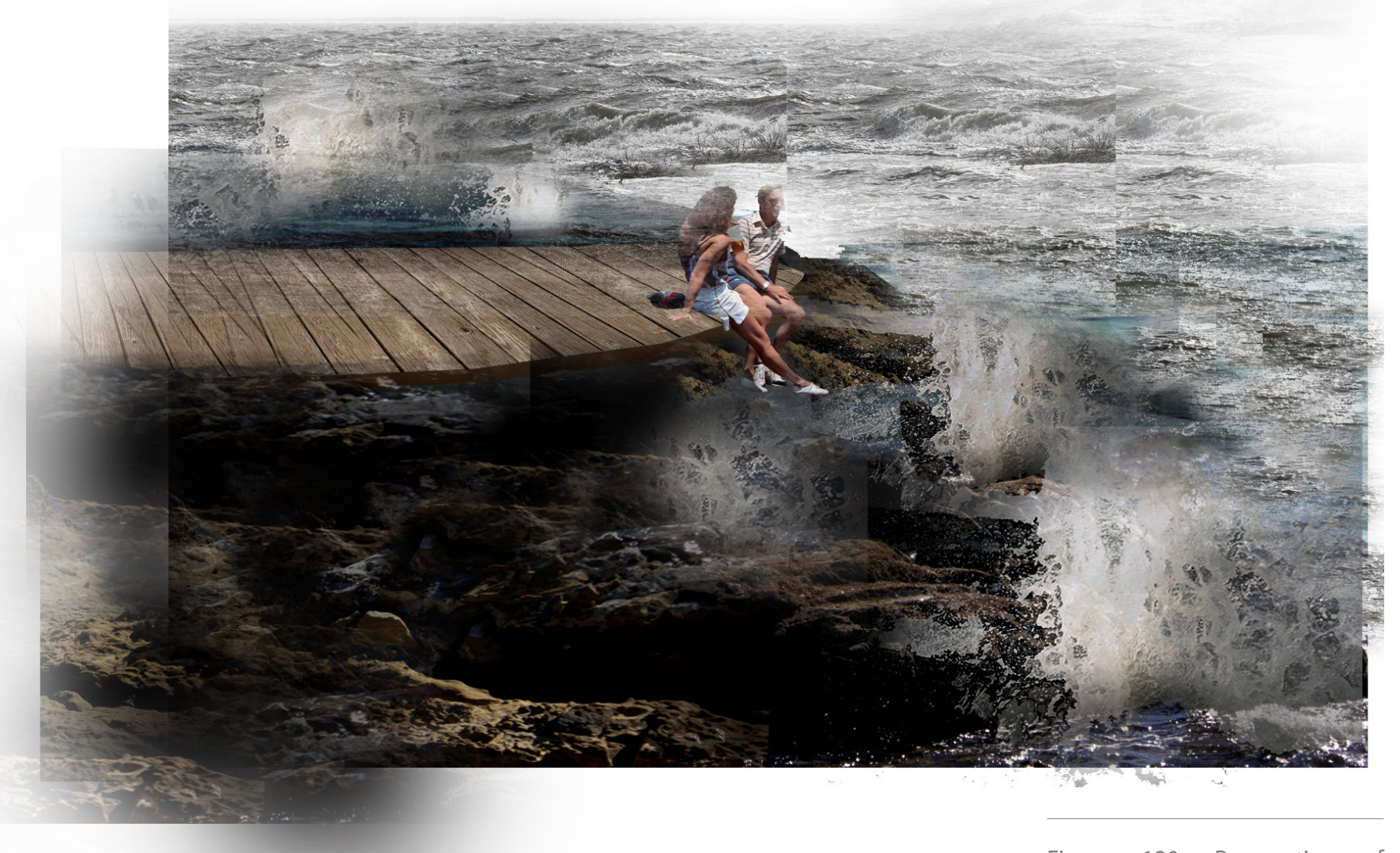

Figure 120. Perspective of
climatic affects. Image by author 

The boardwalk within the tidal pools is designed so and down into the harbour for recreational activities.

The boardwalk is designed to create different levels and access to the harbour and tidal pools.
The stairs and levels respond to the rocky terrain and contours of the site.

The boardwalks descent continues down into the water, allowing swimming and diving to take

place.

This is the final connection between the trigger

sites, the reclaimed land and the harbour. There is no predetermined activity designed for. There is an allowance for multiple uses to take place on

A visual and physical connection with the natural environment is created, while viewing the
surrounding suburbs and Wellington's CBD.

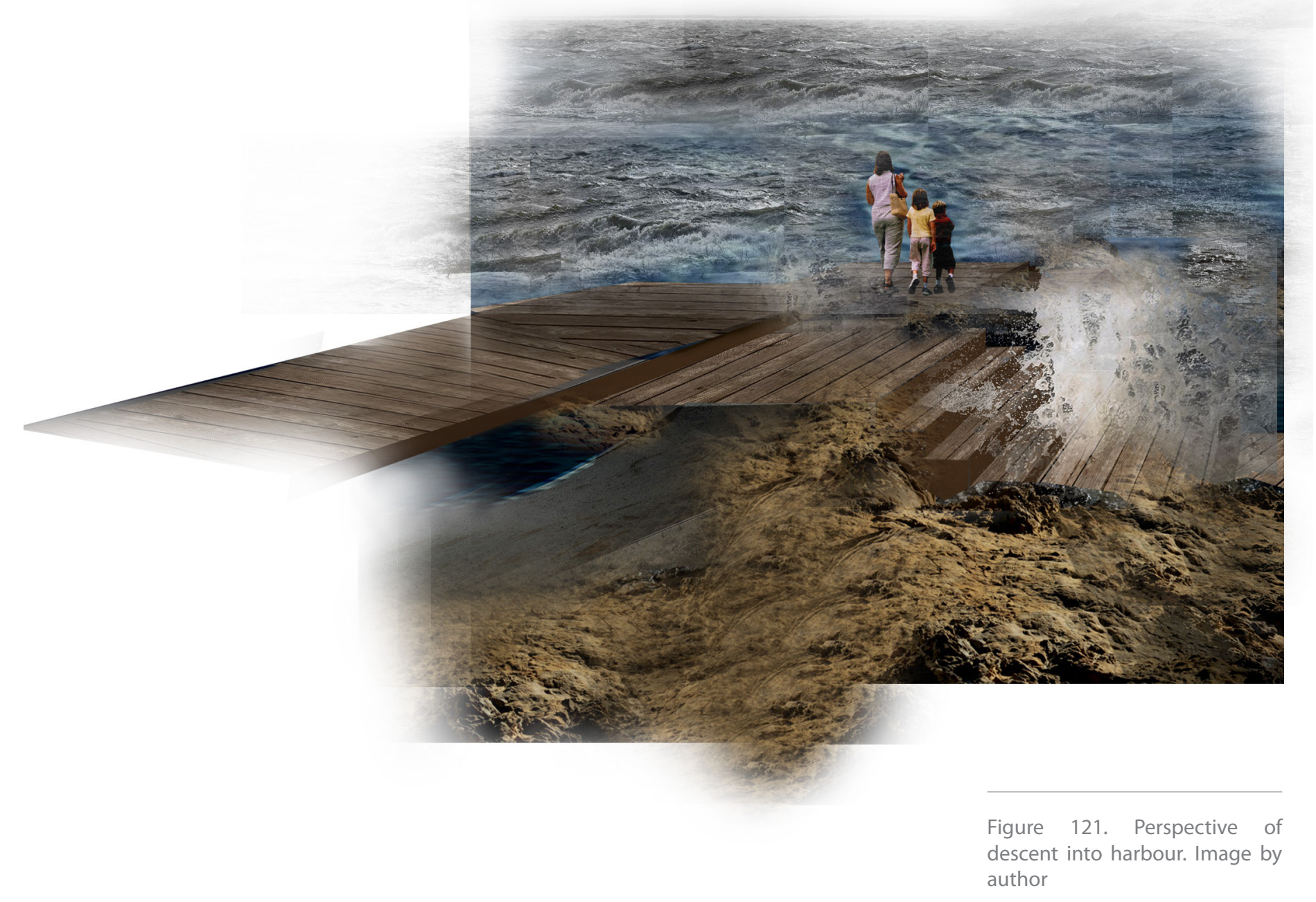


Over time, the natural environment will overtake the timber boardwalk

Figure 122. Detail of boardwalk

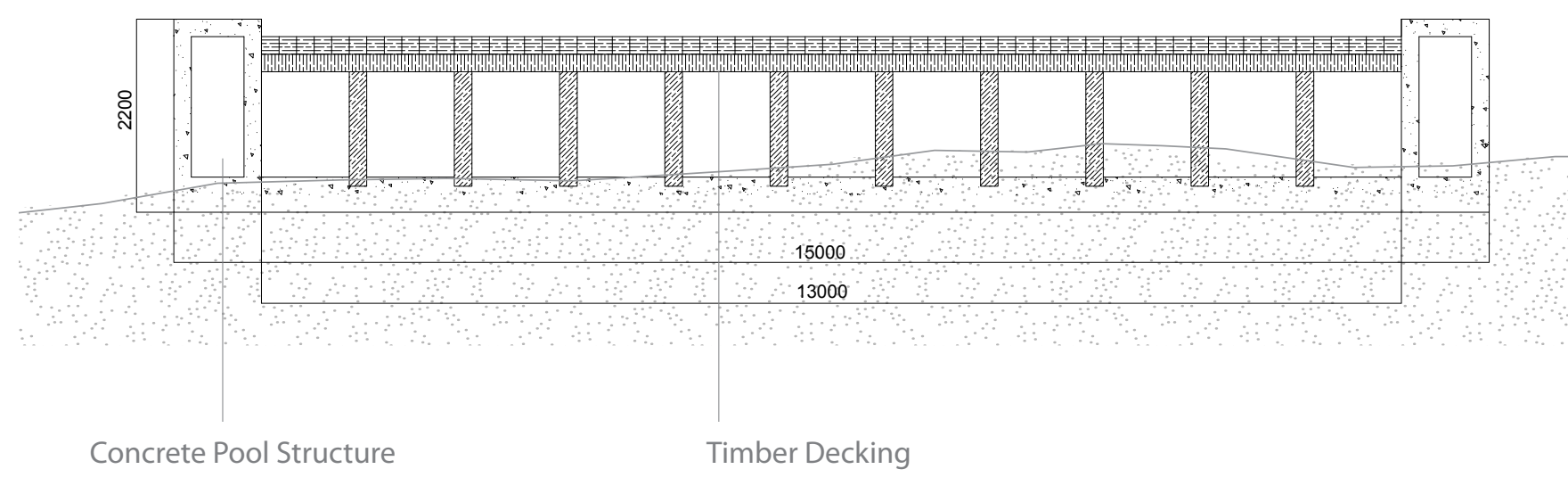

@ 1:100. Image by author

All size, dimension and

connectors to structur 

Memory can be represented physically within the This thesis has explored how memory can be This thesis has explored how memory can be urban development. More specifically, the concept of the man-made landscape was explored, and how andscape architects can anchor memory within the collective and individual identity of the public, using scales of design, temporality, program, time, materiality and process as tools within the design process.

Site analysis, using Marot's steps in approach to site case studies and design experimentation allowed full investigation into the representation of memory within the landscape, specifically within Shelly Bay, process was the realisation that memory is fluid Memory is in the eye of the beholder and specifically. subjective to time, place, and the designer. The development of a number of design ideas within this thesis shows the number of tangents and decisions needed to chose a specific avenue of history and memory to navigate and represent. The aim of the design is that over time, the form, materials and program will become traces upon Shelly Bay, ingrained within the collective identity, and creating new memories upon the site.

Description of and Reflection on Design Approach

The design approach was formed through the analysis of Sebastien Marot's four necessary steps highlighted in 'The Return of the Landscape. Considering Marot's approach allowed the focus on the site to became the principle factor upon making design decisions. This is The site antysis of Shelly of research on memory. historical festures that could possibly be revived relationships and processes, habitats and spaces that xist between them and transitional spaces that could be connected and amplifed on site. This approach, combined with frequent site visits, allowed an indepth understanding of the historical, cultural and topological features, and how these functioned within the current built environment. The resulting design has retained and amplified the relationships that currently work. Elements and spaces were added to connect, activate and ground Shelly Bay within Wellington's expanding urban public realm.

The site analysis and theoretical research into retaining memory within the landscape led to two possible design options. Option one explored whether it was possible to recreate the historical coastal edge of the site. The aim was to challenge the impact that manmade infrastructure has had upon the memory of landscape, and specifically, upon Shelly Bay. Option two investigated the concept of bridging the historical presently. This site with a design that activates the site presenly. Thisconceptainedtohighlight hehistorica interventions. Bo n a cohesiveway with new design past memories of the site while providing function designs for the public use of the site in present and future occupation. This was achieved through the design of three interventions named within this thesis as trigger sites.

The development of design option one explored the site through the re-creation of memory. The primary element that displayed this concept was the canal. This dissected the reclaimed land, following the historica coastline at the base of the foothills. The canal was designed to act as a physical connection between al three trigger sites. An analysis of this design revealed that the canal intervention may be perceived as negative reflection of land reclamation and the manmade landscape. The act of reclamation within Shelly Bay created a flat site that has allowed present day occupation. The development of design option two takes this analysis into account with the removal of Investigating two possible design options helped to address every angle on the site, however it may have restricted a more in-depth design investigation into one design idea. As the aim of this thesis was to investigate the abstract idea of memory within the practice of landscape architecture, as well as a design that retains the memory of a site, a wider design scope 
was needed to consider which action upon the site was the most

Critique of Design

A theoretical investigation into the design of memory within the urban landscape formulated a number of objectives that were chosen to develop the design. These included scales of design, permanence, materiality, program and time. The final design displays an in-depth enquiry into the permanence/ temporal quality in terms of program and scales of design. This has been explored within the investigation of materiality, durability and trace. The concept of permanence would be explored within the choice of materials and finishes. The three sites display differen the site anc us by punic. The type of ments fishes used has formed temporary and permats

These spaces reflect the context and climate of the site over time, while also responding to the collective memory of the site in its current degraded state. The exploration into the temporal qualities of the materials has been explored in detailed design. Further investigation would reveal a more comprehensive analysis of the materials on the site over time.

The approach to design through site revealed the ypologies. The design focused on three trigger sites highlighting different memories on site. A masterplan was formed to realise the relationships between these sites. The scale of the site created an issue with the amount of information being dealt with and the scale of detail designed. The approach to the master plan Bay. In design option one, the cans and spati layout restricted vehicle access to most of the northern part of the bay. This was balanced by the use of the existing road in the foothills, and the re-contouring of part of the hill to re-connect vehicles with the coast. After assessing this design, it was decided that service access and vehicle access were too important to restrict. This was hindered by the design of the canal. Design option two addresses these issues and resolves plan.

The design of the canal was the initial 'hunch' within the outlined research question in relation to the site of Shelly Bay. Ideally, the final design would include this structure. Realistically, and as a landscape architecture project, access, service and connectivity were too significant and priority was given to these elements within the final design.

\section{Further Research}

Naturally this research may lead to other approaches in dealing with memory and site. While this designaddressed the notion of site specifilly. It came to the conclusion that the choice of a site directly influences and affects the investigation of memory and subsequent elements.

Implications of Research Outcome for Theory/Practice

Research has shown that cities are expanding, and Wellington will expand its urban realm over the nex fifty years. The design presently offered an approach specifically within Shelly Bay and within New Zealand. spever, the initial steps and analysis taken towards the design show a unique way of approaching historical site with the intention of regeneration within the environment, for the public, and for the future urban and economic growth of Wellington. Within this context, it has been proposed that the final design outcome of this thesis, combined with the supporting .

\section{The final design outcome can be seen as an example} of how to approach sites of memory. The subsequent research elements, (scales of design, permequence, materiality, process and time) can be utilised to investigate a site. Public space is becoming vital within condensed urban cities. The approach to design 
explored within this thesis can be utilised within different scales of design. One of these scales could include memorial parks and monuments displayed
throughout cities in New Zealand, and the world. A re-invention of the practicality, integration, and public use of these spaces is needed. The approach to design theoretical outcomes of memory in relation to design and the final design outcomes highlight how places of memory can be anchored, connected, activated and grounded within growing cities.

It has been argued that memory can be revealed in tangible and intangible ways. Capturing and revealing memory through design is not the same as memorializing the past. To anchor memory within site, interchangeable permanency over time must be 
7. List of Figures 
Figure 23. An agitation for the reopening of the Point, its depot at Shelly Bay, the entrance to which is shown above. The depot itself is shown in the lower photograph, taken from the summit drive along Mount Victoria. (Evening Post, 16 October 1945). Alexander Turnbull Library, Wellington New Zealand. Sourced from http://beta.natlib.govt.nz/records/6889139 on 12/07/2012

Figure 24. A submarine explosion at Shelly Bay, Wellington, December 1905. Photo by L.M. Croll. Sourced from http://beta.natlib.govt.nz/records on 12/07/2012

Figure 25. Launch Marlyn under repair at Shelly Bay, Wellington. Berthold, Martin Grant, 1951 - : Negatives of coastal shipping. Sourced from Ref: 1/4-025492-F. Alexander Turnbull Library, Wellington, New Zealand, on 12/07/2012

Figure 26. Evans Bay, Wellington, including Miramar Wharf and Shelly Bay, and looking towards Lyall Bay. Whites Aviation Ltd :Photographs. Sourced from Ref:WA-30316-F. Alexander Turnbull Library, Wellington, New Zealand. http://beta.natlib.govt.nz/records/23259171 on 12/07/2012

Figure 27. Launch Marlyn sunk at Shelly Bay, Wellington. Berthold, Martin Grant, 1951- : Negatives of coastal shipping. Sourced from Ref: 1/4-025498-F. Alexander Turnbull Library, Wellington, New Zealand, on 12/07/2012

Figure 28. Section of Shelly Bay topography. Original 1:50 @ A0. Image by author Figure 29. The current form of Shelly Bay's coastline and foothills. Not to scale. Image by author Figure 30. Bathymetry plan of Shelly Bay. Original 1:2000 @ A3. Image by author

Figure 31. Diagram illustrating edge conditions of the site. Image by author

Figure 32. Perspective of Shelly Bay. Sourced from Google Earth

Figure 33. Photo collage of current site conditions in Shelly Bay. Photos by author Figure 34. Shelly Bay site plan. Original 1:2000 @ A3. Image by author

Figure 35. Timeline map of Shelly Bay. Original 1:2000 @ A3. Image by author

Figure 36. Decaying wharves. Image by author

Figure 37. Sketches of Shelly Bay's current state, 2012. Images by author

Figure 38. Diagram of relationships and connections on site. Image by author

Figure 39. Diagrams of urban encroachment upon Shelly Bay. Image by author

Figure 40. Diagrams showing trigger sites in relation to site analysis. Image by author

Figure 41. Decaying building in Shelly Bay, 2012. Photo by author

Figure 42. Wellington waterfront reclamation map. Not to scale. Image by author

Figure 43. Submarine and Torpedo Mining Corps annual camp, Shelly Bay, Wellington. Sourced from Ref: 1/1-020236-G. Alexander Turnbull Library, Wellington, New Zealand on 12/07/2012

Figure 44. Perspective of Oyster Tecture design by Scape. Sourced from

http://www.scapestudio.com/projects/oyster-tecture/ on 03/08/2012 
Figure 45. Perspective of Oyster Tecture design by Scape. Sourced from

http://www.scapestudio.com/projects/oyster-tecture/ on 03/08/2012

Figure 46. Plan of Oyster Tecture design by Scape. Sourced from

http://www.scapestudio.com/projects/oyster-tecture/ on 03/08/2012

Figure 47. Diagram: Blurring the edges. Image by author

Figure 48. Diagram: Accentuating existing memory signs. Image by author

Figure 49. Pedestrian tunnel bridge in Parc de Lancy by Georges Descombes. Sourced from

http://strabic.fr/Memoire-s-des-territoires.html on 03/08/2012

Figure 50. Perspective of pedestrian descent from foothills to harbour, highlighting the design of a canal. Image by author

Figure 51. Perspective of multi-layer marina design. Image by author

Figure 52. Perspective of new wharf area, canal and waterfront walkway. Image by author

Figure 53. Perspective of cantilevered lookout from foothills. Image by author

Figure 54. Perspective of tidal pools, canal and lookout. Image by author

Figure 55. Perspective of pedestrian bridge and canal. Image by author

Figure 56. Perspective of canal and decaying wharves. Image by author

Figure 57. Decaying wharves in Shelly Bay, 2012. Photo by author

Figure 58. Sydney public temporary design. Sourced from http://www.cityofsydney.nsw.gov.au/

customhouse/whatson/PreviousExhibitions.html on 10/06/2012

Figure 59. Rust in Shelly Bay. Photo by Graeme Perry. Sourced from

http://www.flickr.com/photos/graemeperry/6894277379/ on 20/04/2012

Figure 60. Images of current materials used within the built environment of Shelly Bay, 2012. Photos by author

Figure 61. Crissy Field Tidal Marsh Restoration design by Hargreaves Associates. Sourced from http://www.hargreaves.com/projects/PublicParks/CrissyField/ on 10/06/2012

Figure 62. Perspective of Shelly Bay point. Image by author

Figure 63. Diagram: Historical edge of site. Image by author

Figure 64. Diagram: Reclaimed land. Image by author

Figure 65. Diagram: Design option one and two. Image by author

Figure 66. Diagram of'Ecomusee' site. Image by author

Figure 67. Diagram of site program. Image by author

Figure 68. Diagrams and plan of trigger sites. Plan original 1:30,000 @ A0. Image by author

Figure 69. Design Option One: Masterplan. Original 1:30,000 @ A0. Image by author

Figure 70. Open space diagram. Image by author 
Figure 71. Hydrology diagram. Image by author Figure 72. Land-use diagram. Image by author

Figure 73. Connectivity diagram. Image by author

Figure 74. Plan showing trigger sites. Original 1:30,000 @ A0. Image by author

Figure 75. Perspective of walkway meeting harbour. Image by author

Figure 76. Section A. Walkway bridging reclaimed land and canal. Original 1:100 @ A3. Image by author

Figure 77. Perspective of ferry wharf. Image by author

Figure 78. Section B. Wharf connecting harbour to café and foothills. Original 1:100 @ A3. Image by author

Figure 79. Perspective of lookout. Image by author

Figure 80. Perspective of tidal pools. Image by author

Figure 81. Design option two: Masterplan. Original 1:30,000 @ A0. Image by author

Figure 82. Access plan. Original 1:30,000 @ A0. Image by author

Figure 83. Diagram of trigger sites. Image by author

Figure 84. Site plan of Floating Walkway. Not to scale. Image by author

Figure 85. Perspective of floating walkway. Image by author

Figure 86. Plan of site A. Original 1:50 @ A0. Image by author

Figure 87. Material timeline. Image by author

Figure 88. Sectional perspective of bridge. Image by author

Figure 89. Image of stairway descent from bridge into harbour. Image by author

Figure 90. Image of stairway ascent into foothills. Image by author

Figure 91. Detail plan of bridge structure @ 1:50. Image by author

Figure 92. Section of bridge and stairs descent into harbour @ 1:50. Image by author

Figure 93. Section of platform in ascent into foothills, 'Soundbox', @ 1:50. Image by author

Figure 94. Site Plan of Ferry Wharf and Market Space. Not to scale. Image by author

Figure 95. Perspective of ferry wharf. Image by author

Figure 96. Plan of site B. Original 1:50 @ A0. Image by author

Figure 97. Material timeline. Image by author

Figure 98. Perspective of interior market space. Image by author

Figure 99 . Perspective of ferry port and wharf levels. Image by author

Figure 100. Perspective of climatic affects upon wharf. Image by author

Figure 101. Elevation of concrete piles @ 1:50. Image by author

Figure 102. Section of boardwalk @ 1:50. Image by author

Figure 103. Cross-section of wharf levels and market space interior @ 1:100. Image by author

Figure 104. Sections of seating and barriers @ 1:30. Image by author 
Figure 105. Site plan of lookout and tidal pools. Not to scale. Image by author Figure 106. Perspective of lookout. Image by author

Figure 107. Plan of site lookout. Original 1:50 @ A0. Image by author

Figure 108. Material timeline. Image by autho

Figure 109. View of entry to lookout. Image of author

Figure 110. View of sunken interior. Image by author

Figure 111. View of northern wing exterior. Image by author

Figure 112. View of ascent to lookout via raised walkway. Image by author

Figure 113. Section of raised walkway @ 1:100. Image by author

Figure 114. Elevation of concrete cutout structure @ 1:100. Image by author

Figure 115. Cross-section of cantilevered lookout @ 1:20. Image by author

Figure 116. Section of cantilever @ 1:70. Image by author

Figure 117. Perspective of tidal pools. Image of author

Figure 118. Plan of tidal pools. Original 1:50 @ A0. Image by author

Figure 119. Material timeline. Image by author

Figure 120. Perspective of climatic affects. Image by author

Figure 121. Perspective of descent into harbour. Image by author

Figure 122. Detail of boardwalk. Not to scale. Image by author

Figure 123. Section of tidal pools @ 1:100. Image by autho 
8. Bibliography

Berkes, F; Colding, J; Folke, C. (2000). Rediscovery of Traditional Ecological Knowledge as Adaptive Management. Ecological Applications Vol. 10, No. 5.p1251-1262.

Berleant, A. (2003). The Aesthetic in Place. In Menin, S (Ed). (2003). Constructing Place; Mind and Matter p41-55. London: Routledge.

Berry, V, Calio, K, Lawler, M, Mongard, J. (2002). Where is the Collective Landscape? Landscape Design: Regional Identity, perceptions of emotions and place, 309, 22-24.

Camlins Landscape Architects. (2011). Camlins Projects. Retrieved July 15, 2012, from Camlins :http://www.camlins.com

Council, W. C. (2006). Urban Development Strategy: Directing growth and delivering quality. Wellington: Wellington City Council.

Crinson, M. (2005). Urban Memory. In M. Crinson, Urban Memory: History and Amnesia in the Modern City (pp. xi-xiii). New York: Taylor and Francis Group.

F.G.Breman. (1977). Amsterdam-Green Spaces for a City on Land Recovered from the Sea. In I.F. Architects, The Man-Made Landscape: Musuems and Monuments (pp. 31-44). Paris.

Forty, A. (2005). Concrete and Memory. In M. Crinson, Urban Memory (pp. 75-92). New York: Taylor and Francis Group.

Hauser, S. (2006). Making Musuems of Industrial Heritage Sites. In P. Oswalt, Shrinking Cities, Volume 2: Interventions (pp. 816-822). Germany: Hatje Cantz Verlag.

Hayden, F. R. (2006). Temporary Urban Spaces: Concepts for the Use of City Spaces. Switzerland: Birkhauser.

Hough, M. (1990). Out of Place: Restoring Identity to the Regional Landscape. London: Yale University Press.

Huisman, J. (2008). Turbulance in the Countryside. In B. V. Meggelen (Ed.), Memory and Transformation: International Triennial Apeldoorn (pp. 143-145). Rotterdam: NAi Publishers.

Jandirk Hoekstra, B. V. (2008). Memory and Transformation. In B. V. Meggelen (Ed.), Memory and Transformation: International Triennial Apeldoorn (pp. 13-19). Rotterdam: NAi Publishers. Kirkwood, N. (2004). Weathering and Durability in Landscape Architecture. New Jersey, USA John Wiley \& Sons.

Libeskind, D. (2003). Foundations of Memory. Landscape Design: Sacred Landscapes (322) 
Marot, S. (1998). The Return of the Landscape. In C. D. Michael Desvigne, The Return of the Landscape (pp. 6-10). Whitney Library of Design.

Marot, S. (2003). Urbanism and the Art of Memory. Spain: SYL.ES.

Minner, K. (2011, September 1). Oyster Tecture and the Gowanus Canal. Retrieved October 5 2012, from archdaily: http://www.archidaily.com

Miramar Peninsula. (2011). Shelly Bay. Retrieved July 15th, 2012, from http://www.miramarpeninsula.org.nz/contact-us/

Mossop, E. (2006). Landscapes of Infrastructure. The Landscape Urbanism , 121-122.

Mutu, M. (1994). The Use and Meaning of Maori Words borrowed into English for discussing resource management and conservation in Aotearoa/New Zealand. New Zealand: The New Zealand Conservation Authority.

Neumann, D. (2007). Tribute in Light: Iconography of a Memorial. In A. Marcus, Visualizing the City. Abingdon: Routledge.

Rodrigo, R. (2011). Between Remembrance and Recreation: Containing Memory in Urban Landscapes. Memory Collection , 1 (1).

Scape. (2004). Oyster-Tecture, MoMA Rising Currents Exhibition. Retrieved June 12, 2012, from Scape Landscape Architecture: http://www.scapestudio.com

Schama, S. (1995). Landscape and Memory. New York: Alfred A. Knope, INC

Speed, F. (2003). The Sacred Environment: An Investigation of the Sacred and its Implications for Place-Making. In S. Menin (Ed.), Constructing Place; Mind and Matter (pp. 55-66). London: Routledge.

The Shrieking Violet. (2011, July 16). The Shrieking Violet. Retrieved August 20, 2012, from

Ancoats Peeps: Dan Dubowitz and the Presence of Absence: http://theshriekingviolets.blogspot. co.nz

Treib, M. (1999). Nature Recalled. In J. Corner (Ed.), Recovering Landscape: Essays in Contemporary Landscape Architecture (pp. 29-41). New York: Architectural Press.

Treib, M. (2001). The Content of Landscape Form (the limits of formalism). Landscape Journal , $20(2), 119-140$. 
Tyrer, P. (2005). Clocking off in Ancoats: Time and Remembrance in the Post Industrial City. In M. Crinson, Urban Memory (pp. 51-67). New York: Taylor and Francis Group.

Waters, D. (2002). Shelly Bay Air Force Base. Retrieved April 10, 2012, from Captial Defence: http://capitaldefence orconhosting net.nz

Wellington City Council. (2006, July). Urban Development Strategy. Retrieved April 10, 2012 from Wellington City Council: http://www.wcc.co.nz

Wellington City Council. (2009, september). Surburban Centres Review. Retrieved April 10, 2012, from Wellington City Council: http://www.wcc.co.nz

Wellington Waterfront Ltd. (2004). Waterfront Reclamation. Retrieved September 10, 2012, from Positively Wellington Waterfront: http://www.wellingtonwaterfront.co.nz

Wolschke-Bulmahn, J. (2001). Places of Commemoration: Search for Identity and Landscape

Design. Washington, D.C: Dumbarton Oaks. 
Our 50-year growth concept

9. Appendices

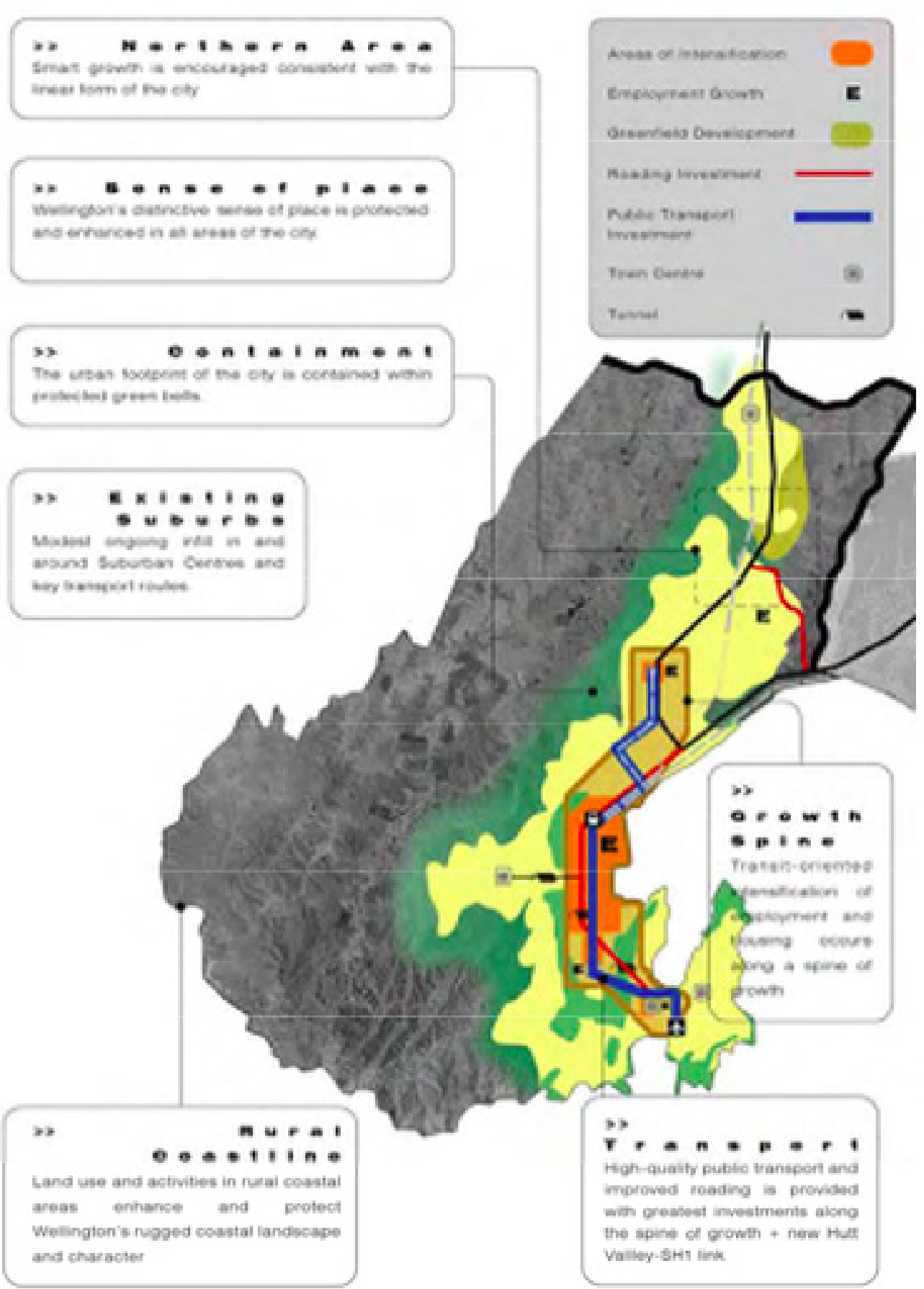




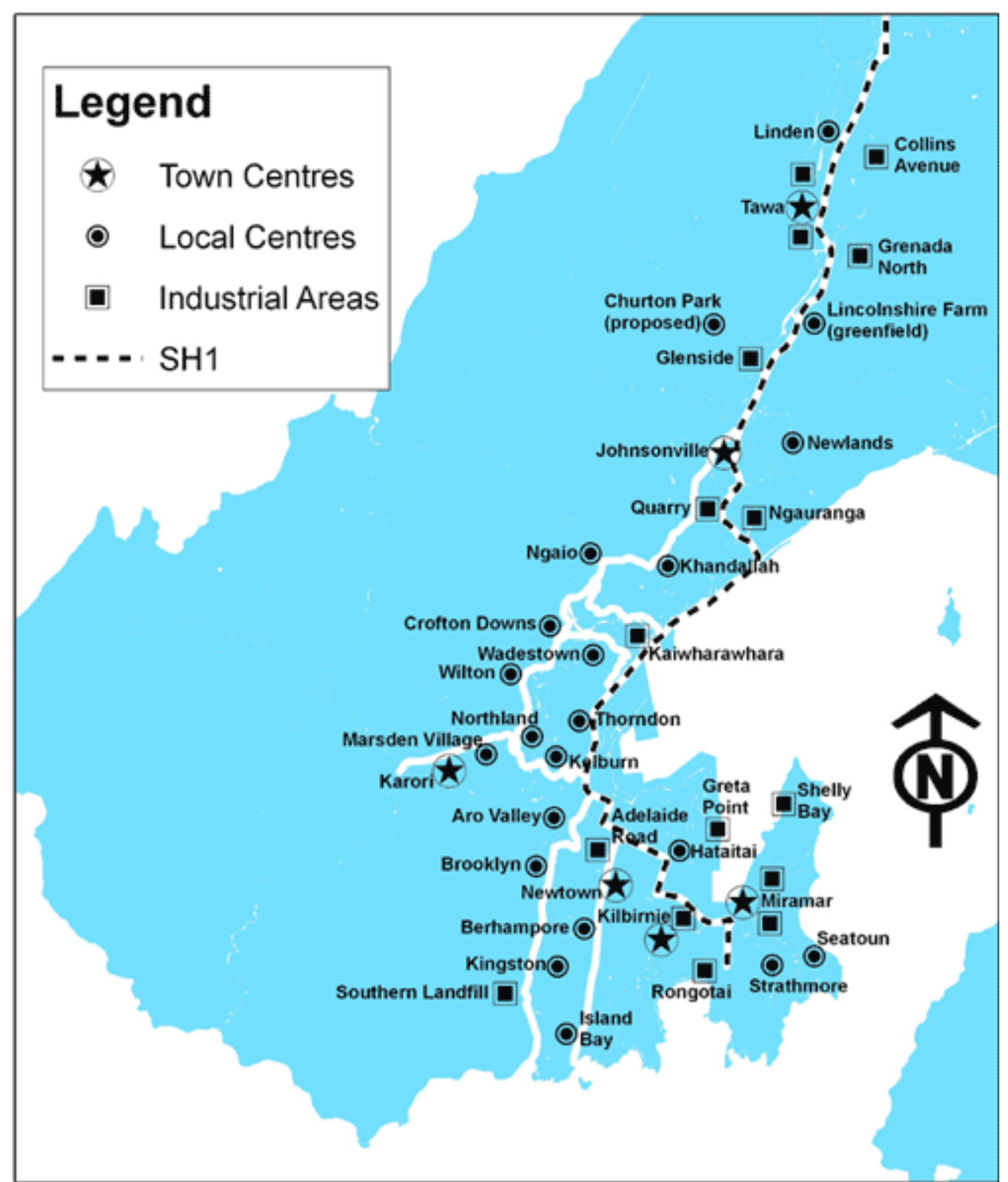

Design Matrix

\begin{tabular}{|c|c|c|}
\hline THEORY & SITE & DESIGN \\
\hline Renewing Memory & Challenging Reclamation & $\begin{array}{l}\text { Breaking down edges of the site: } \\
\text { Harbour, reclaimed land, natural hill }\end{array}$ \\
\hline Time and Permenance & $\begin{array}{l}\text { - The sea: Tidel levels } \\
\text { - Palette of site: Buitt forms, } \\
\text { wharves, rocky coast, } \\
\text { winding coast and road, }\end{array}$ & $\begin{array}{l}\text { Activation through programme and } \\
\text { public space design. Designs that } \\
\text { address time, past presint and future. }\end{array}$ \\
\hline $\begin{array}{l}\text { The man-made landscape } \\
\text {-Nature vs. Bilut form } \\
\text {-Builtorrm vs. Nature }\end{array}$ & $\begin{array}{l}\text {-Wharves } \\
\text {-Reclaimed Land }\end{array}$ & $\begin{array}{l}\text { Highlight forces on each other, } \\
\text { choosing a position to take and } \\
\text { reflect to public }\end{array}$ \\
\hline $\begin{array}{l}\text { The aesthetics of memory } \\
\text { and time }\end{array}$ & $\begin{array}{l}\text { Degradation of site, } \\
\text { weathering, materiality. } \\
\text { - Site context- harbour, salt } \\
\text { spray, wind. }\end{array}$ & $\begin{array}{l}\text { Detailed design - planning and } \\
\text { allowing for degradation or perme- } \\
\text { nance }\end{array}$ \\
\hline
\end{tabular}



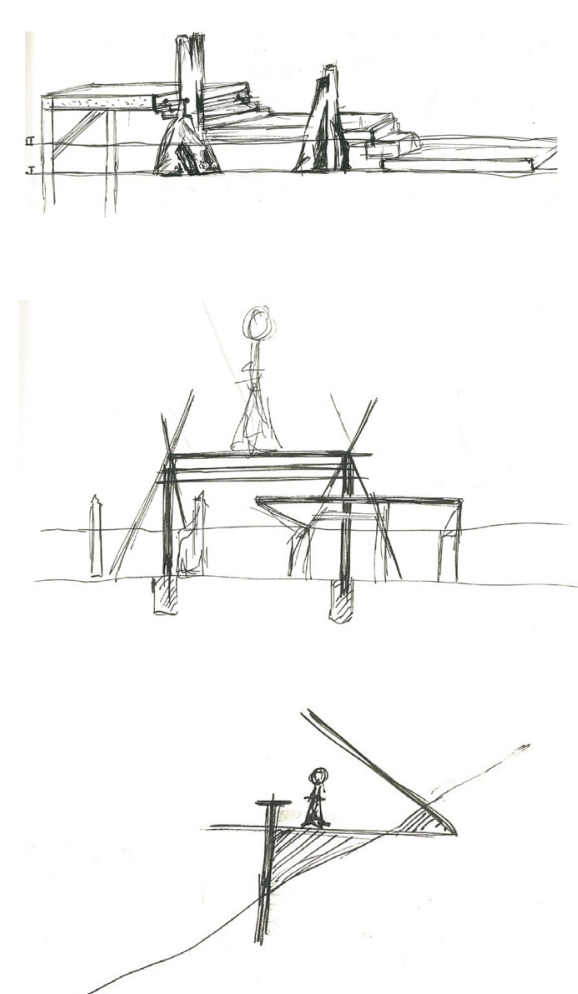
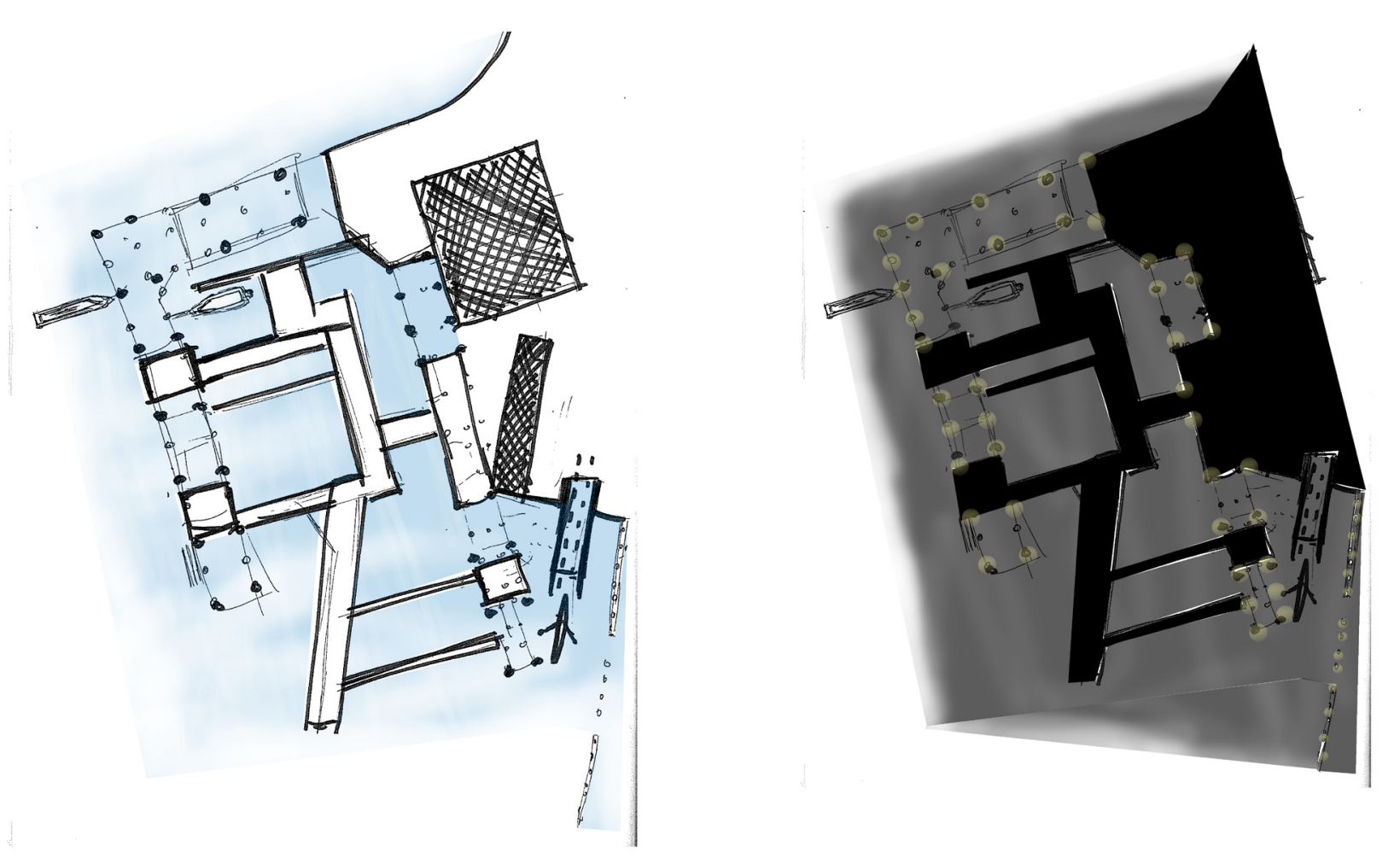

204

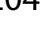



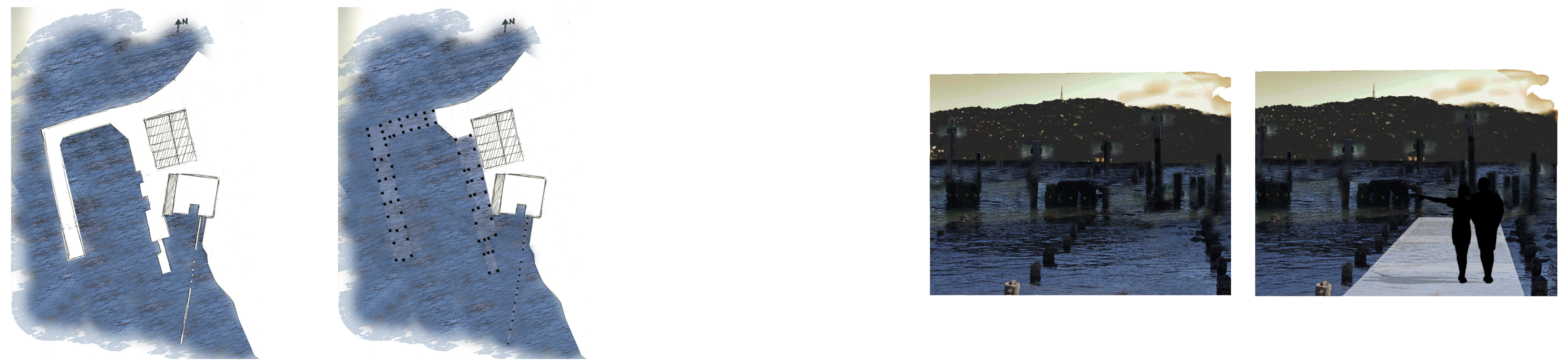
